der gröfste Theil dessen angehört, was die hebräische Sagengeschichte und speciell der Elohist (Ephraimit) von den Verhältnissen Aegyptens zu berichten weifs, dürfte sich bei weiterem Eindringen der Forschung immer mehr herausstellen; $\mathbf{v g l}$. einstweilen A. Erman in der ägypt. Ztschr. 1883, S. 59, Anm. 2.

\title{
Ueber das Ich der Psalmen.
}

Von Rudolf Smend, Professor in Basel.

Nach der gegenwärtig herrschenden Auslegung, deren mafsgebende Vertreter hier Ewald und Hupfeld sind, erscheint der kanonische Psalter in hohem Malse oder vielmehr der Hauptsache nach als ein Denkmal der persönlichen Frömmigkeit. Denn in nahezu 80 Liedern des Psalters redet ein Ich, das man individuell zu deuten pflegt. Diese Lieder machen aber nicht nur ihrer Zahl nach reichlich die Hälfte des Psalters aus, im Ganzen bedeuten sie auch inhaltlich mehr als die übrigen ${ }^{1}$ ). Hiermit ist indessen

1) Folgende Aufzählung mag das Gesagte veranschaulichen. Es handelt sich um Ps. 3. 4. 5. 6. 7. 9 f. 11. 13. 16. 17. 18. 19 b. 22.23. 25. 26.27 a. b. 28. 30. 31. 32. 34 (v. 2-5. 12). 35. 36 (v. 12). 38. 39. 40. 41.42 f. 49 (v. $4-6.16$ ). 51. 52 (v. 10. 11). 54. 55. 56. 57. 59. 61. 62. 63. 64.66 (จ. $13-20$ ). 69. 71. 73. 77. 84. 86. 88.89 (v. 2. 3. 48. 51). 92 (v. 5. 11. 12. 16). 94 (จ. 16-19. 22. 23). 101. 102. 103.104 (v. 1. 33-35). 109. 116. 118. 119. 120. 121. 122. 123. 130. 131. 138. 139. 140. 141. 142. 143. 144. 145. 146. Natürlich sehe ich von solchen Fällen ab, in denen mehr gelegentlich ein Ich auftritt (wie 37, $25.35 \mathrm{f}$. 45,2 . 78,1 . 2. 110,1 . I11, 1. 137,5 . 6 oder auch 68,25 . 83, 14), und halte mich an diejenigen, in denen das Ich als der wesentliche Träger der Empfindung erscheint. Aber bedeutsam tritt ein Ich noch hervor 8, 4 (vgl. dag. v. 2. 10). 20, 7 (vgl. dag. v. 6. 8-10). 44, 5.

Zeitschrift f. d. alttest. Wiss. Jabrgang 8. 1888. 
die Thatsache zusammenzuhalten, dafs der Psalter das Gesangbuch des zweiten Tempels war ${ }^{1}$ ). Der Tempelgesang war nämlich Gemeindegesang, obwohl er zunächst von den levitischen Sängern ausgeführt wurde. Er begleitete das Tamid, das von Gemeinde wegen dargebrachte und für jeden Tag des Jahres gesetzlich feststehende Opfer. Wie ist es nun zu begreifen, dafs hierbei eine so grofse Zahl von Liedern verwendet wurde, die nach dem herrschenden

7. 16 (übrigens : wir). 45, 18. 60, 11 (übrigens : wir). 65, 4 (vgl. dag. v. 4-6). 74, 12 (vgl. dag. v. 9). 75, 10 (vgl. dag. v. 2). 85, 9 (vgl. dag. v. 5-8. 10. 13). 106, 4 (vgl. dag. v. 6. 7. 47). 135, 5 (vgl. dag. v. 2. 5). Individuell wird ferner das $\mathrm{Du}$ in Ps. 37. 91. 128 und der Mann in Ps. 1 verstanden.

1) Freilich sind die talmudischen Nachrichten über die Verwendung der Psalmen in der Tempel-Liturgie sehr dürftig, aber jene Thatsache wird durch die musikalischen Bemerkungen in den Psalmüberschriften hinreichend gesichert. Diese Bemerkungen finden sich überdies namentlich bei den Psalmen, in denen ein Ich redet. Wo sie dagegen fehlen, ergiebt sich meistens um so deutlicher aus dem Character der betreffenden Lieder, dafs sie von vornherein für den öffentlichen Gottesdienst bestimmt waren. Vgl. Ewald, Dichter des A. B. ${ }^{2}$ I 1 S. 238 f. Kuenen, Onderzoek III S. 349. Delitzsch, Commentar über die Psalmen ${ }^{3}$ S. 23. - Besondere Aufmerksamkeit verdienen hierbei noch der erste und letzte Psalm, die gewifs nicht zufällig an ihrer Stelle stehn. Der Sinn von Ps. 150 bedarf keiner Erläuterung, dagegen wird Ps. 1 meistens mifsverstanden. Hier werden nämlich nicht die einzelnen Frommen und Gottlosen einander gegenübergestellt, sondern von der beiderseitigen Gesammtheit ist die Rede. Die Gottlosen gehn in der messianischen Zeit zu Grunde ( $v$. 5), weil ihnen die innere Qualität dauernden Bestandes fehlt ( $v$. 4). Deshalb mufs aber auch v. 1-3 von der Gesammtheit der Frommen die Rede sein. Der Mann $v$. 1 ist geradezu die Gemeinde. Auch Jer. 17, 5 ff. geht auf die Gesammtheit des Volkes. Vgl. ferner Ps. 52, 10. 92, 13 ff. sowie 32, 12. 35, 9. 39, 12. 40, 5. 94, 12. Klagel. 3, 1. 27. 39 und unten die Bemerkungen zu diesen Stellen. Etwas anders ist schon Ps. 128. Aber auch dies Lied preist alle (v. 1) frommen Juden, also die Gemeinde ( .6 ), glücklich. Der Unterschied von Ps. 1 und Ps. 128 besteht darin, dafs Ps. 128 von der Gegenwart, Ps. 1 dagegen von der messianischen Zukunft handelt. Der Psalter wird somit auch von einem Gemeindeliede eingeleitet, das zweifellos als Einleitung für das Buch gedichtet ist. 
Verständnifs zumeist höchst persönlicher Natur sind? Dafs die Ausleger diese Frage nicht stellen, mag z. Th. durch den vorwiegend individualistischen Character der evangelischen Gesangbücher veranlafst sein ${ }^{1}$ ). Aber beim offciellen Tempeldienst in Jerusalem handelte sichs zweifellos um die Gemeinde und nicht um die einzelnen Seelen.

Nun konnten freilich Psalmen, in denen ein Einzelner redet, auch als Gemeindelieder gebraucht werden, sofern nur der Gegenstand des Liedes die ganze Gemeinde anging. Die Gemeinde kann sich z. B. das Lied ihres Heerführers, der dem Feinde gegenübersteht, aneignen (Ps. 4). Denn die Sache ihres Führers ist unmittelbar auch die ihrige. Ebenso mag das Gebet eines Hauptes der Frommen, das als solches von den Gottlosen angefeindet wird, von der Gemeinde übernommen werden (Ps. 62). Auch kann das subjective Erlebnifs des Einzelnen für die Gesammtheit von besonderem Interesse sein, went jeder Fromme dasselbe durchzumachen hat. So die Ueberwindung des Zweifels durch den Dichter des 73. Psalms. Ferner mögen die Empfindungen, mit denen ein Jude der Diaspora die heilige Stadt betreten hat, bei der Gemeinde lebhaften Anklang finden (Ps. 122). Dagegen mufs es schon befremden, dafs sich im Psalter Lieder so rein persönlicher Art finden sollen, wie die Elegie Ps. 39 es angeblich ist. Höchst individualistisch sollen auch Ps. 16. 17 sein, nach der herrschenden Auslegung sprechen sie individuell die Erwartung der Unsterblichkeit aus. Damit hat die Gemeinde zunächst nichts zu thun. Noch verwunderlicher ist es aber, wenn das Anliegen der Gesammtheit im Psalter vielfach, ja vorwiegend in subjectivem Ausdruck vorgebracht wird. Es ist doch sonderbar, wenn hier über die

1) Wenigstens von Hupfeld möchte auch dies gelten, der die Nachkläuge der Psalmen im evangelischen Kirchenliede mit übrigens erfreulichem Interesse verfolgt hat. 
Noth der Gemeinde rein personlich reflectirt wird (Ps. 77), wenn das Gebet für den Konig (Ps. 61), das Verlangen nach der messianischen Zukunft (Ps. 89) im Munde eines Einzelnen laut wird und ebenso ein Einzelner dem Jahve fur die Rettung der Gemeinde (Ps. 138) und für sein Walten in Israel (Ps. 145. 146) dankt. Ein Lied, das aus einer Belagerung Jerusalems stammt, soll sich wesentlich um die persönliche Sicherheit des Dichters drehen (Ps. 59). Ebenso handelt Ps. 66 von einer Rettung Israels aus grofser Gefahr, aber der Redende soll im Tempel nur für seine Person danken (จ. 13-20). Endlos war die Verfolgung, die die Gemeinde der Frommen von den Gottlosen erlitt, eine lange Reihe von Psalmen haben sie zum Gegenstand; aber nach der herrschenden Auslegung redet in allen diesen Liedern zunächst wenigstens ein einzelner Verfolgter ${ }^{1}$ ). Warum nimmt hier niemals die Gesammtheit das Wort? Es handelte sich hier doch um das furchtbarste Problem, das die Gemeinde quälte. Sie hatte zweifellos auch ein besseres Recht, die grimmigen Flüche von Ps. 69. 109 auszusprechen, als der Einzelne. Sehr sonderbar nimmt

1) Ps. 5. 9 f. 11. 17. 19 b. 25. 27 a. 34. 36. 52. 55. 64. 69. 92. 94. 101. 104. 109. 119. 120. 139. 140. 141. Besonders individualistisch erscheint hier Ps. 55. Man meint, den Dichter beschäftige trotz der Allgemeinheit der Noth vor allem seine frühere Freundschaft mit einem nunmehrigen Haupte der Gottlosen. - Auch Ps. 26. 28. 39. 49. 73 gehören hierher. Vom Gegensatz der Frommen gegen die Gottlosen handeln ferner Ps. 1. 12. 14. 15. 24. 37. 50. 58. 125. - Von Verfolgung, die die Gemeinde von Seiten der Heiden erleidet, resp. dem Gegensatz gegen diese, handeln die Ich-Psalmen 3. 4. 9 f. 27 a. 35.41. 42 f. 56. 59. 66. 74. 89. 118. 119. 135. 144, die Wir-Psalmen 20. 21. 33. 44. (46). 60. 66. 68. 74. 79. 80. 81. 89. (115). 135. 136. 137. (Lieder, in denen Ich und Wir gleichmäfsig neben einander erscheinen, zăble ich hier auf beiden Seiten). - Unbestimmt bleibt die Natur der Feinde in den Ich-Psalmen 6. 7. 13. 22. 23.27 b. 30. 31. 38. 40. 51. 54. 57. 61. 63. 71. 75. 86. 88. 102. 116. 129. 138. 142.143 und den Wir-Psalmen 75. 123. 124. 
sich auch die Reihe von Liedern aus, die man gewöhnlich als Krankenlieder deutet ${ }^{1}$ ). Was sollen diese Lieder im officiellen Gottesdienst der jüdischen Gemeinde? Ps. 30 war nach seiner Ueberschrift und nach Mischna Soferim XVIII 2 das Lied des Tempelweihfestes, das sich bekanntlich auf die Reinigung des Tempels durch Judas Makkabäus bezog ${ }^{2}$ ). Dieser Psalm soll aber eigentlich den Dank eines Einzelnen für Genesung von schwerer Krankheit aussprechen. Danäch hätte die jüdische Gemeinde hier jedenfalls einen seltsamen Geschmack bewiesen. Uebrigens wurde das Lied auch bei Darbringung der Bikkurim (Dt. 26) von den Leviten gesungen (M. Bikkurim III 4).

Man möchte nun annehmen, dafs die jüdische Gemeinde dies Lied eben nicht als das Lied eines wiedergenesenen Kranken verstanden, dafs sie in der Krankheit vielmehr nur ein Bild ihrer einstigen Noth gesehen hätte. Ja man würde weiter annehmen müssen, dafs das Ich der Psalmen im Tempelgesang durchweg auf die Gemeinde bezogen wäre, die das Subject des Gottesdienstes war. Alle jene Lieder müfsten also durch den Tempelgebrauch zu Gemeindeliedern umgestempelt sein. Aber die Frage bliebe doch bestehn : wie kam es, dals das jüdische Gemeinbewufstsein ein so ungeheures Anlehn beim religiösen Individualismus machte ${ }^{3}$ )

1) Ps. 6. 22. 30. 38. 41. 69. 88. 102.

2) Vgl. Riehm in Hupfelds Commentar ${ }^{2}$ z. St.

9) Die Lieder, in denen die Gemeinde mit Wir redet, sind nicht balb so zahlreich wie die Ich-Psalmen. Ich weifs wohl, dafs es Gemeindelieder giebt ohne Wir und individualistisch gehaltene ohne Ich geben kann, immerhin mag eine Aufzählung der in den Psalmen vorkommenden Wir hier Platz finden. Einen ungefähren Mafsstab gewinnt man dadurch doch. Ps. 8; 2. 10 (vgl. dag. v. 4). 20, 6. 8-10 (vgl. dag. v. 7). 21, 14. 33, 20-22. 44 (vgl. dag. v. 5. 7. 16). 46. 47. 48. 50 , 3. 60 (vgl. dag. v. 11). 65 (vgl. dag. v. 4). 66, 6. 8-12 (vgl. dag. v. $13-20$ ). 67. 68, 20. 21. 29 (vgl. dag. v. 25). 74, 9 (vgl. dag. v. 12). 75, 2 (vgl. dag. v. 10). 78, 3-5 (vgl. dag. v. 1. 2). 79. 80. 81, 
Aus ganz allgemeinen Grtinden ist ein solches Anlehn aber wenig wabrscheinlich. Freilich gab es im Judenthum einen hoch entwickelten religiosen Individualismus, wie namentlich das Buch Nehemia, das Buch Hiob (?) and überbaupt die Weisheitsliteratur zeigt. Aber daraus folgt nicht, dafs dieser Individualismus vor allem im Psalter seine Spuren hinterlassen baben mưf(ste ${ }^{1}$ ). Zum Ausdruck des religiösen Gemeinbewufstseins konnten die Ergüsse der individuellen Frömmigkeit in der Regel durchaus nicht dienen. Denn die Gemeinde stand Gott und der Welt in ganz anderer Weise gegenüber als der Einzelne, sie hatte gröfsere Schulden und Leiden, gröfsere Ansprüche und Hoffnungen. Gott gegenüber fühlte sie sich unter dem Zorn, weil die ungeheure Schuld der gesammten Vergangenheit auf ihr lastete. Ihr Leiden war ferner der denkbar gröfste Widerspruch zwischen Ideal und Wirklichkeit, die gesammte Menschheit mufste sie als ihren erbitterten Feind betrachten, dem sie wehrlos gegenüberstand. Umgekehrt waren ihre Ansprüche grenzenlos, der ganzen Welt gegenüber war sie im Recht und sie stand überhaupt auf der Hoffnung, dafs sie als die Trägerin der Sache Gottes einst über die ganze Welt triumphiren sollte. Das religiöse Bewufstsein des Einzelnen lehnte sich dagegen auch im Judenthum überall an das Gemeinbewufstsein an, der Einzelne mufste sich zuletzt immer auf seine Zugehörigkeit zur Gemeinde besinnen, wenn er sich seiner Zugehörigkeit

2. 4. 85 (vgl. dag. v. 9). 90. 95. 98, 3. 99. 100, 3. 105, 7. 106, 6. 7. 47 (vgl. dag. v. 4). 113, 5. 115. 117, 2. 123, 2-4 (vgl. dag. v. 1). 124. 126. 135, 2. 5 (vgl. dag. v. 5). 136, 23. 24. 137. 147. Vereinzelt findet sich sonst Wir neben Ich : 17,11 . 22, 5. 40, 4. 6. 59, 12. 62, 9. $71,20.84,10.89,18.19 .94,23.103,10.12 .14 .116,5.118,23$. 24. 26. 27. 122, 1. 9. 129,8 . 141, 7. $144,12-14$. - Dagegen tritt in der Anrede viel öfter ein Ihr als ein $\mathrm{Du}$ auf.

1) Es giebt im Psalter zweifellos einige Lieder, die mehr individualisten Characters sind. Vgl. übrigens Hiob 33, $27 \mathrm{ff}$. 
zu Jahve bewufst werden wollte. Schon deshalb ist es widersinnig, wenn nach der herrschenden Auslegung in Ps. 130. 131 der Einzelne sein persönliches Gottvertrauen, das seine persönliche Sache betrifft, der Gemeinde zum Muster stellt.

Auch mufste das Gemeinbewufstsein durchaus im Stande sein, sich selbständig den Ausdruck zu schaffen, dessen es bedurfte. Schwerlich hat es sonst in der Welt ein Gemeindegebet von solcher Gewalt gegeben, das dabei so sehr Gebet gewesen wäre, wie das jüdische. Denn dies Gebet ging auf concrete Ziele, auf die Erhaltung der Gemeinde gegenüber den Gottlosen und den Heiden, auf ihre Rettung aus der augenblicklichen Gefahr und unabweislich forderte es seine Erhörung durch sichtbare Thatsachen. Denn an dieser Erhộrung hing die Wahrheit der Religion, das Dasein Gottes. Anderseits war die Gemeinde der Welt gegenüber ganz wesentlich auf ihr Gebet gestellt, mit diesem rein geistigen Mittel mufste sie sich behaupten. Wenn die Wahrheit dieser Sätze nicht von selbst einleuchtet, so ergiebt sich dieselbe freilich erst aus dem Verständnifs der Psalmen, das ich für das richtige halte. Inzwischen darf ich schon hier auf ein Wort verweisen wie Ps. 8, 3 : „Aus dem Munde von Kindern und Säuglingen „hast Du Dir eine Macht gegründet um Deiner Bedränger "willen, um ein Ende zu machen dem Feinde und dem „Rachgierigen". Es bleibt allerdings dunkel, weshalb hier gerade Kinder und Säuglinge genannt werden, aber zweifellos handelt sichs um die Abtreibung der Feinde Jahves durch das gemeinsame Gebet ${ }^{1}$ ). Die Annahme, dals die durchweg grofsartigsten und gewaltigsten Lieder

1) Wie man die eminent geistliche Denkweise, die sich in diesen Worten verrăth, dem israelitischen Alterthnm und gar der Zeit Davids zutrauen kann, verstehe ich nicht. Damals offenbarte Jahves Macht sich in anderer Art. 
des Psalters (und um diese handelt sichs bei den IchPsalmen) ursprünglich individuellen Characters waren und erst nachträglich Gemeindelieder geworden seien, - ist also an und für sich ernsten Bedenken unterworfen ${ }^{1}$ ). Ehe man eine solche Annahme macht, ist es eine unansweichliche Frage, ob denn das Ich jener Psalmen nicht von vornherein die Gemeinde bedeutet habe.

In der That ist es eine sehr alte Meinung, dafs das Ich der Psalmen vielfach auf die Gemeinde zu beziehen sei. Im Targum wird das Ich von einigen Psalmen aus drücklich auf Israel bezogen (Ps. 23. 38. ว̌6. 69. 88), was bei dem meist wörtlichen Character der Uebersetzung ins Gewicht fällt. Auch LXX deutet die Ueberschrift von Ps. 56 dem entsprechend. Zieht man hierbei den Tempelgebrauch des Psalters in Betracht, so wird man hier mit Recht von einer Tradition reden dürfen, die vom Midrasch verschieden ist. Bei den Juden des Mittelalters wurden viele Psalmen in dieser Weise verstanden, namentlich von Raschi, übrigens auch von Aben Esra und Kimchi. Zum Theil beruht es gewifs auf jüdischem Einflufs, dafs dies Verständnifs betr. einiger Psalmen schon früh bei den christlichen Exegeten Eingang fand, die das Ich dann naturlich gern auf die Kirche bezogen ${ }^{2}$ ). Vor allem ist

1) Das werden selbst diejenigen zugeben müssen, die da meinen, ein grofser Theil des Psalters sei der jüdischen Gemeinde aus dem israelitischen Alterthum überkommen. Auch Ewald hält $3 / 5$ der Psalmen für exilisch und nachexilisch, darunter 35 Ich-Psalmen. Eine grofse Zahl von vorexilischen Psalmen kann übrigens nur annehmen, wer die Psalmüberschriften zum Ausgangspunkt für die Kritik und Erklärung der Psalmen nimmt. M. E. haben Erklärung und Kritik des Psalters vielmehr davon auszugehen, dafs er das Gesangbuch des zwंeiten Tempels war. Vgl. Bleek, Einleitung in das A. T.4 S. 507. Inzwischen werden die hier folgenden Untersuchungen von dieser Frage wenig berührt.

$\left.{ }^{2}\right)$ So versteht Lusebius (vgl. auch den Syrer der Londoner Polyglotte) Ps. 5, Athanasius Ps. 56 als Gebet der Kirche. Nach Athanasius 
diese Auslegung aber von älteren protestantischen Auslegern beliebt worden, wobei Esrom Rudinger obenan steht ${ }^{1}$ ). Erst in neuerer und neuester Zeit hat man allgemein mit der Deutung des Ich auf die Kirche zugleich auch die auf die jüdische Gemeinde fallen lassen und auf Grund der Verfasserangaben nicht nur in den Davidischen Psalmen sondern dem entsprechend auch in den anonym überlieferten das Ich durchweg individuell zu verstehn gesucht. Hierin war unter den protestantischen Auslegern namentlich Calvin vorangegangen. Die grundsätzliche Abwendung von der allegorischen Exegese hat aber neuerdings einerseits zu einer falsch historisirenden und anderseits zu einer rationalisirenden Psalmauslegung geführt. Der lebhafte Wunsch Ewalds, wenigstens einige Psalmen als Davidisch und also auch aus dem Leben Davids begreifen zu können, hat ihn veranlafst, das Ich der Psalmen fast ${ }^{2}$ ) überall individuell zu deuten. Hupfeld dagegen, der die historisirende Deutung Ewald's trefflich widerlegte, war eine allzu nüchterne Natur, als dafs er sich in die durchgängige Personification der Gemeinde hätte finden können. In seinem verdienstvollen Commentar läfst er nirgendwo die Deutung des Ich auf die Gemeinde zu, -

und Eusebius betet Ps. 42.43 das reuige Israel zu Christus, anderswo findet Athanasius den Chor der Propheten oder der Apostel (Ps. 64. 71. 102). Die Pilgerlieder Ps. 120 ff. werden sogar meistens auf das aus dem Exil heimkehrende Israel bezogen. In weitem Umfang deutet Pseudo-Hieronymus das Ich der Psalmen auf die Kirche. Mir steht in Basel nicht die nöthige Literatur zu Gebote, um dies weiter zu verfolgen.

1) Er sagt z. B. zu Ps. 119 (V pag. 94) : servat autem enallagen personae usitatam et paene propriam posterioris aetatis psalmographis, ut in sua persona verba faciant de populo. Rudinger ist zu dieser Annahme überall da geneigt, wo ein Ich-Psalm nicht in der Ueberschrift dem David oder einem seiner Tempelsänger beigelegt wird. Das ist etwas sonderbar, aber auch lehrreich.

2) Anders verfährt Ewald bei Ps. 9. 118. 144. 
vermuthlich in dem richtigen Gefühl, dafs hier schon das kleinste Zugeständnifs von grö(ster Tragweite sein mufs ${ }^{1}$ ). Die Uebereinstimmung dieser beiden grofsen Gegner, das vereinigte Gewicht ihrer wohlbegründeten Autorität, hat hier die m. E. richtige Erkenntnifs bis jetzt niedergehalten, obwohl dieselbe seit Anfang dieses Jahrhunderts neu angebahnt und auch ausgesprochen war. Auch hier hat De Wette den Anstofs gegeben, obwohl er selbst die Beobachtungen, die er machte, nur sehr unvollkommen verwerthet hat ${ }^{2}$ ). Ihm fiel auf, dafs in sehr vielen Psalmen in durchaus gleicher Weise von Verfolgung die Rede ist, die das redende Ich erleidet, und er forderte hierfür eine einheitliche Erklärung. Er fand dieselbe in dem Nationalunglück der Hebräer, das sich durch ihre ganze Geschichte hinzog, und verstand unter den Verfolgern zunächst überall die Heiden. Das letztere war durchaus verkehrt, wie Hupfeld bewies, aber das Problem war damit nicht aus der Welt geschafft und die Ueberzeugung De Wette's, dafs öffentliches Unglück den Hintergrund aller dieser Lieder bilde, ist um so bemerkenswerther, als er das in ihnen auftretende Ich gleichwohl individuell verstehn wollte. Hierin hat schon Rosenmüller unter Rückgang auf die älteren Ausleger De Wette corrigirt, indem er in manchen Psalmen das Ich auf die Gemeinde bezog. Vor allem aber hat Olshausen De Wette's Gedanken weiter verfolgt und den Psalter durchweg als das Gesangbuch der Gemeinde des zweiten Tempels gedeutet. Dafs sein Psalmcommentar. für die alttestamentliche Philologie epochemachend ist, wird

1) Wie sehr es Hupfeld hier an Verständnifs für die von ihm bestrittene Auffassung fehlte, ersieht man namentlich aus $\S 4$ der seinen Commentar einleitenden Untersuchungen (am Schlufs) sowie aus den Vorbemerkungen zur Erklärung von Ps. 23. 38.

2) In seinem Aufsatz : Beytrag zur Characteristik des Hebraismus in Daub und Creuzer, Studien III (1807 Heidelberg) S. $241 \mathrm{ff}$. 
gegenwärtig allgemein anerkannt, dals ihm aber auch für die Auslegung der Psalmen eine sehr bohe Bedeutung zukommt, will ich zu zeigen versuchen. Ein Fehlgriff, wie er bei einem so vorsichtigen Forscher geradezu unbegreiflich erscheinen mufs, ist freilich in dieser Beziehung für den Erfolg seines Buches verhängnifsvoll geworden. Richtig sah er, dafs die Verfolger im Psalter fast mehr noch die Gottlosen als die Heiden sind, aber er sah nicht, dafs die Partei der Gottlosen seit dem Exil zu allen Zeiten in der jüdischen Gemeinde bestanden hat und bestanden haben $m u \Upsilon s$, weil sie mit dem Rest von politischer Selbständigkeit, den die Gemeinde des zweiten Tempels hatte, ohne weiteres gesetzt war. Er meinte vielmehr die Spaltung der Gemeinde in Eromme und Gottlose nur aus der syrischen Religionsverfolgung . begreifen zu können und weil er deshalb unter den Gottlosen schlechtweg die Hellenisten verstand, erklärte er den Psalter der Hauptsache nach für makkabäisch ${ }^{1}$ ). Indessen ist der sachliche Werth seines Commentars durch diesen freilich durchgängigen Irrthum weniger geschädigt, als man meinen könnte. Noch nachtheiliger ist es vielleicht für Olshausen's augenblicklichen Erfolg geworden, dafs er zumeist nur die Eindrücke wiedergiebt, die die verschiedenen Lieder auf ihn machen, ohne jedoch diese Eindrücke in ihre einzelnen Momente zu zerlegen, und somit die Nothwendigkeit, die weitaus meisten Lieder des Psalters als Gemeindelieder zu verstehen, förmlich zu beweisen. In dieser Beziehung versuche ich Olshausen zu ergänzen. Während er übrigens nach De Wette's Vorgang in manchen Gemeindeliedern das Ich noch individuell deutet, meine ich hiervon absehn müssen, kann

1) In Wahrheit sind es nur einige wenige Psalmen, die eine Deutung auf die Makkabaerzeit fordern, die weitaus meisten ertragen eine solche Deutung m. E. nicht. 
bei solchen Liedern uberhaupt noch weniger individuelle Färbung zugestehn, als das von seiner Seite geschieht ${ }^{1}$ ).

Wenn das Volk Israel im A. T. als ein Individuum, Mann oder Weib, vorgestellt wird, wenn es mit Ich redet oder mit Du angeredet wird, so liegt dabei zunächst wenigstens keine rhetorische oder poetische Figur vor, die mit Bewulstsein gesucht würde ${ }^{2}$ ). Es handelt sich hier vielmehr um einen ganz unwillkürlichen Ausdruck des Gemeingefühls. Nicht nur die Dichter und Propheten nennen ihr

i) Vgl. Olshausen, die Psalmen (kurzgef. Exeg. Handb. zum A. T.) S. $3 \mathrm{f}$.

2) Prof. Th. Plüss macht mich gütigst auf einige classische Parallelen aufmerksam, die für das Folgende von Interesse sind. „Am Schlufs des Săculargesangs von Horaz sagt der Chor von Knaben und Mädchen :

haec Iovem sentire deosque cunctos

spem bonam certamque domum reporto,

doctus et Phoebi chorus et Dianae

dicere laudes.

In den Chorliedern der Tragödie spricht der Chor bäufig in der orsten Person Singularis von sich, so z. B. Soph. Oed. Rex 1086 :

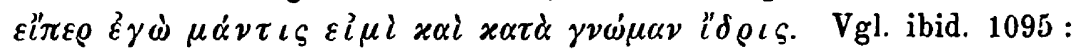

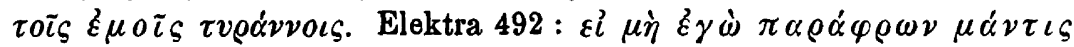

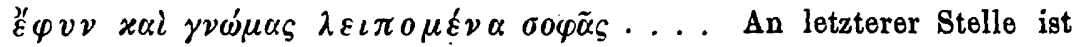

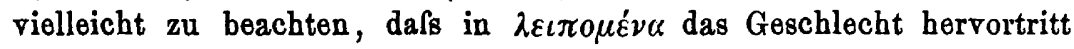
(es sind Frauen von Mykenä), während doch das Chorlied von einer Mehrheit recitativ gesungen gedacht wird, die erste Pers. Sing. also doch wohl ideal gemeint ist, nicht die einzelne Choreutin als Individuum bezeichnend, ist doch die ideale Person nicht geschlechtlos.

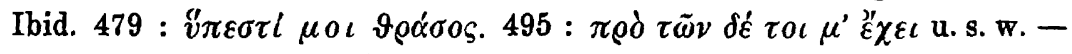
Im Dialog spricht die Chorführerin, aber sie vertritt in ibrem Singularis immer die Gesammtheit; daneben gebraucht sie auch den Pluralis, wo man oft zweifelbaft sein kann, ob es wirklich Mebrheitsplural sein soll oder nur die Form, wie sie im Griechischen jede einzelne Person überall von sich gebraucht. - Auch bei Pindar in den Chorgesängen redet der Chor in der ersten Sing. von sich. Man bezieht das auch wohl an einzelnen Stellen auf den Dichter, oft hat dies aber keinen Sinn. Und wenn dann der Chor etwa die Gemeinde einer Stadt, eine ideale Gemeinschaft, repräsentirt, so tritt hier diese als eine einheitliche Person auf." 
Volk den israelitischen Mann, den Bürger von Juda oder die Tochter Sion, auch den prosaischen Erzählern ist diese Redeweise geläufig (Jos. 9, 6 ff. 17, 14. Jud. 7, 23. 8, 1. 22. 20, $17 \mathrm{ff}$.). „Vielleicht wohnst $\mathrm{Du}$ in meiner Mitte", sagt Israel zu den Gesandten von Gibeon (Jos. 9, 7). „Du sollst nicht durch mich hindurchziehn, sonst trete ich "Dir mit dem Schwerte entgegen", damit weist Edom die Bitte Israels um Durchzug ab (Num. 20, 18 vgl. v. 14-21. 21, 22. Dt. 2, 27-29. Jud. 11, 19). „Ich will vor Israel fliehen", sagt der Aegypter (Ex. 14, 25). Auch kleinere Gemeinschaften reden in dieser Weise, so das Haus Joseph zu Josua (Jos. 17, 14 ff.), der Stamm Juda zu Simeon (Jud. 1, 3), die Stadt Ekron (1 Sam. 5, 10), die Juden von Betel (Zach. 7, 3) und die Heiden von jeder Stadt (Zach. 8, 21).

Wie diese Redeweise aber im Verkehr von Volk zu Volk erscheint ${ }^{1}$ ), so hat sie namentlich auch in der Religion ihre Stelle, die ja ein Wechselverhältnils zwischen Gott und Volk ist. Gern reden die Propheten zum Volke mit $\mathrm{Du}$, ebenso das Gesetz, namentlich in den Dekalogen von Ex. 20. 34, im Bundesbuch und im Deuteronomium. Umgekehrt lassen die Propheten auch das Volk mit Ich reden. Besonders merkwürdig ist die Stelle Mi. 6, 1 ff., wo Gott und Volk förmlich confrontirt werden. Jahve redet das Volk hier geradezu mit „Du Mensch" ${ }^{4}$ an (v. 8). Der Knecht Jahves redet bei Deutero-Jesaja als Ich (49, 1-5. 50, 4-10. 61, 1 ff. 10. 12. 62, 1. 63, 7. 15) und auch sonst ist diese Einführung des Volkes bei den Propheten häufig genug (Jes. 12, 1. 2. 25, 1. 26, 9. 40, 27. 48, 5. 7. 49, 14. Jer. 3, 4. 4, 19-21. 31. 10, 19. 20. 23. 24. 31, 18. 19. Hos. 2, 7. 9. 14. 18. Mi. 7, 1. 7-10. Hab. 3, 2. 7. 14. 16. 18. 19) ${ }^{2}$ ).

1) Sehr beliebt ist auch die Personification fremder Völker bei den Propheten, ich erinnere vor anderen an die der Chaldäer Hab. 2.

2) Man könnte versucht sein, auch Jo. 1, 6. 7. 19 so zu verstehn. 
Natürlich findet diese Redeweise sich auch im öffentlichen Cultus. ${ }_{n}$ Jahve ist meine Fahne", heifst der Altar Ex. 17, 15 im Munde des Volkes. Um den Namen Jahve's sammeln sich die Stämme Israels zum Kampfe gegen den Feind. Wie das Volk beim Gottesdienst mit Du gesegnet wird (Num. 6, 22 ff.), so redet es seinerseits zu Jahve mit Ich. Das liturgische Formular Dt. 26, 3. 5 ff. $13 \mathrm{ff}$. ist ursprünglich nicht den Einzelnen, sondern der Gemeinde in den Mund gelegt ${ }^{1}$ ).

Mit dem gottesdienstlichen Gesange verhielt sichs ebenso. Dafs Hab. 3 die Gemeinde redet, wird allgemein anerkannt (vgl. bes. v. 14. 18. 19). Aber auch im Liede der Debora Jud. 5 (v. 3. 9. 13. 21) ${ }^{2}$ ) und in dem Liede Ex. 15 (v. 1. 2) ist Israel am Wort. Hierher gehören auch die prophetischen Stellen Jes. 12, 1.2. 25, 1. Jer. 10, 23-25. Mi. 7, 7 ff., die z. Th. einen durchaus psalmartigen Charakter tragen; ferner Thren. 1, 11-22. 2, 11. 21. 22. cap. $3^{3}$ ). Im Psalter Salomos redet sehr oft ein Ich, das

1) Im zweiten Tempel wurde die Formel freilich von jedem einzelnen Darbringer aufgesagt, resp. von einzelnen Gruppen. Die Erstlinge reiften nicht überall zu gleicher Zeit. Vgl. Mischna Bikkurim III, 7. Philonea ed. Tischendorf p. $69,15 \mathrm{ff}$. und überhaupt Schürer, Gesch. des jüd. Volkes II, S. 197. Maimonides wird im Irrthum sein, wenn er meint, dafs das ganze Volk die Worte im Chor recitirte. Aber damit verräth er das richtige Verständnifs, das auch Philo hat. Dieser läfst freilich die Einzelnen recitiren, setzt aber für Ich überall Wir.

$\left.{ }^{2}\right)$ Betr. v. 7 vgl. Reufs zur St. Bleek, Einleitung 4 S. 190 Anm. Kuenen, Onderzoek." I S. 346.

3) Auch Thren. 3 bedeutet das redende Ich die Gemeinde. $\mathrm{Zu}$ meist wird hier in der 1. Pers. Sing. geredet, womit v. 40-47 die 1. Plur. wechselt. Nach der gegenwärtig herrschenden Erklärung handelt das Lied deshalb von den Leiden eines Einzelnen, die freilich mit den Schicksalen des ganzen Volkes zusammenhingen. Hierdurch entsteht aber der Eindruck des Wirrwarrs und der Langeweile, den das Lied gewöhnlich macht. In Wahrheit fehlt alles Individuelle. Nirgendwo wird gesagt, was der Einzelne besonders zu leiden habe. Die zahlreichen Bilder, in denen das Leiden des Redenden vorgestellt 
überall die Gemeinde bedeutet $(1,1-3.7$. 2, 15. 16. 24 . 30. 35. 3, 1. 5, 1. 3. 10. 8, 1. 3-7. 12, 1. 13, 1. 15, 1. 16, 1-12). Sollte das in den Psalmen Davids nie vorkommen?

Bemerkenswerth ist die grofse Freiheit, mit der die Personification angewandt wird. Wo die Sünde des Volks als Ehebruch und das Volk als eine Ehebrecherin vorgestellt wird,

wird ( . 1-16. 35. 36. 52-54), lassen uns hierüber völlig im Dunkeln. Deutlich ist nur, dafs er von Feinden verfolgt und verspottet wird (v. 35. 36. 52. 53. 58 ff. v. 14), was ebenso von der Gesammtheit gilt (v. 40-47). Mitten im Flufs der Gedanken, wo es sich um die Ursache der Noth handelt, tritt plötzlich die 1. Plur. ein, um nachher ebenso unerwartet wieder der 1. Sing. Platz zu machen. Jetzt klagt der Redende auch für seine Person über die Noth des Volkes und erfleht deren Aufhebung ( $v$. 48-51), um dann ohne weiteres wieder auf seine individuelle Noth und Rettung zu kommen ( $\nabla .52 \mathrm{ff}$.), bei der er bis zum Schlufs verweilt. Zuletzt scheint hier doch alles darauf anzukommen, dafs er gerettet wird,- seinetwegen soll Jahve die Heiden strafen und vernichten. Offenbar betrachtet der Redende sein Leiden als ein ganz besonderes und unvergleichliches, wie er v. $1 \mathrm{ff}$. nachdrücklich sagt. Wäre er nun von der Gesammtheit des Volkes verschieden, dann müfste er aber auch sagen, in wiefern sein Leiden ein eigenartiges ist. $\mathrm{Da}$ er das mit keinem Worte thut, so mufs er eben mit der Gesammtheit des Volkes identisch sein (vgl. 1, 12. 2, 13). Nun begreift sich sofort die endlose Häufung von Bildern, in denen das Leiden des Redenden geschildert wird, ohne dafs irgendwie concret gesagt würde, was ihm fehle. Es handelt sich um das allbekannte Unglück der Gesammtheit. Deutlich reden v. 22. 23 von Jahve's ewiger Gnade gegen Israel, das von ihm nicht auf ewig verworfen werden kann (v. 31). Es ist Israels Theil (v. 24). In Betracht kommt überhaupt die Gewifsheit, mit der der Redende seine Rettung erwartet (v. 32.56 ff.). Dafs die Perfecta v. 56-58 auf die Zukunft gehn, beweist der dazwischen stehende Jussiv ( $v$. 56) und die Imperative (v. 59. 63), sowie der Schlufs v. 64 ff. Dagegen ist v. 14 עמים herzustellen, übrigens würde selbst y der Annahme der Personification nicht im Wege stehn. Die Worte v. 27 bedeuten, dafs das Volk noch eine weite Zukunft vor sich sieht. Versteht man das Volk als das redende Subject, so gewinnt das ganze lied bedeutend und zeigt, abgesehn von einigen kleineren Wiederholungen, einen wohl geordneten Gedankengang. Unbedenklich kann es dann mit den übrigen Klageliedern concurriren. Uebrigens ist die Deutung auf das Volk alt (vgl. z. B. Calov z. St.), neuerdings hat sogar Hupfeld ihr beigepflichtet (zu Ps. 38). 
entsteht zuweilen eine consequent durchgeführte Allegorie. In anderen Fällen kommt es aber nicht dazu. Die Personification des wahren Israel wird Jes. 53 so weit getrieben, dafs Ewald meint, das Leiden eines einzelnen prophetischen Märtyrers liege der Schilderung zu Grunde. In Wahrheit stimmen die einzelnen Züge der Schilderung durchaus nicht zusammen. Der Leidende erscheint zuerst als ein Aussätziger, dann als ein Gerichteter. Der Hebräer hat auch in solchem Fall an dem bunten Wechsel der Bilder mehr Freude als an der Durchführung eines einzigen. Mit Thr. 3 verhält sichs ebenso. Entgegen den Gesetzen unserer Rhetorik wird ferner keine Rücksicht darauf genommen, ob die einzelnen Züge der Schilderung auf die Gesammtheit gedeutet werden können oder nicht. Man kann gar nicht ausdeuten, was Jes. 53 von der Beurtheilung gesagt wird, die Leiden und Tod des Knechts bei seinem Volke gefunden hatten. Ebenso steht es natürlich mit seinem Begräbnifs (v. 9) und dem Leibe seiner Mutter (49, 1. 5). Ueberhaupt aber gefällt man sich darin, die Person Israels oder Jerusalems so lebendig wie möglich vorzustellen. Nicht nur Seele und Geist (Jes. 26, 9. 53, 10 ff. 61, 10. Jer. 4, 31. Thren. 1, 16. 3, 17), sondern auch Fleisch und Bein (Hab. 3, 16. Thren. 1, 13. 3, 4), ja sämmtliche Körpertheile vom Scheitel bis zur Sohle (Jes. 1, 5.6) werden ihr mit Vorliebe beigelegt. Vgl. z. B. Jud. 5, 9. Jes. 49, 2. 50, 4 ff. 53, 7. Jer. 4, 19. 31. 31, 19. Mich. 7, 10. Hab. 3, 16. 19. Thren. 1. 3 passim. Merkwürdig ist noch die Personification des Landes Juda Jes. 7, 20.

In vielen Fällen wird übrigens einfach Ich statt Wir gesetzt, ohne dafs von einer eigentlichen Personification die Rede sein könnte. An den Stellen Num. 20, 14 ff. 21, 22. Ut. 2, 29. Jud. 11, 19 wechselt deshalb ohne weiteres Wir mit Ich und umgekehrt. Es geschieht das mit. derselben Leichtigkeit, mit der bei den Propheten und im Gesetz $\mathrm{Du}$ in Ihr und $\mathrm{Er}$ in Sie übergeht. Ebenso im 
Psalter Salomos (2, 28. 8, 3. 30. 31. 33. 35. 36. 39. 13, $1-3$, womit die oben angeführten Stellen zu vergleichen sind). Auch Mi. 7, $7 \mathrm{ff}$. entspricht dem Ich ( $\nabla .7-10$ ) zuletzt ein Wir (v. 17-20).

Umgekehrt giebt es Fälle, wo das allgemeine Ich oder Du eigentlich in Wir oder $\mathrm{Ihr}$ übergehn sollte, aber weil einmal angenommen auch beibehalten wird. Oft beziehen nämlich Ich und Du sich zuerst auf die Gesammtheit, aber im Lauf der Rede treten an die Stelle der Gesammtheit die einzelnen Individuen, ohne dafs darum das lch oder $\mathrm{Du}$ aufgegeben würde. Also kann ein allgemeines Ich oder $\mathrm{Du}$ in ein individuelles übergehn und umgekehrt. So z. B. im Dekalog von Ex. 20. Hier müssen die Sätze จ. 12. 16. 17 individuell verstanden werden, während จ. 2.3 und danach auch v. 4.5 zweifellos das Volk angeredet ist. In v. 10 liegt die Sache am Schlufs ebenso, aber vorher und in den übrigen Sätzen steht das Du individuell (vgl. auch Dillmann, Exod. Lev. S. 217 med.). Oefter hat so in demselben Verse das Du zuerst allgemeine und sofort darauf individuelle Bedeutung. Das ist eine unreine Redeweise. Ebenso heifst es Ex. 23, 26 zu Israel : "Kein kinderloses und unfruchtbares Weib soll es in „Dir geben, die Zahl Deiner Lebenstage will ich voll „machen“. Es sollte heifsen : „Die Zahl Eurer Lebens"tage ${ }^{\mu}$.

Aehnlich steht es mit dem Ich in Ps. Sal. 16. Die Gemeinde der Frommen dankt hier Gott, dafs er sie nur züchtigte, während er die Gottlosen vernichtete. Dabei aber bittet sie v. 7 ff. wie ein einzelner Frommer um Bewahrung vor den Sünden, die ihre Gegner ins Verderben stürzten; vgl. Ps. 141, 3 f. Hier wäre auch besser ein Wir eingetreten ${ }^{1}$ ).

1) Anders Wellhausen, Pharis. u. Sadd. S. 160.

Zeitschrift f. d. alttest. Wiss. Jahrgang 8, 1888. 
Das Sonderbarste ist aber, dals ofter bei Personification des Volkes statt Ich, Du, Er ein Wir, Ihr oder Sie auftritt. Es wird auf die Vielheit der Volksglieder übertragen, was allein von der Einheit des Volkes gesagt sein sollte. Jes. 46, 3. 4 sagt Jahve zum Volke : „Ihr, die ihr „(von mir) getragen seid vom Mutterleibe an, gehoben vom "Mutterschofse an! Auch bis in (euer) Alter bin ich der-

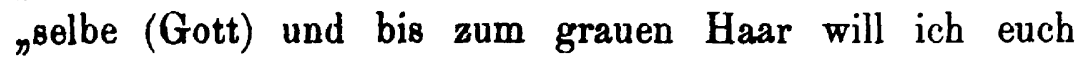
„tragen". Zu Grunde liegt hier die Personification des Volkes, das Jahre vom Beginn seiner Geschichte an gehegt und gepflegt hat und bis zuletzt hegen und pflegen will. Die Personification wird aber durchbrochen, indem das Volk nun doch nicht mit $\mathrm{Du}$, sondern mit Ihr angeredet wird. Ebenso sacren die Israeliten Jer. 3, 24. 25 : "Die Schande (d. h. der Baalsdienst) frafs den Erwerb „unserer Väter von unserer Jugend an" d. h. so lange das Volk Israel besteht. Hos. 11, 3. 4 ist Efraim zuerst als ein Knabe und dann als ein arbeitender Stier vorgestellt, gleichwohl wird auch hier vom Volke im Plural geredet. Ez. 37, 11 sagen die Judäer : „unsere Gebeine sind ver„dorrt, unsere Hoffnung ist dahin, es ist aus mit uns". Israel gleicht einem längst verwesten Leichnam, dessen Auferweckung undenkbar ist. Dennoch reden die Judäer mit Wir. Dem entsprechend hat sich nun sogar die Darstellung in v. $1 \mathrm{ff}$. gestaltet, wo die Gebeine Israels durch die Gabeine der erschlagenen Israeliten ersetzt sind. Vgl. noch Ez. 33, 10. Hos. 6, 1. 2. Thren. 4, 18.

Hiernach ist es denn auch nicht zu verwundern, dals Ioh und $\mathrm{Du}$ im Zusammenhange desselben Stückes verschiedenen Umfang haben können. Hab. 3 scheint das Ich des Propheten $(1,2.3 .12 .2,1.2)$ in das der Gemeinde überzugehn ${ }^{1}$ ). In einzelnen Fällen kann deshalb

1) Stade (diese Zeitschrift 1884 S. 157) bat mich nicht völlig davon überzeugt, dafs Hab. 3 andern Ursprungs ist als c. 1. 2. 
auch das Ich des Dichters neben dem der Gemeinde auftreten.

Die hier kurz berührten Punkte verdienten eine nähere Erörterung, zu der es mir jetzt an Zeit fehlt. Indessen wird das Vorstehende für meinen gegenwärtigen Zweck genügen. Die hebräische Ausdrucksweise zeigt auch hier einen auffallenden Mangel an Präcision, der nicht nur aus der Unbeholfenheit der Sprache, sondern weiter aus der psychischen Anlage des Hebräers zu erklären ist. Mit der Lebhaftigkeit seiner Empfindung geht eine gewisse Unbestimmtheit der Auffassung überall Hand in Hand. Bei Entscheidung der Frage also, ob das Ich eines Liedes auf die Gemeinde gedeutet werden mufs, darf man unmöglich die Forderung stellen, dafs jeder einzelne Satz des betreffenden Liedes in seinem logischen Wortsinn unmittelbare Anwendung auf die Gesammtheit ertrage. Wenigstens werden wir uns auf einzelne Fälle gefafst machen müssen, wo das keineswegs so ist. Lassen sonst nur sichere Indicien ein Lied als Gemeindelied erkennen, so darf dieser oder jener mehr individuell klingende Satz uns daran nicht irre machen. Denn die Deutung des Ich auf die Gesammtheit will überall cum grano salis verstanden sein.

In Ps. 129 wird Israel ausdrücklich mit Ich redend eingeführt (v. 1), Hupfeld (zu Ps. 38) will aber die Deutung des Ich auf die Gemeinde nirgends zulassen, wo dieselbe nicht vom Dichter selbst mit dürren Worten verlangt werde ${ }^{1}$ ). Unzweideutig sind indessen Beispiele wie Ps.

1) Im Folgenden untersuche ich sämmtliche Psalmen, in denen ein Ich bedeutungsvoll auftritt, auf die Natur desselben. Wahrend ich dabei aber weiterhin die betreffenden Psalmen einfach ihrer Reihenfolge nach bespreche, nehme ich hier zunächst einige Lieder vorweg. Denn einmal möchte ich vorläufig feststellen, dafs das Ich der Psalmen in einigen Fällen wirklich die Gemeinde bedeutet. Uebrigens aber liegt 
74, 12. 44, 5. 7. 16. An ersterer Stelle heilst es : ${ }_{n}$ Aber „Gott ist mein König von Alters her, der Rettungsthaten „vollführte inmitten der Erde. Hier kann das Ich (vgl. dagegen Wir v. 9) nur die von den Heiden verfolgte Gemeinde vorstellen. Denn erstlich handelt sichs um die Noth der Gemeinde. Zweitens ist Jahve der König Israels und nicht des einzelnen Israeliten. Endlich sagt das redende Ich, dafs Jahve sich von Alters her als sein König erwiesen habe. LXX hat dem Sinne nach richtig : $\beta \alpha \sigma i \lambda \varepsilon \dot{v}_{\varsigma}$ ijuõv. - Ebenso findet sich Ps. 44, 5. 7. 16 neben sonst durchgängigem Wir ein Ich, das auf die Gemeinde bezogen werden mufs. Auch hier ist Jahve der König Jakobs (v. 5) und nicht um persönliche Schmach handelt sich's, sondern um die der Gemeinde (v. 16). Bei v. 7 ist zu beachten, dafs der ersten Person Singularis im Vordersatz die erste Pluralis im Nachsatz entspricht ${ }^{1}$ ).

In den genannten Fällen wechselt Ich mit Wir, es kommt aber vor allem auf die Lieder an, in denen überall ein Ich redet. Hierbei gehe ich von Ps. 6 aus. Ich thue das nicht deshalb, weil ich hier die Gegner am leichtesten zu überzeugen hoffte, vielmehr wird die Richtigkeit meiner Beurtheilung von Ps. 6 sich z. Th. erst bei Besprechung anderer verwandter Lieder mit voller Evidenz ergeben. Wohl aber tritt bei diesem viel discutirten Liede die Unzulänglichkeit der herrschenden Auslegung deutlich zu Tage und übrigens finden sich hier eine Reihe von Momenten vereinigt, die sonst meistens zerstreut auftreten.

mir daran, gewisse typische Fälle zusammenzustellen. - Man möchte für die folgende Untersuchung von vornherein eine gewisse Grenze fordern, sofern nämlich einige Lieder des Psalters nicht nur dem David beigelegt, sondern auch auf einen bestimmten Zeitpunkt seines Lebens zurückgeführt, also von der betr. Ueberschrift wenigstens individuell gedeutet zu sein scheinen. Die Erledigung dieses Einwandes verschiebe ich auf den Scblufs dieser Abhandlung.

1) Die Perfecta v. 8.9 gehn m. E. auf die Zukunft. 
Der hier Redende ist in grofser Noth, die seinen Untergang herbeizuführen scheint. Er kann diese Noth nur als Schickung des Zornes Jahves betrachten, der mit ihm wegen seiner Sünden ins Gericht gehen und ihn vernichten will. Aufs tiefste erschüttert ruft er Jahve um Gnade an, er möge seinen Diener retten, der dafür seinen Namen in der Welt verherrlichen will. Denn im Todtenreich preist Niemand den Jahve. Schon lange hat der Leidende geseufzt und geweint, er ist darüber matt geworden und seine Augen sind eingefallen. Was nämlich sein Leiden noch besonders bitter macht, ist der Gedanke, dafs sein Untergang der Triumph seiner gottlosen Feinde wäre. Gerade an diesem Punkte schlägt aber die Klage auf einmal in die Gewifsheit der Rettung um. Die bösen Feinde werden nicht Recht behalten, vielmehr wird Jahve den Leidenden retten, plötzlich werden die Gegner vom göttlichen Zorn getroffen werden.

Vor allen Dingen ist der hier Redende von Feinden verfolgt. Denn v. 8, wo die Klage ihren Höhepunkt erreicht, heifst es : „Eingefallen ist vor Gram mein Auge, „es ist gealtert wegen aller meiner Dränger ${ }^{\text {( } 1)}$ ). Danach mufs das Leiden wenigstens hauptsächlich in Verfolgung bestehn. Hierin wird man dadurch bestärkt, dals bei der Aussicht auf Rettung (v. 9-11) allein die bösen Feinde in Betracht kommen, nicht aber eine zu hebende Krankheit. Schliefslich ist der Wortlaut von v. 9-11 entscheidend. Beschämt müssen die Feinde zurückweichen, indem sie plötzlich erschrecken, d. h. sie werden plötzlich von einem schweren Schlage getroffen und damit nimmt das Leiden des Redenden ein Ende. Nun ist es aber mit der Verfolgung hier eine eigene Sache. Von Seiten der zahlreichen Verfolger droht dem Redenden nicht unmittelbar der Tod,

1) מכל ist freilich sehr hart, man erwartet. 
er meint vielmehr an dem Kammer zu sterben, den sie ihm bereiten. Nur den Sinn können die Worte v. 8 baben. Obendrein sagt der Redende aber auch, er sei krank : „Sei mir gnädig, o Jahre, denn ich bin siech! Heile „mich, o Jahre, denn meine Gebeine sind erschrocken! "Und meine Seele ist sehr erschrocken und Du, o Jahve,

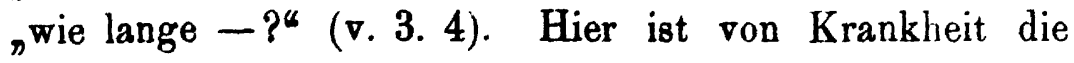
Rede. Man kann dem nicht dadurch entgehn, daf man die einzelnen Ausdrïcke bildlich deutet. Das Verbum רפא kann freilich in übertragenem Sinne jede Art der Wiederherstellung bedeuten (z. B. Jer. 17, 14) und אמלל kann auch das Schmachten vor Kummer bezeichnen (Jer. 15, 9). Die Steigerung von v. 3 zu v. 4 zwingt auch nicht an leibliche Krankheit zu denken. Es ist der hebräischen Vorstellungsweise ganz entsprechend, dafs der Schrecken zuerst die Glieder und dann das Lebenscentrum, die Seele, ergreift.' Gleichwohl wollen diese verschiedenen Momente zu einem Gesammtbild vereinigt sein und nicht einen blofsen Seelenzustand als vielmehr leibliche Krankheit schildern. Das verlangt die Analogie der übrigen Psalmen dieser Art (Ps. 22. 30. 38. 41. 102), wo überall feindliche Verfolgung und Krankheit neben einander stehn. Namentlich kommt Ps. 38 in Betracht, der in dieser Hinsicht für das Verständnifs von Ps. 6 malsgebend sein mufs. Versteht man ferner v. $3 \mathrm{ff}$. nur vom Seelenzustand des Redenden, dann wäre bis zum Schlufs von v. 8 von seinem Leiden gar nichts gesagt. Man giebt denn auch meistens $\mathrm{zu}$, dafs v. 3. 4 von Krankheit reden, versucht aber die Ausflucht, dafs die Krankheit nur Bild der Verfolgung sei. Indessen ist diese Annahme gänzlich unzulässig, so lange man das Ich des Liedes individuell deutet. Unmöglich kann die Verfolgung, die ein Einzelner leidet, unter dem Bilde einer Krankheit dargestellt werden und zwar so, dafs wir von der Verfolgung zunächst überhaupt gar nichts erführen und erst nachträglich merkten (v. 8-11), dafs es sich 
eben nicht um Krankheit, sondern um Verfolgung handele. Jedem Dichter ist es doch um den vollen und unmittelbaren Ausdruck seiner Empfindung zu thun. Nur so kann er sich selbst genügen und auf andere wirken. Hier dagegen (und in einer ganzen Reihe ähnlicher Fälle) hätte der Dichter seine Lage aufs sonderbarste verschleiert und sich selbst den wunderlichsten Hemmschuh angelegt ${ }^{1}$ ). Vermuthlich ist es diese Einsicht gewesen, was Ewald bewog, allem anderen zum Trotz das Leiden des Dichters als wirkliche Krankheit zu betrachten. In der That bleibt nichts anderes übrig, wenn man das Ich persönlich versteht. Weiter mufs dann die Krankheit mit der Verfolgung in nächster Beziehung stehn und durch dieselbe verursacht sein. Furcht und Hoffnung, Klage und Jubel (v. 3-8. 9-11) müssen nothwendig einander entsprechen, das verlangt die gewaltige Leidenschaft, die das Lied bewegt. Man mülste sonst den hier geäufserten Empfindungen jede innere Wahrheit aberkennen. Ueberdies ist es deutlich, dafs die Niederlage der Feinde dem Redenden ebenso gewils die Genesung bringt, wie der Kummer über die Verfolgung ihn todtkrank macht. Jedenfalls wäre der Redende, wenn er ein Individuum vorstellte, in einer höchst singulären Lage. Man müfste deshalb auch erwarten, dafs er ihre einzigartige Complication irgendwie darlegte. Sonderbarer Weise kehrt jedoch dieselbe räthselhafte Situation genau so in Ps. 13 wieder und ähnlich sind die vorhin genannten ${ }_{n}$ Krankenlieder" alle. Soweit die Ausleger diese Schwierigkeiten überhaupt empfinden, helfen sie sich (wie z. B. Hupfeld) mit der Ausflucht, der Dichter meine es nicht ernst, wenn er von Todesgefahr rede. Wer ihm aber Uebertreibung zuschiebt, hat ihn offenbar nicht verstanden.

1) Natürlich ist es etwas ganz anderes, wenn Jeremia einmal $(15,18)$ die Endlosigkeit seiner Leiden mit einer unheilbaren Krankheit vergleicht. Da liegt die Bildlichkeit der Redeweise am Tage. 
Thatsächlich kommt die herrschende Auslegung von Ps. 6 tiberall auf Rathlosigkeit hinaus.

Ein befriedigendes Verständnifs von Ps. 6 ergiebt sich dagegen, sobald man einsieht, dafs hier das verfolgte Israel redet. Es handelt sich um die gemeine Noth, die allen wohlbekannt ist; Jedermann weifs, was dabei in Rede steht. Deshalb kann sofort bildlich von ihr geredet werden, ohne dafs die bildliche Redeweise eine Verschleierung der Wirklichkeit wäre. Sie ist jetzt auch kein Hemmnifs für den unmittelbaren Ausdruck der Empfindung. Vielmehr entspricht die Personification nicht nur der Lebendigkeit, mit der die Gemeinde ihr Verhältnifs zu Jahve auffalst, sie ermöglicht auch die lebendigste Auffassung und Darstellung der Leiden der Gesammtheit. Sobald aber die Personification gegeben ist, ist auch das Bild gegeben. Das Leiden eines Einzelnen wird am anschaulichsten in der Krankheit; wie beliebt es war, Israels Leiden als Krankheit vorzustellen, weifs Jeder aus den Propheten ${ }^{1}$ ). Aus der Personification der Gemeinde begreift sich sodann der Mangel an Anschaulichkeit in der Schilderung, das Ineinanderfliefsen von Sache und Bild; Verfolgung und Krankheit. Auch v. 8 wird so verständlich. Die Gemeinde erliegt nicht überall dem Schwert ihrer Verfolger, unter dem Druck der Heiden und der Gottlosen meint sie vielmehr hinzusiechen. Freilich mufs nun auch v. 7 zur Personification gehören ${ }^{2}$ ).

In Betracht kommt ferner die nahe Verwandtschaft von v. 2 mit Jer. 10, 24, wo ebenfalls die Gemeinde redet.

1) Jes. 1, 5. 6. 17, 11. 33, 24. 53, 3 ff. Hos. 5, 13. Thren. 1, 13.

2) Von apologetischer Seite hört man zuweilen die Frage, wie doch Jes. 53, wenn dort das wahre Israel gemeint wäre, überhaupt verstanden werden konnte. Diese Frage ist wohl begründet und allein in Psalmen wie diesem and vielen anderen kann man eine befriedigende Antwort finden. 
Auch erscheint jetzt v. 6 in einem völlig anderen Lichte. Mit dem Untergange der Gemeinde würde das Lob Jahves auf Erden ein Ende haben - deshalb soll und mufs Jahve die Gemeinde erhalten ${ }^{1}$ ). An dem Lobe eines einzelnen Frommen kann ihm soviel nicht liegen. Schon aus diesen Gründen mufs Rosenmüller Recht gegeben werden, wenn er für Ps. 6 die Deutung erneuert, die bereits Aben Ezra zur Wahl stellt.

Wichtig ist aber auch der plötzliche Uebergang von der fast verzweifelten Klage zur Gewilsheit der Rettung. Wie sollen wir es uns vorstellen, dals ein Einzelner, mag er nun krank oder von Feinden verfolgt sein, mitten in der Verzweiflung plötzlich in sich selbst die völlige Gewifsheit findet, dafs Jahve ihn retten werde? Es handelt sich hier freilich um seelische Vorgänge, die sich einer zureichenden Erklärung schliefslich entziehen. Inzwischen kehrt diese Erscheinung ähnlich in manchen anderen Psalmen wieder ${ }^{2}$ ) und deshalb mufs hier wie anderswo nach ihren Vorbedingungen gefragt werden. Die Ausleger machen sich hierum zu wenig Sorge und wo sie die Frage überhaupt stellen, thun sie sie sofort mit Gewaltstreichen $a b$, die kaum einer Widerlegung bedürfen. Nur so kann ich es bezeichnen, wenn man vermuthet, der zuversichtliche Schlufs sei erst beigefügt, nachdem die Rettung eingetreten

1) nIch werde nicht sterben, sondern leben und die Thaten Jahves verkündigen". So sagt, wie auch Ewald zugiebt, 118, 17 die jüdische Gemeinde. Die Verkündigung der Gröfse Jahves ist ihre geschichtliche Aufgabe, in deren Lösung sie nersetzlich ist. Im Grunde ist es dasselbe wie das Verbum Dei manet in aeternum (Jes. 40, 8). Vgl. noch 115,16 ff. 26,6 ff. $30,10.13 .57,10.71,17.88,11$ ff. $89,2.104$, 33. 34. 145,21 . Bis einst die Weltherrschaft Jabves in anderer Weise offenbar wird, thront er über den Lobliedern Israels (22, 4).

2) 7,15 ff. $13,6.22,22$ ff. $26,12.27,13.28,6$ ff. $31,6.8 \mathrm{ff}$. 22 ff. $41,13.14 .56,13$ f. 57,7 ff. 69,31 ff. $86,12.13 .116,8$ f. 16. Vgl. auch Ps. Sal. 5, 18-22. 
war ${ }^{1}$ ), oder auch annimmt, der Dichter vergegenwärtige sich nach der Rettung das Gebet, das die Rettung erflehte, und stelle ihm zugleich seinen Erfolg und den Dank für die Rettung an die Seite ${ }^{2}$ ). Im ersteren Falle wird die zweifellose Einheit dieser Lieder preisgegeben, im letzteren ihre ebenso zweifellose Lebenswahrheit. Sie entstammen der Noth und Gefahr und ebenso absichtlich wie naturwahr treten Verzweiflung und zuversichtliche Hoffnung einander gegenüber. Deshalb mufs man fragen : konnte der Einzelne angesichts drohender Todesgefahr mit derartiger Zuversicht auf Rettung hoffen, wie das in diesen Psalmen geschieht? Im Allgemeinen sind solche Ansprüche des Individuums im A. T. nicht sehr berechtigt und die zuversichtliche Erwartung ihrer Erfüllung unerhört. Um das zu verstehen, mülste man annehmen, dafs der Tod des Redenden an sich den Untergang der guten Sache und den Triumph der Gottlosigkeit bedeutete. Aber das ist bei einer Einzelperson nicht leicht vorstellbar und der Redende sollte dann doch irgendwie andeuten, dafs und weshalb er soviel für Jahve werth sei. Statt dessen sagt er nur indirect, dals er Jahve für seine Rettung preisen würde (v. 6) und übrigens fühlt er sich um seiner Sünden willen als Gegenstand des göttlichen Zorns (v. 2). Man hat freilich diesen Psalm und einige andere verwandte dem Jeremia ${ }^{3}$ ) beilegen wollen, vielleicht in dem unbestimmten Gefühl, dals solche Ansprüche nur aus ganz aufserordentlichen Verhältnissen begreiflich seien - aber, um von anderem zu schweigen - wo wäre in diesen Psalmen das eigenthümliche prophetische Berufsbewufstsein Jeremia's zu finden, auf dem allein solche Ansprüche beruhn könnten?

1) So Ewald zu Ps. 28. 31.

2) So selbst Olshausen zu Ps. 28. 31.

3) Vgl. Jer. 20, 13. Es fragt sich aber auch noch, ob diese Worte nicht ex post geschrieben sind. 
Dagegen ist dies Schwanken zwischen Verzweiflung und Zuversicht für das israelitische oder vielmehr jüdische Gemeinbewufstsein characteristisch. Immer wieder möchte die Gemeinde unter dem Druck der Schuld und des göttlichen Zornes verzagen, immer wieder erscheint ihr stets neues Unglück die Endlosigkeit des göttlichen Zornes zu beweisen, der sie zuletzt vernichten will, und dabei steht doch die Gewifsheit der messianischen Zukunft und also auch der immer neuen Rettung der Gemeinde unerschütterlich fest. Diese beiden gegensätzlichen Stimmungen liegen im jüdischen Bewufstsein dicht neben einander. Sie treten hier und oft nur scheinbar unvermittelt einander gegenüber, in Wahrheit ist überall die eine von der anderen bedingt. So oft auch die Gemeinde von den Gottlosen oder von der Heidenwelt verschlungen zu werden scheint, als ob Jahve sie um ihrer Sünden willen vertilgen wollte, zuletzt können die gottlosen Feinde nicht triumphiren, die Gemeinde Jahves mufs erhalten bleiben : „Weicht von mir alle ihr Uebelthäter ! Ob hier die Gottlosen (vgl. 139, 19) oder Heiden gemeint sind, bleibt unklar.

Könnte bei Ps. 6 bezüglich des Verhältnisses von Krankheit und Verfolgung noch irgend ein $Z$ weifel bestehn, bei Ps. 38 ist jeder Zweifel ausgeschlossen und damit gewinnt die oben begründete Erklärung von Ps. 6 noch gröfsere Sicherheit. Der hier Redende fühlte sich von Gottes Zorn getroffen, der ihn gezüchtigt und seine Pfeile auf ihn abgeschossen hat. An seinem Leibe ist nichts mehr heil, seine Striemen stinken und eitern (v. 2-6. 8). Sein Leiden erscheint geradezu als Aussatz, seine Angehörigen und Freunde meiden ihn deshalb (v. 12). Nachher ist aber von Krankheit kaum noch die Rede (v. 18), vielmehr wird der Redende von grausamen Feinden geschmäht und verfolgt, die ihn gern zu Fall bringen möchten (v. 17. 18), ihm mit List und Trug beizukommen suchen (v. 13. 20) und nach seinem Leben trachten (v. 13). Man 
fragt billig, weshalb doch der von aller Welt verlassene Mann noch mit Lüge und Heimtücke verfolgt wird, weshalb seine Feinde ihm, dem hoffnungslos Kranken, ans Leben wollen. Diese Frage ist um so nothwendiger, weil es sich mit Ps. 41 genau ebenso verhält. Dazu kommt, dafs die Klagen zumeist (v. 3-12) von der Krankheit reden (vgl. dag. v. 13), während bei der Bitte um Rettung nur die Feinde ins Auge gefalst werden (v. 14-23) ${ }^{1}$ ). Man sieht sich somit auch hier zu der Annahme gedrängt, dafs die Krankheit eben nur Bild des Leidens ist, das in Wahrheit in Verfolgung besteht. Hitzig, der seinerseits den Jeremia für den Verf. hält und die Schläge v. $3 \mathrm{ff}$. unerschrocken auf Jer. 20, 2 bezieht, läugnet mit Recht, dafs Verfolgung, die ein Einzelner erleidet, in solcher Weise allegorisirt werden könne. Diese Einsicht führt aber nothwendig zu dem Schlufs, dafs die Gemeinde redet. Die Verwandtschaft von v. 4 ff. mit Jes. 1, 5 f., von v. 14 f. mit Jes. 53, 7 und von v. 12 mit Jes. 53, 3. 4 liegt auf der Hand. Schon das Targum und später Raschi haben das Lied auf die Gemeinde bezogen.

Auch bei Ps. 22 gelangt man zu keinem befriedigenden Verständnifs, so lange man in dem redenden Subject ein Individuum sucht. Unlösbar erscheint dann der Contrast, in dem der erste Theil des Liedes (v. 2-22) mit dem zweiten (v. 23-32) steht. Dort ist es mit dem Redenden aufs äufserste gekommen, er ist dem Untergange nahe (v. 16. 21) und fleht um schleunige Rettung - hier schlägt plötzlich mitten in v. 22 der ängstliche Hülferuf in die zuversichtliche Erwartung der Rettung um ${ }^{2}$ ) und sofort verspricht er nicht sowohl seinen Dank für die

1) Hierin gleicht das Lied durchaus dem 6. Psalm.

2) עניתנ kann natürlich nur Perf. proph. sein. Einen Precativ giebts im Hebräischen nicht. Vgl. A. Müller in Guericke's Zeitschrift 1877 S. $199 \mathrm{ff}$. 
Rettung (v. 23. 26) als er ihn vielmehr schon abstattet. Der ganze Same Jakobs soll den Jahve für die Rettung des Redenden loben (จ. 24. 20̃). Das höchste Glück wird Israel zu Theil (v. 27) und alle Heiden bekehren sich zu Jahve, der seine Weltherrschaft aufrichtet (v. 28-30). Alle zukünftigen Geschlechter werden ihm dienen und ihn für den Erweis seiner Gerechtigkeit preisen (v. 31. 32) ${ }^{1}$ ). Wohin verliert sich der Dichter! Woher dieser plötzliche und völlige Umschlag seiner Stimmung? Unmöglich kann der letztere mit Calvin daher erklärt werden, dafs die Rettung eben schon eingetreten sei. Woher dann aber eine solche Gewifsheit der Rettung, dafs der Redende sich selbst darüber fast schon vergessen und von der Zukunft Israels und der Bekehrung der ganzen Welt mit soviel Worten reden kann ${ }^{2}$ )? Nun ist die Rettung des Redenden offenbar für ganz Israel von der gröfsten Bedeutung, deshalb soll das ganze Volk den Jahve dafür ehren und fürchten (v. 24. 25). Vor der Hand liegt es, auch v. 31.32 dahin zu verstehn, dafs eben hierfür Jahve in alle Zukunft gepriesen werden soll. Ueberdies handelt es sich v. 27 um die messianische Zukunft, das messianische Glück Israels beweist den Heiden die alleinige Gottheit Jahves $\left(\right.$ v. 28 ${ }^{3}$ ). Die Rettung des Redenden ist aber nicht nur ein Angeld auf die Erfüllung der Zukunftshoffnung, sie

1) Offenbar richtig hat man v. 32 יבאו zu v. 31 gezogen und

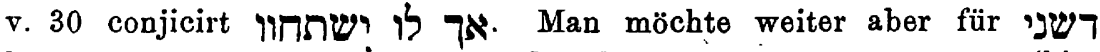

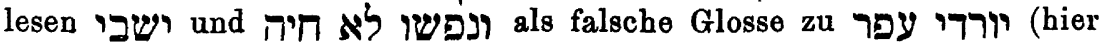
$=$ Sterbliche, nicht $=$ Verstorbene) streichen.

2) Ewald : „Eine nahe Aussicht, zu der sich der Dulder zu ernheben wagt, führt ihn weiter zur entfernteren, diese wieder durch nsich selbst zu noch entfernteren und höberen."

${ }^{3}$ ) Es ist durchaus willkürlich, wenn Hofmann und Hupfeld den engen Zusammenhang von v. $28 \mathrm{ff}$. mit dem Vorhergehenden läugnen und in diesen Versen nichts als eine weitere Lobpreisung Jahves sehn wollen. 
steht damit vielmehr in thatsächlichem Zusammenhang. Deun augenscheinlich geht die Rede v. 27 in gleichem Tenor fort, ein Uebergang zu einem entfernteren Gegenstand ist nicht zu erkennen. Verständlich wird der Gedankengang in v. 23-32 nur dann, wenn das redende Ich die Gemeinde ist. Gerade in Nothzeiten war die messianische Hoffnung in der Gemeinde lebendig, je gröfser die Noth war, um so viel näher erschien die messianische $\mathrm{Zu}$ kunft. Wie dagegen die Rettung eines einzelnen Märtyrers die unmittelbare $\mathrm{Nähe}$ der messianischen Zeit bedeuten könne, ist schwer abzusehn. In einer Lage Jeremias (Jer. 37), aus der Hitzig das Lied begreifen möchte, versteht man, abgesehn von allem andern, diese Erwartung durchaus nicht, und wie ein unbekannter Dulder, der im Exil unter den Heiden lebte, sich selbst eine solche Bedeutung hätte beilegen sollen, bleibt unerfindlich trotz aller Worte, die Ewald hierfür aufbietet. Auch bleibt so die plötzlich auftretende Gewifsheit der Rettung unerklärlich. Nur die Gemeinde kennt eine derartige Gewifsheit, für den Einzelnen mülste dieselbe in ganz bestimmter Weise motivirt sein. Statt dessen sagt der Redende nichts von seinem besonderen Verhältnifs zu Gott, er sagt auch nichts von seiner Schuld oder Unschuld. Erst hinterdrein bezeichnet er seine Feinde als Uebelthäter ( seine Rettung als einen Erweis der göttlichen Gerechtigkeit (v. 32), sonst redet er nur von seinem Gottvertrauen. Das Gemeinbewuโstsein bedarf eben keiner näheren Darlegung.

Uebrigens finden sich auch sonst Andeutungen genug, die auf das m. E. allein richtige Verständnifs hinweisen. In v. 4-6 erinnert der Redende an die wunderbaren Rettungen, die das Volk Israel von Alters her erfahren hat und wofür die Loblieder Israels den Jahve preisen, und hält damit vorwurfsvoll sein Elend zusammen. Darf ein Einzelner seine persönliche Sache in solcher Weise mit 
der Sache Israels auf eine Stufe stellen? Zudem klingen die Ausdrücke v. 7 an Jes. 41, 14. 52, 14. 53, 3 an. Bemerkenswerth ist ferner die Undurchsichtigkeit der Schilderung v. 13-22. Trotz vieler Worte und Bilder bekommt man keine klare Vorstellung von der Lage des Redenden, von der Wirkung der Verfolgung auf ihn. Die Ausleger sträuben sich mit Recht dagegen, v. 19 wörtlich zu verstehn, aber bei v. 15. 16. 18 ist das ebensowenig angängig. Soll man denn wirklich annehmen, der Verfolgte sei vor Kummer abgemagert und deshalb der Spott seiner Feinde? Vielmehr liegt hier wiederum das Bild der Krankheit vor. Bei v. 15. 16 möchte man an die Angst denken, die ein von wilden Thieren Verfolgter empfindet, aber auch hier spielt offenbar das Bild der Krankheit hinein. Jedenfalls erscheint es widersinnig, dals ein Einzelner die Wirkung der erlittenen Verfolgung in solcher Art als Krankheit schildern sollte, wie das hier der Fall wäre. Oder will man auch hier an wirkliche Krankheit denken, die durch die Verfolgung herbeigeführt wäre? Diese Unklarheit der Schilderung, womit der Mangel an stetigem Gedankenfortschritt hier (v. 13. 14.17.21.22. v. 15. 16. 18. 19. - v. 12. 20) und im zweiten Theile (v. 23. 26. - v. 24. 25. 27) zusammenhängt, bedarf der Erklärung, und das um so mehr, als sie mit grolser Lebhaftigkeit und Tiefe der Empfindung gepaart ist. Ich darf mich hier wohl auf den unbefriedigenden Eindruck berufen, den dieser Psalm bei der herrschenden Auffassung jedem Leser hinterläfst. Eine Erklärung ergiebt sich allein bei der Annahme, dafs hier eine Personification der Gemeinde vorliegt. Die Personification führt nothwendig zur Verwischung aller concreten Umstände, sie verursacht Farblosigkeit und Verschwommenheit der Darstellung und muโs deshalb auch einen begabten Dichter unsicher machen. Indessen ist so die Zerflossenheit vieler Lieder dieser Art zu erklären. 
Schon Raschi und Kimchi haben den 22. Psalm auf die jüdische Gemeinde (und ihre Leiden im Exil) bezogen, neuerdings hat zuerst Rosenmüller diese Deutung wiederaufgenommen. Hupfeld weifs dagegen nur einzuwenden, dals der Redende v. 23. 26 zwischen sich und anderen Jahvedienern unterscheide. Aber bei der zweifellos nachexilischen Entstehung des Liedes erledigt sich dieser Einwurf schon damit, dafs Noth und Rettung zunächst natürlich nur die Gemeinde in Judäa betrafen, nichtsdestoweniger aber die Judenschaft der ganzen Welt angingen. Uebrigens sieht man nicht ein, weshalb die Gemeinde nicht zwischen sich selbst und ihren Gliedern unterscheiden könnte. Israel ist verschieden von den Israeliten (Hos. 1. 2) und Rahel von ihren Kindern (Jer. 31, 15 ff.) ${ }^{1}$ ). Dagegen sind v. 10. 11 nach Jes. 49,1 zu verstehn.

Ps. 23 wird vom Targum auf Israels Wanderung durch die Wüste und auf das Exil bezogen und in der That kann als Subject des Liedes wohl nur die Gemeinde verstanden werden. Aufser Olshausen nimmt freilich Niemand Anstofs daran, dafs nach der herrschenden Auslegung der Einzelne sich hier als ein einzelnes Schaf vorstellen soll, das Jahve als Hirt weide. Aber der Hirt weidet nicht einzelne Schafe, sondern eine Heerde und Jahve heifst sonst überall der Hirte Israels und Israel Jahves Heerde ${ }^{2}$ ). Nur einmal heifst es im Munde Jakobs, dafs Jahve ihn. geweidet habe (Gen. 48, 15), aber Jakob war kein Einzelner und übrigens ist er das Volk in nuce. Ferner soll

1) Vgl. sonst 68, 27. 149, 1 sowie 26, 12. 35, 18. 27. 40,4. $10 \mathrm{f}$. $66,16.69$, 7. 33. 109, 30. 116, 14. 18. 142, 8. Ferner gehören hierher 51, 10. 106, 4. 5, auch 11,1 u. s. f.

2) Vgl. z. B. Gen. 49, 24. Jes. 40, 11. Jer. 31, 10. Ps. 80, 2. 28, 9. Ez. 34, 14 ff. sowie Jes. 63, 11. Jer. 23, 1 ff. Ez. 34. Mi. 7, 14. Zach. 9, 16. Ps. 74, 1. 79, 13. 95, 7. 100, 3. Bekanntlich bedeutet das Verbum רעה öfter herrschen (z. B. 2 Sam. 5, 2. Mi. 5, 3) und ${ }_{n}$ Hirt" steht bei den Propheten sehr gewöhnlich für ${ }_{n}$ König ${ }^{*}$. 
Jahve um seines Namens willen den Redenden beglücken (v. 3). Nun sagt freilich Deuterojesaja einmal, Jahve habe jedes einzelne Glied seines Volkes zu seiner Ehre geschaffen und deshalb müsse er jeden einzelnen Juden befreien, der in die Heidenwelt verschlagen sei (Jes. 43, 7). Aber einem derartigen Postulat Deuterojesajas entsprach keineswegs das Bewufstsein und der Anspruch der einzelnen Frommen. Jahves Ehre haftete am Volke, in Israels Schicksalen mufste seine alleinige Gottheit offenbar werden, nicht aber im Ergehen der Individuen $\left.{ }^{1}\right)$. Auch der Schlufs จ. 5. 6 ist nur dann recht verständlich, wenn die Gemeinde redet. Die Gemeinde weifs sich als Jahves Schützling, Gast und Hausgenossen, sofern sie in Jahves Lande wohnt und zum Tempel Zutritt hat. Hierin hat sie nicht nur die Gewähr der göttlichen Gnade, vielmehr erscheint alle Gnade. Jahves als hierin einbegriffen. Das Wohnen im heiligen Lande und in der Nähe des Tempels bedeutet für die Gemeinde das Heil in seinem ganzen Umfang, die Vertreibung von hier die Verstofsung und Vernichtung der Gemeinde. Einstmals war es ihr so ergangen, aber nie wieder sollte es dahin kommen. Was ich Stud. u. Krit. 1884 S. 720 ff. hierüber ausgeführt habe, bedarf in sofern der Correctur, als ich in der Anwendung dieser Vorstellung auf die Einzelnen zu weit gegangen bin (a. a. O. S. 723). Wohl war der Tempel wie für die Gemeinde so auch für den Einzelnen von höchster Bedeutung (Ps. 122), aber schwerlich konnte der Einzelne sich so als Jahves Gast und Hausgenossen und Jahve als seinen Wirth, Patron und Hausherrn betrachten, wie das hier und an anderen Stellen geschieht. So vertraut stand nur die Gesammtheit,

1) Vgl. Jos. 7, 9. 1 Sam. 12, 22. Jes. 48, 9. Jer. 14, 7. 21. Ez. 20, 9. 14. 22. 44. Ps. 79, 9. 106, 8. 115, 1 sowie Ex. 9, 16. 2 Sam. 7, 26. Jes. 64, 1. Ez. 36, 20. 23 u. a. St. Danach sind aber auch die Stellen Ps. 25, 11. 31, 4. 109, 21. 143, 11 zu beurtheilen.

Zeitschrift f. d. alttest. Wiss. Jahrgang 8. 1888. 
nicht aber der Einzelne Jahve gegenüber. Ferner konnte der Einzelne im Allgemeinen sehr wohl fern vom Tempel leben und umgekehrt schützte ihn die Nähe des Tempels keineswegs vor aller Noth. Dagegen wäre die Vertreibung der Gemeinde von der heiligen Stätte das Ende der Religion gewesen. Hierauf ist der so oft wiederkehrende Ausdruck der Freude, beim Heiligthum bleiben zu dürfen, und die Bitte um Erhaltung dieses höchsten Glückes zu beziehen ${ }^{1}$ ). Die Bewirthung, von der hier die Rede ist, wird deshalb auch nicht den Lebensunterhalt des Einzelnen, sondern den dem ganzen Volke bescheerten Erntesegen bedeuten (Ps. 36, 9. 65, 5). Endlich gewinnen nun die Worte ער צ. 5 einen besseren Sinn. Nicht ein kleinlicher Seitenblick auf diese und jene Privatfeindschaft spielt in diesen herrlichen Ausdruck des Gottvertrauens hinein. Gemeint sind vielmehr die Gottlosen oder die Heiden, von denen die Gemeinde unaufhörlich bedroht ist : all ihre Bosheit kann die Gnade Jahves gegen sein Volk nicht abschneiden ${ }^{2}$ ).

Wenn überhaupt ästhetische Gründe keine kritischen sind, für die Exegese kommen die ersteren doch in Betracht, sofern es sich um die innere Harmonie der Stimmung handelt. Es ist wahr, dafs der Feindeshals im A. T. eine grofse Rolle spielt und auch der Hals gegen persönliche Feinde und die Freude über ihren Untergang oft nicht als im Widerspruch mit der Frömmigkeit empfunden wird (vgl. z. B. Jes. Sir. 25, 7). Gleichwohl ist den

1) 5,5 ff. $15,1.16,11.24,3.27,4$ ff. $31,21.36,8$ ff. $41,13$. 51, 13. 52, 10. 61,5 . $65,5.84,5.91,1$. 92, 14. 102, 29. 132, 13 ff. $140,14$.

2) Dafs bei Personification der Gemeinde auch von ihrer Lebensdauer die Rede ist (v. 6), macht keine Schwierigkeit. Ein ewiger Bestand der Gemeinde ist nicht selbstverständlich. Vgl. 27, 4. 31, 11. $63,5.102,4$. 104, 33. 116, 2. 146, 2 und besonders 102, $24 \mathrm{f}$. 
Psalmen in dieser Hinsicht vielfach Unrecht widerfahren, indem man auf persönliche Verhältnisse bezog, was in Wahrheit die Gemeinde und ihren Gegensatz gegen die Gottlosen und die Heiden betrifft. Am deutlichsten ist das bei Ps. 30. Redet hier ein Einzelner, dann kann dies Lied nur als Dank für die Rettung aus tödtlicher Krankheit verstanden werden und die Krankheit hier so wenig wie anderswo (vgl. oben zu Ps. 6) Bild einer Verfolgung sein, die ihn betroffen hätte. Aufs äufserste war es mit ihm gekommen, schon sollte er ins Todtenreich hinabsinken, als Jahve ihn ins Leben zurückrief und ihn heilte (v. 3. 4. 9. 10). Aber welch ein widerwärtiger Contrast entsteht nun! Auf der einen Seite die aufrichtigste Einsicht in die innere Nothwendigkeit des schwersten Leidens, das den Redenden einer falschen Sicherheit entrifs (v. 7), das freudigste Gottvertrauen (v: 6), der herzlichste Dank für die erfahrene Rettung, das Bewufstsein, dafs das neugeschenkte Leben allein dem fortwährenden Lobe Gottes gewidmet sein könne (v. 13) - und auf der anderen Seite ginge der Dank gegen Gott doch zuerst dahin, dafs die Schadenfreude eines persönlichen Feindes, der einen tödtlichen Ausgang der Krankheit erwartete, vereitelt sei (v. 2). Ein solches Verständnifs mufs seiner inneren Unwahrheit wegen abgelehnt werden. Thatsächlich redet aber die Gesammtheit der Frommen, die denn auch v. 5 zum Dank gegen Gott aufgerufen wird. So hat auch die jüdische Gemeinde das Lied verstanden (s. o. S. 53). Nun ist die Krankheit wirklich nur Bild der Verfolgung, welche die Gemeinde von ihren Feinden erlitt. Sie dankt Gott dafür, dafs er die gottlose Welt nicht triumphiren liefs ${ }^{1}$ ).

1) „Züchtige Du uns nach Deinem Willen, aber den Heiden gieb ${ }_{n}$ uns nicht preis! Denn wenn $\mathrm{Du}$ die Pest sendest, so giebst $\mathrm{Du}$ ihr nunseretwegen Auftrag, weil Du barmherzig bist und nicht zürnst, um nuns zu vernichten“ (Ps. Sal. 7, 3. 4). Die Heiden wollen überall die 
Jahre hat sie aber auch deshalb gerettet, damit sie nun um so mehr ihrer geschichtlichen Aufgabe, das Lob Jahves in der Welt zu verkínden, sich widme ( v. 10).

Dafs in Ps. 9 (v. 2-5. 14. 15) das redende Ich die Gemeinde bedeute, sagt schon Pseudo-Hieronymus z. St. : iste psalmus totus in persona ecclesiae per prophetam de Antichristo cantatur. Unter den Neueren hat dagegen allein Ewald dies eingesehn. Evident ergiebt sich das Subject des Psalms, sobald man den Sinn des Ganzen richtig versteht, und hier ist De Wette auf halbem Wege stehn geblieben ${ }^{1}$ ).

Gemeinde vernichten, aber weiter kommt folgendes in Betracht. Pest und Hungersnoth sind Schickungen der Gottheit und müвsen als solche verstanden werden, aber durch die Verfolgung von Seiten der Heiden wird immer wieder die Macht Jabves und die Wabrheit des Glaubens in Frage gestellt. Aehnlich steht es mit der Unterdrückung der Frommen durch die Gottlosen. Umgekehrt ist es aber auch ein Triumph des Glaubens, wenn die Verfolger der Gemeinde schliefslich unterliegen. Damit beweist Jahve erstlich seine Macht und zweitens seine Gnade gegen Israel. Auch in letzterer Hinsicht sind solche Erweise von Zeit zu Zeit unentbehrlich; vgl. 41, 12. Denn die Noth besteht eigentlich fortwährend. Deshalb spielt der Gegensatz gegen die Heiden und die Gottlosen in den Psalmen eine so grolse Rolle, während von anderen Leiden der Gemeinde wenig die Rede ist.

1) Bekanntlich bildeten Ps. 9. 10 ursprünglich Einen alphabetischen . Psalm, in dem das Alphabet mit jedem Distichon fortschritt. Erhalten

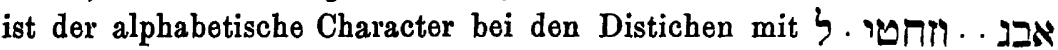
תרשת . . . . . während bei den übrigen Distichen der alphabetische Anfang zerstört ist, was bei absichtlicher Umarbeitung des Originals oder auch bei einer Restauration nach zufälliger Verstümmelung geschehen sein kann. Wie stark diese Bearbeitung im Uebrigen eingegriffen haben mag, ist schwer zu sagen. Olshausen meint, dafs sie sich auch auf die übrigen Distichen erstreckt habe. Er vermuthet auch, dafs der Unterschied von Ps. 9 und 10, sofern hier die Bitte und dort der Dank vorwiegt, vielleicht erst durch die Bearbeitung entstanden sei. Indessen erklärt sich jener Unterschied anderweitig. Ich habe oben die Verszahlen aus den Distichen, deren alphabetischer 
Höchst auffällig ist in Ps. 9. 10 der stetige Wechsel des Dankes fürr erfahrene Hülfe und der Bitte um solche. Ewald setzt das Lied in die Zeit von Ninives Zerstörung und bezieht auf dies Ereignifs den hier ausgesprochenen Dank für Jahves richterliches Einschreiten, während er die Bitten um Rettung aus der damaligen Ueberschwemmung Palästinas durch die Aegypter und der in eben jener Zeit (unter Jojakim) in Jerusalem herrschenden Gottlosigkeit erklärt. Aufser De Wette verstehn sämmtliche Ausleger das Lied dahin, dafs es theils Dank für eine vor kurzem erfolgte Rettung und zugleich Bitte um weitere Hülfe sei. Bei dieser Auffassung hinterläfst das Lied den Eindruck heillosen Wirrwarrs. Wie ist der helle Jubel 9, 2. 3. 12 mit der flehentlichen, fast verzweifelten Bitte $9,10.11 .20 .21 .10,1$ ff. $12.13 \mathrm{zu}$ reimen? Wie ist es zu verstehen, dafs Jahve sich jetzt eben auf seinen Stuhl gesetzt und Gericht gehalten hat $(9,5)$, wenn anderseits sein Gericht ein zukünftiges ist und sein Stuhl erst bereit steht $(9,8.9)$ ? Hielt Jahve mitten in seinem Werke inne? Einerseits ist's mit den Heiden $(9,6$. 7. 16. 10, 16) und den Gottlosen (9, 6. 17) völlig und für immer zu Ende und die Noth vorüber $(9,13)$, anderseits ist ihre Niederwerfung Gegenstand der Hoffnung (9, 10. 11). Auf ewig darf Jahvie die Gemeinde nicht im Stich lassen $(9,19)$, endlich soll er der furchtbaren Verfolgung ein Ende machen, den Trotz der Gottlosen (9, 18. 10, 1. 2-11. 12. 13. 15) und der Heiden brechen (19, 18. 20. 21. 10, 18). Vgl. noch 9, 13 mit 9, 19. 10, 11. 12. Nirgendwo ist ein Uebergang vom einen zum andern zu entdecken, der Dichter fällt vielmehr beständig vom einen ins andere,

Character erhalten ist, fett drucken lassen. Man wird daraus sehen, dafs die sicher überarbeiteten Verse sich ihrem Sinne nach von den anderen gar nicht unterscheiden, also auch der Sinn des Ganzen von der Bearbeitung schwerlich alterirt ist. 
nur dafs Ps. 9 das eine und Ps. 10 das andere vorwiegt, auch handelt Ps. 9 mehr von den Heiden, Ps. 10 mehr von den Gottlosen. Zudem sind die bereits vernichteten Feinde schlechtweg שיבים (9, 4. 7), שנאים $(9,6.16)$, עשע $(9,6.17)$ und ebenso die noch zu vernichtenden אוים (9, 18. 20. 21), אנוש (9, 20. 21. 10, 18), רשע (9, 18. 10, 1. 3. 4. 13. 15), רע (10, 15). Man beachte vor allem die Folge von 9, 16. 17. 18. In Wahrheit ist überall von dem zukünftigen Weltgericht die Rede, wo Jahve der Herrschaft der Heiden in der Welt und der Herrschaft der Gottlosen in der Gemeinde ein Ende machen wird. Sein Kommen steht einerseits dem Glauben fest, anderseits ist es Gegenstand des sehnlichsten Verlangens, beides liegt im jüdischen Gemeinbewufstsein unmittelbar neben einander. Auch erklärt sich leicht, weshalb betr. der Vernichtung der Gottlosen die Bitte vorwiegt, betr. des Untergangs der Heiden dagegen der Dank. Die Heiden sind nicht in unmittelbarer Nähe wie die Gottlosen, der Druck, den man von jenen erfährt, wird nicht so beständig empfunden wie der von diesen, deshalb kann der Untergang der Heiden in der Imagination leichter als vollendete Thatsache vorgestellt werden. Die Perfecta als sog. Perfecta prophetica zu verstehn, macht gar keine Schwierigkeit ${ }^{1}$ ). Nun ergiebt sich aber von selbst, dafs das redende Ich die Gemeinde vorstellt.

1) Einer demnächst von mir zu veröffentlichenden Untersuchung über die messianische Hoffnung in den Psalmen will ich nicht vorgreifen, ich bemerke hier nur, dafs die Ausdehnung, in der die Psalmendichter das sogenannte Perf. proph. anwenden, von den Exegeten weit unterschätzt wird. Ein besonders deutliches Beispiel ist Ps. 85. Die Perfecta, mit denen dies Lied v. 2-4 beginnt, müssen auf die Zukunft gehn, die Uebersetzung im Präteritum oder Plusquamperfectum ist unmöglich. Wenn Jahve schon einmal alle Sünden völlig vergeben und allem Zorne ein Ende gemacht hat (v. 2.3) und nun wieder zürnt und scheinbar auf ewig zürnen will (v. 5, 6), so fragt man doch, weshalb 
Uebrigens ist es beachtenswerth, dafs die Gemeinde in den Psalmen auch mit $\mathrm{Du}$ angeredet wird. Bezüglich Ps. 50, 7 ff. 81,8 ff. ist nichts zu sagen und von Ps. 128 war oben S. 50 die Rede. Aber auch Ps. 37. 91 gehören hierher.

Ps. 91 handelt nicht schlechthin von dem Schutze, den Jahve gewährt, vielmehr wird dabei, wie Ewald richtig sieht, auf die Nähe des Heiligthums reflectirt (v. 1 vgl. 36,8 f. 61,5 . 84, 5. 132, 14 ff. Ruth 2, 12). Danach zielt das Lied aber nicht auf einen einzelnen Frommen, sondern auf die Gemeinde bezw. auf alle Frommen, die in der Nähe des Tempels wohnen. Es ist ferner Characteristikum der Gemeinde gegenüber den Heiden, dafs sie den Namen Jahves kennt (v. 14), d. h. ihn anzurufen weifs und wirklich anruft. Die Gesammtheit und nicht der Einzelne erlebt die messianische Zukunft (v. 16). Zu v. 16a vgl. man Ex. 23, 26. Auch die überschwängliche Verheifsung $\nabla .7$ bekommt so einen besseren Sinn und das Einfallen der göttlichen Stimme (v. 14-16) erscheint natürlicher. Die wilden Thiere v. 13 möchten die Heidenvölker bedeuten.

Ebenso verhält sichs mit Ps. 37. Gegenüber dem Glück der Gottlosen, die v. 7 schlechtweg als die Glücklichen bezeichnet werden, warnt dies Lied die Frommen

denn der Zorn wiederkehrte. Mindestens sollte gesagt sein, dals er wiederkehrte. Aber, wie Kimchi richtig bemerkt, hat der Zorn nach v. 6 noch nie ein Ende gehabt. Die völlige Vergebung und völlige Aufhebung des Zorns sind ihrer Natur nach etwas Definitives, sie bedeuten das messianische Heil, das aber bisber noch nicht eingetreten ist. Auch שוב שבות (v. 2) kann nur diesen Sinn haben. Also treten auch hier zuversichtliche Erwartung der messianischen Zukunft (v. 2-4), flehentliche Bitte um ihr endliches Kommen (v. 5-8) und Verheifsung desselben (v. 9-14) neben einander. - Aehnlich verhält sichs mit Ps. 126, wo die nevere Auslegung ebenfalls die bessere Einsicht der Alten verloren hat. - Bei Ps. 14 sieht Ewald richtig. 
vor Mifomuth, Zorn and Neid (v. 2. 7. 8) und vertröstet sie mit dem Hinweis auf die messianische Zukunft. Da werden die Gottlosen ausgerottet (v. 9. 10. 22. 28. 34. 38) and die Frommen erben das Land (จ. 3. 9. 11. 22. 27. 29. 34. 37). Daneben findet sich freilich wiederholt die Behauptung, dafs auch schon in der Gegenwart die gerechte Vergeltung nicht fehle (จ. 19. 21. 24-26. 35. 36). Indessen ist das doch nur ein Angeld auf die letzte grofse Abrechnung. Gegenwärtig muls der einzelne Fromme sich vielleicht damit begnügen, dafs Jahve alle seine Schicksale bestimmt hat (v. 18. 23). Dabei aber haben die Frommen die Gewifsheit, dals ihr Erbtheil ewig besteht, dals wenigstens ihren Nachkommen das höchste Heil zu Theil wird (v. 18). Denn einmal kommt die messianische Zeit, jeden Augenblick kann sie eintreten (v. 10). Das Du richtet sich auch hier weniger an die einzelnen Frommen, als an die Gemeinde (vgl. v. 27. 34). Es handelt sich um den Gegensatz der Parteien, die Frommen werden von den Gottlosen verfolgt (v. 12. 14. 32. 33. 40). Das richtige Verständnifs hat Gottlieb Studer (Hiob S. $201 \mathrm{ff}$.).

Ps. 3. 4. Mit Recht läfst Olshausen die Frage unentschieden, ob in Ps. 3 das Volk oder ein Fürst, dessen Sache zugleich die Sache des Volkes ist, der Redende sei. Dafs in einem derartigen Fall die Sache zweifelhaft bleiben kann, ist natürlich. Auch durch v. 6, so persönlich er klingt und so gewifs er persönlicher Stimmung entstammt, ist die Möglichkeit, dafs hier Personification vorliege, nicht ausgeschlossen. Dagegen wird man wegen der nahen Verwandtschaft des Liedes mit Ps. 4 stets geneigt sein, dasselbe Volkshaupt, das dort scheinbar am Wort ist, auch hier als das redende Subject zu betrachten. Uebrigens werden die Perfecta 3, 8 zuversichtliche Erwartung ausdrücken. Denn die Gewifsheit des Sieges beruht nicht 
sowohl darauf, dafs Jahve die Heiden oder die Gottlosen früher schon gedemüthigt hat, als vielmehr darauf, dafs seine Gemeinde zuletzt über alle ihre Gegner triumphiren mufs. Jetzt haben die Feinde ihre Zähne noch. Ueber das Perfectum 4, 2 kann ich nicht anders urtheilen.

Ps. 5. Von den Gottlosen verfolgt findet der Redende im Zutritt zum Tempel die Gewilsheit seiner Rettung. So gewifs der im Tempel wohnende Gott die Gottlosen von sich stöfst und vernichtet (v. 5-7), so gewifs mufs er den Redenden erhalten (v. 8). Es ist nicht abzusehn, wie der Zutritt zum Heiligthum, das die Gottlosen doch auch wohl betreten, dem einzelnen Frommen Sicherheit vor jenen Verfolgern gewährleisten könnte. Dagegen hat die Gemeinde in der Zulassung zur Nähe Gottes und zu seinem Dienst allerdings die Bürgschaft ihres endlichen Triumphes über ihre Gegner. Jahve muls die Gemeinde, die er hier einmal gegründet hat, das Feld behaupten lassen. In Wahrheit handelt es sich nicht um die Verfolgung eines Einzelnen, sondern die Gesammtheit der Frommen bedarf des göttlichen Schutzes (v. 12), sie wird auch mit dem Gerechten จ. 13 bezeichnet sein. Ebenso werden v. 10 die Gottlosen zuerst als ein Individuum vorgestellt, sofort tritt aber an die Stelle des Singulars der Plural ${ }^{1}$ ). Bemerkenswerth ist ferner, dafs nach dem einleitenden Aufruf um Erhörung ( $.2-4$ ) die Bitte zunächst nicht direct ausgesprochen, sondern ihr Inhalt als selbstverständlich vorausgesetzt wird. „Ich schaue aus nach Erhörung, denn Du hast kein Gefallen an der Gottlosigkeit und duldest die Bösen nicht in Deiner Nähe ${ }^{\star}$ u. s. w. (v. 5-7). Damit wird nicht etwa ein langathmiger Erfahrungssatz in dem Sinne ausgesprochen : „wie Du überhaupt die Gott-

1) Vgl. noch 7, 5. 6: 15-17. 10, 2 ff. 13, 3. 5. 14, 1. 17, 12. 13. $35,8.36,2$ ff. 55,14 f. 21. $109,6-19$. Ebenso die Heiden $118,13$. 
losen vertilgst, so vertilge auch meine gottlosen Feinde*. Vielmehr mufs Jahve bei der letzten Entscheidung die Gottlosen sämmtlich vernichten und die Gemeinde wartet darauf, denn einmal mufs es dahin kommen. Ueberhaupt wird mehr noch als die Rettung des Redenden der Sturz der Gottlosen erbeten, mit dem letzteren ist die erstere gegeben. Auch das führt darauf, dafs die Gemeinde am Wort ist. Ich bemerke noch, dals Jahve hier als „mein König" angeredet wird (v. 3 vgl. oben S. 68). Schliefslich wird es so möglich, v. 4 von dem täglichen Gottesdienst der Gemeinde zu verstehen. $Z u$ אצפה vgl. das freilich viel alterthümlichere Num. 23,3 f. 15 f. Der Syrer der Londoner Polyglotte hat als das Subject des Liedes die Kirche verstanden, was auch Eusebius zuläfst.

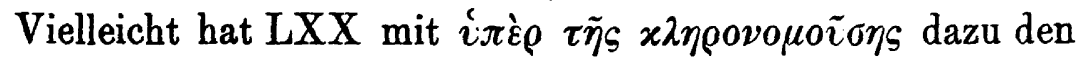
Anlafs gegeben. Aber auch Raschi deutet das Lied auf das Volk Israel.

Ps. 6. S. o. S. 68.

Ps. 7. Ein unschuldig Verfolgter ruft Jahve um Hülfe an. Eine Zeit allgemeiner Abrechnung scheint bevorzustehn. Jahve hat ein grofses Völkergericht bestellt, möchte es doch wirklich dazu kommen und Jahve von der Gemeinde der Völker umgeben sich auf den Richterstuhl

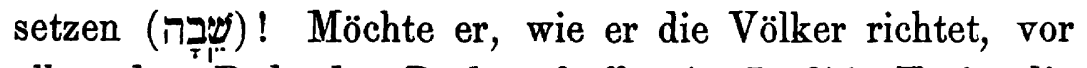
allem dem Redenden Recht schaffen (v. 7-9)! Es ist die Erwartung des Weltgerichts, was den Redenden bewegt, wenngleich er sich übrigens auch der immerfort waltenden Gerechtigkeit Jahves getröstet (v. 12). Wie kann nun aber ein Einzelner seine persönliche Sache in eine solche Beziehung zum Weltgericht stellen? Wie sollte er verlangen, dals Jahve das begonnene Völkergericht wirklich durchführen möge, damit so auch er zu seinem Rechte komme? Ein solcher Anspruch wäre im Munde eines Einzelnen ebenso unbegreiflich wie er im Munde der Ge- 
meinde höchst natürlich ist ${ }^{1}$ ). In Wirklichkeit handelt sichs um den Principienkampf der Gerechten und der Gottlosen (v. 10. 11), wobei man freilich zweifeln kann, ob רשעים die Gottlosen in Israel oder Heiden und dem entsprechend ob צריק die Frommen in Israel oder die Gemeinde im Gegensatz zu heidnischen Feinden bezeichnet.

Ps. 8, 4. S. zu Ps. 104.

Ps. 9. 10. S. o. S. 84 .

Ps. 11 treten neben dem redenden Ich andere Personen auf, die man für Gesinnungsgenossen halten mufs. Denn solche sind es, die zu ihm sagen : „Siehe die Gott„losen spannen den Bogen, sie richten auf der Sehne ihren ${ }_{\pi}$ Pfeil, um im Dunkeln auf die Redlichen zu schielsen" (v. 2). Inzwischen folgt daraus keineswegs, dafs der hier Angeredete ein Einzelner, etwa ein Haupt der Frommen, ist. Der Zuruf, der an ihn ergeht : „fliehet auf euer Gebirge, ihr Vögel“, , besagt nichts anderes, als dafs die Sache der Frommen verloren sei und sie vor den Gottlosen das Feld räumen müssen. Von einem Rath, der einem Einzelnen ertheilt würde, steht nichts da. Vielmehr scheinen die Worte an eine Mehrheit gerichtet zu sein. Dem entsprechend fafst auch die Antwort v. 4-7 nur die Gesammtheit ins Auge. Bei der letzten Entscheidung werden die Gottlosen untergehn, die Redlichen dagegen Jahves Angesicht schauen d. h. die Offenbarung seiner Herrlichkeit auf dem Sion (vgl. zu 17, 15). Somit bleibt nichts Individuelles übrig, so gut wie der צישר v v.

1) Irriger Weise meìnt man trơtz v. 9, dafs die Heidenvölker lediglich Zuschaner des Gerichts sein sollten. Man wird aber zugeben müssen, dafs schon das letztere zu einer persönlichen Streitsache nicht pafst. Noch richtiger als die obẹ angegebene Deutung erscheint mir eine andere, wonach צו צ. 7 ein Perf. proph. wăre und die Bitte sofort in zuversichtliche Erwartung umschlüge. 
die Gesammtheit der Frommen 1). Dafs die Gemeinde hier wie anderswo zwischen sich and den einzelnen Frommen einen Unterschied macht, ist ganz in der Ordnung (vgl. zu 22, 23. 26).

P. 13. Der Betende ist von Feinden verfolgt. Schon lange währt seine Noth, Jahve scheint ihn vergessen zu haben. Endlos sind seine Sorgen und sein Kummer, immerfort behält der Gegner die Oberhand. Möchte Jahve doch endlich dareinsehn und den Leidenden erfreuen, sonst vergeht er im Elend und der Triumph des Feindes wird ein definitiver! Aber weil das letztere doch nicht sein kann, weicht die Verzweiflung am Ende der zuversichtlichen Gewifsheit der Rettung. - Bei aller Innigkeit und Kraft der Empfindung characterisirt auch dies Lied ein völliger Mangel an individuellen und überhaupt an concreten Zügen. Man ahnt, dafs der Redende sich seinem Gegner gegenüber im Recht weifs, dals sein Feind der Feind Gottes ist, aber er sagt das mit keinem Worte, er redet nur von Jahves Güte (v. 6). Der Feind will seinen Tod, aber wie er ihn umbringen möchte, bleibt wiederum unausgesprochen. Man hat nur den bestimmten Eindruck, dafs der Redende hier wie in Ps. 6 schliefslich dem Kummer zu erliegen fürchtet, der ihm von seinem Gegner bereitet wird: Schon ist er todesschwach (v. 4). Wir hätten hier also wieder dieselbe singuläre Situation, dafs ein Einzelner unter endloser Verfolgung, die er von einem persönlichen Feinde erleidet, vor Gram fast schon stirbt, in der höchsten Gefahr aber, weil er in seinem Feinde den Feind Gottes erkennt, seiner Rettung völlig gewifs wird. Das Räthsel wird ebenso zu lösen sein wie bei Ps. 6. Auch die Farblosigkeit des Liedes ist wiederum daraus zu er-

1) Jahve prüft die Menschen und namentlich die Frommen d. h. or nimmt Notiz von ihrer. Frömmigkeit und Gottlosigkeit und behandelt sie demgemäls. 
klären, dafs das Gemeinbewufstsein keiner näheren Darlegung bedarf. Das richtige Verständnifs hat Raschi und neuerdings Rosenmüller.

Ps. 16. Bezüglich des Schlusses v. 9-11 sind die Ausleger in grolser Verlegenheit. Die Emphase und die Ueberschwänglichkeit der Ausdrücke, womit hier die Erwartung einer steten Bewahrung vor dem Tode ausgesprochen wird, ist in der That sehr auffallend. Man hilft sich wohl mit der Annahme, der Dichter habe vielleicht eben damals in Todesgefahr geschwebt. Aber das שמרני v. 1 berechtigt zu dieser Vermuthung noch nicht, die übrigens durch die ganze Haltung von v. $5 \mathrm{ff}$. ausgeschlossen erscheint. Ebenso wenig darf man v. 9-11 dahin verstehn, dafs Jahve den Dichter nicht vor der Zeit sterben lassen werde. Unbefangene Leser werden hier immer die Erwartung völliger Bewahrung vor dem Tode finden. Ewald und Hupfeld meinen deshalb, dafs v. 10.11 die Ahnung persönlicher Unsterblichkeit ausgesprochen werde. Aber auch das ist unmöglich. Wenn es v. 9. 10 heifst : „auch mein Fleisch wird sicher wohnen, denn Du wirst meine Seele nicht dem Todtenreich preisgeben noch zulassen, dafs Dein Frommer die Grube sehe ${ }^{*}$, - so ist da, wie namentlich die letzten Worte zeigen, nicht von sicherer Grabesruhe und Rettung aus dem Grabe, sondern von immerwährender Erhaltung des gegenwärtigen Lebens die Rede. Persönliche Unsterblichkeit war aber ohne vorangegangenen Tod trotz Henoch und Elia für das Individuum nicht denkbar. Auf ein Leben nach dem Tode kann deshalb auch v. 11 nicht gehen. Denn nachdem v. 9.10 mit solcher Emphase von der Erhaltung des gegenwärtigen Lebens geredet ist, hätte nothwendig das vorherige Sterben erwähnt werden müssen, wenn v. 11 ein jenseitiges Leben verstanden werden sollte.

Alle Schwierigkeit hebt sich sofort, wenn wir als das redende Subject die Gemeinde betrachten, deren ewige 
Erhaltung allerdings ein Postulat des Glaubens ist. Hierdurch gewinnt der ganze Psalm einen besseren Sinn. Es ist die Gemeinde, die sich v. $1 \mathrm{ff}$. mit den götzendienerischen Heiden vergleicht. Diese fahren schlimm mit den Götzen, dagegen ist Israels Erbtheil Jahve. Der hat Israel berathen $d$. $h$. er hat das Volk den rechten Gottesdienst gelehrt und erhält es darin beständig durch die Leitung seines (Yeistes, der ihm den göttlichen Willen und damit den Weg des Lebens kund thut. So kann Israel auf ewig im Genufs all der Güter leben, die an die Nähe des im Tempel wohnenden Gottes geknüpft sind (v. 11).

Ps. 17. Der Redende bittet um Rettung vor Verfolgern (v. $7 \mathrm{ff}$.), in denen wir nicht einzelne Gottlose, sondern ihre ganze Partei zu erkennen haben. Es sind die רשים oder der schlechtweg (v. 9. 13), es ist das Genus, das geschildert wird (v. 10. 14). Vgl. übrigens v. 12 mit 10, 8 ff. u. ä. St. Redete nun ein Einzelner, so wären wir hier wieder einmal zu der Annahme gedrängt, dafs er ein hervorragendes Haupt der Frommen war, dafs er deshalb von der ganzen Gegenpartei verfolgt wurde und umgekehrt an seiner Rettung ein allgemeines Glaubensinteresse hing. So könnte man es zur Noth erklären, dafs zu seiner Rettung die Niederwerfung der Gottlosen erforderlich ist (v. 13), dafs Jahve mit wunderbaren Erweisen seiner Gnade für ihn eintreten soll, um die Wahrheit des Glaubens ins Licht zu stellen. Indessen nimmt Calvin an dieser letzteren Forderung (v. ?) mit Recht Anstofs und vollends unbegreiflich ist mir im Munde eines Einzelnen v. 8 : „Bewahre mich wie Deinen Augapfel" ${ }^{4}$. Das ist sonst hyperbolische Bezeichnung der Vorsorge Jahves für Israel, die einem Einzelnen niemals in gleichem Mafse zugewandt sein kann (Dt. 32, 10. Zach. 2, 12 vgl. Prov. 7, 2).

Bezieht man dagegen das Lied auf die von den Gottlosen verfolgte Gemeinde der Frommen, so wird auch der 
vielerklärte Schlufs v. 15 verständlich. Der Verfolgte ist in grofser Noth, inständig verlangt er nach Schutz und Rettung. Deshalb mufs das v. 15 Gesagte zu seiner Rettung in nächster Beziehung stehn, ja damit wesentlich identisch sein. Unmöglich kann sichs hier um ein Schauen Gottes nach dem Tode handeln, nachdem vorher alles auf die Bewahrung vor dem Tode abgestellt ist. Durchaus willkürlich und unbefriedigend sind aber auch die Erklärungen, wonach die Ausdrücke „Gott schauen“, „sich an Gottes Gestalt sättigen" blofse Bilder für die Erfahrung der göttlichen Hülfe oder der geistigen Gemeinschaft mit Gott sein sollen. Ebenso wenig kann damit das Erscheinen vor Gott im Tempel bezeichnet sein, wo der gerettete Fromme Gott einst danken zu können hofft (Hiob 33, 26). Vielmehr bedeutet das Gottschauen hier so gut wie 11, 7 das Erleben der messianischen Zukunft. Seine Rechtfertigung (das ist hier prצ) will der Redende damit erfahren, dals er die Offenbarung der göttlichen Herrlichkeit erschaut. Denn die Erscheinung Jahves am Ende der Tage bedeutet die Vertilgung der Gottlosen und das Heil der Frommen, in deren Mitte Jahve dann wieder Wohnung nimmt (102, 17. Mtth. 5, 8). Es handelt sich also um etwas, das der Gemeinde im Ganzen zukommt, diese mufs sonach hier das redende Ich $\operatorname{sein}^{1}$ ).

Offenbar ist ferner der v. 14. 10 geschilderte Zustand keineswegs ein solcher, dem der Redende in Aussicht auf ein höheres $i \mathrm{hm}$ beschiedenes Glück mit Gleichmuth zusähe. Er ist vielmehr derart, dals sein Aufhören verlangt

1) Die Schlufsworte wage ich so, wie sie lauten, allerdings auch nicht zu übersetzen : ${ }_{n}$ ich will mich satt sehen, wenn $D u$ Dich regst, an Deiner Gestalt". Aber für ganz unmöglich halte ich diese Uebersetzung auch nicht und jedenfalls wollte der Dichter so etwas sagen $(35$, 23. 44, 24. 59, 6. 78, 65. Hab. 2, 19 vgl. Ps. 73, 20). Vielleicht ist ברקיצ' herzustellen. 
werden mufs, weil die Gottlosen nicht ungestraft bleiben dürfen, und selbstverständlich hört er auf, wenn Jahve, wie v. 13 erbeten wird, einschreitet. Trotz aller Textverderbnisse in $\nabla .14$ kann denn auch kein $Z$ weifel darüber sein, dals der Redende hier seine Noth und das Glück der Gottlosen als einen unerträglichen Gegensatz empfindet und die völlige Aufhebung desselben fordert. Dafs aber das Glück der Gottlosen überhaupt vergeht (und hierauf wird v. 13. 14 reflectirt), wird sonst nur von der messianischen Zukunft erwartet und auf diese mufs sich auch deshalb v. 15 beziehen.

Die starken Betheuerungen der Unschuld (v. 1 ff.) sind im Munde der Gemeinde verständlich, befremden aber im Munde eines einzelnen Frommen. Im Gegensatz gegen die Gottlosen weifs die Gemeinde sich rein und unsträflich, vor allem ist sie sich des Ernstes ihrer Gesinnung und der unwandelbaren Treue gegen Gott bewufst. Ueberdies tritt sie keineswegs nur als empirische GröIse Gott und der Welt gegenüber.

Ps. 18 denke ich in einem anderen Zusammenhang zu behandeln.

Ps. 19. Dafs v. 8-15 die Gemeinde redet, möchte sich aus v. 14 ergeben. Wenigstens ist nicht abzusehn, wie der einzelne Fromme, der in das Wesen der geoffenbarten Religion so tief eingedrungen ist wie der Dichter dieses Liedes, durch die Herrschaft der Gottlosen zur Sünde verführt werden könnte. Wohl aber wird das böse Beispiel der Regierenden für die Masse der Frommen gefährlich (Ps. 125, 3. 119, 134. 110). „Dein Knecht" (v. 12. 14) kann sehr wohl die Gemeinde bezeichnen; vgl. das zu Ps. 116 bemerkte.

Ps. 20. Das v. 7 vereinzelt auftretende Ich (vgl. dagegen „Wir ${ }^{*}$ จ. 6. 8-10) ist der G'emeinde beizulegen. Die subjective Gewifsheit des Individuums würde für die 
in Rede stehende Sache allzu wenig bedeuten. Vgl. 85, 9. $135,5$.

Ps. 22 . S. o. S. 76.

Ps. 23. S. o. S. 80 .

Ps. 25. Am Schlufs (v. 22) wird gebeten, dafs Gott Israel aus allen seinen Nöthen erlösen möge. Nach der herrschenden Auslegung verallgemeinert der Dichter hier zuletzt die bisherige Bitte um seine persönliche Rettung im Hinblick auf das ganze Volk. Allein Rosenmüller schliefst hieraus, dafs die Gemeinde überhaupt das Wort führe, und ältere Ausleger sind ihm in sofern vorangegangen, als sie die Kirche als das redende Ich betrachteten. In der That handelt es sich um die Gemeinde, die wie gewöhnlich von Feinden (v. 2. 19. 20) and zwar von den Gottlosen (v. 3) mit List ( der Rettung des Redenden hängt die Ehre des Namens Jahves (v. 11), Jahve soll ihn retten in Erinnerung an seine uralte Barmherzigkeit, die er Israel von jeher erwiesen hat (v. 6). Im Gegensatz dazu sind die Jugendsünden v. 7 die Sünden des früheren Israel $(129,1.2)$. Die folgenden Verse (v. 8-10) enthalten nicht allgemein gültige Wahrheit, sie drücken vielmehr eine Erwartung aus, die der Bitte v. 4. 5 genau entspricht. Indem Gott die Gemeinde vor Sünden bewahrt, bewahrt er sie vor dem Unheil, das diese nach sich ziehen. Die Sündenvergebung kommt aber dadurch zu Stande, dafs Jahve der Noth ein Ende macht. Obwohl von den Gottlosen hervorgebracht ist die Noth Sündenstrafe. Freilich wird auch auf die einzelnen Frommen Rücksicht genommen, v. 3 stellt dם sie der Gesammtheit gegenüber und v. 12. 13 werden sie zum Beharren in der Gottesfurcht aufgerufen. Ihnen selbst mufs es wohl gehen, ihre Nachkommen aber werden das Land besitzen, nämlich in der messianischen Zukunft, wenn die Gottlosen ausgerottet werden. Dagegen bedeutet עני 16 die Gemeinde (vgl. zu 40, 18). 
Ps. 26. Das Lied ist nahe verwandt mit Ps. 28 (s. d.) und stammt vielleicht aus derselben, jedenfalls aber aus einer gleichartigen Situation. Ueberhaupt wird man jedoch über dieses Gebet ebenso urtheilen müssen wie über jenes. Auch hier ist es doch wohl die Gesammtheit der Frommen, die sich bei drohender Katastrophe der Gesammtheit der Gottlosen gegenüberstellt. Das v. $6 \mathrm{ff}$. Gesagte steht mit 6, 6 u. ä. St. auf einer Stufe. Die Gemeinde, die seinen Altar umkreist und allein in der Welt sein Lob verkündigt, ist für Jabve unentbehrlich. Zu v. 12 vgl. 22, 23. Auch hier tritt die Gewifsheit der Erhörung ebenso plötzlich auf, wie das sonst in den Gemeindeliedern der Fall ist ${ }^{1}$ ).

Ps. 27, 1-6. Wie Ewald richtig sieht, handelt es sich v. 3 nicht um einen rein abstract gedachten Fall, sondern um einen möglichen oder gar wirklichen. Ebenso hat Ewald recht, wenn er auch v. 2 conditional versteht. Die Perfecta sprechen zuversichtliche Erwartung aus wie z. B. 20,9. 36,13. 57,7. Danach mufs entweder ein Fürst oder die Gemeinde das Wort haben, denn einem Privat mann gilt kein Krieg. Dals aber die Gemeinde redet, scheint mir aus v. 4. 5 deutlich hervorzugehn. Die Gemeinde hat im Zutritt zum Heiligthum die Bürgschaft des göttlichen Schutzes (vgl. zu Ps. 23). Sie kann deshalb alle ihre Bitten dahin zusammenfassen, dals Jahve sie nie

1) Die Frommen fordern nicht sowohl die strengste Prüfung ihrer Frömmigkeit kühn heraus, als sie vielmehr darum flehen. Sie besorgen, Gott könnte auf das ganze Volk dreinschlagen, ohne zu richten d. h. ohne von der Frömmigkeit seiner Diener Notiz zu nehmen und zwischen ihnen und den Gottlosen zu unterscheiden. Mit Recht fragt man, wie doch der Einzelne sich so unschuldig fühlen könne. Aber die Unschuld der Gemeinde der Frommen besteht zunächst darin, dafs sie mit den Gottlosen nichts zu thun hat und sie hafst, dafs sie ferner glaubt, Jahres Walten müsse sich zuletzt als ein gerechtes erweisen zum Heil der Gemeinde. Sonst vgl. o. S. 96. Aber allerdings kann Jahve auch walten, ohne zu richten, und dafs er das jetzt nicht thun möge, ist der Inhalt dieses Gebets und mancher ähnlichen. 
(wieder) aus seiner Nähe verstofsen möge. Wie dagegen ein König des vorexilischen Jerusalem auf eine derartige Bitte hätte kommen können, ist nicht abzusehn. Offenbar ist es auch kein König, den Jahve vor seinen Feinden im Heiligthum verbirgt (v. 5), wohl aber steht eine solche Empfindung der geistlichen Gemeinde des zweiten Tempels an. Von ihr allein kann auch gesagt werden, dal's sie in der Andacht des Gottesdienstes ihr höchstes Glück geniefst (v. 4). Danach ist v. 2. 3 von den beiden Feinden die Rede, die die Noth der nachexilischen Gemeinde wesentlich ausmachten, den Gottlosen und den Heiden.

Ps. 27, 7-14. In diesen Versen, die augenscheinlich ein selbständiges Lied ausmachen, tritt vielleicht $\nabla .10$ etwas Individuelles hervor. Indessen würde das für den Gesammtcharakter nichts beweisen; was den Einzelnen wiederfuhr, kann auf die Gesammtheit übertragen sein, so dals hier Ich für Wir stände (vgl. 69,9). Ueberdies können die Worte auch sprüchwörtlich dahin verstanden werden, dafs die Gemeinde von allen, auch den nächsten Freunden im Stich gelassen sei. Uebrigens handelt es sich um Verfolgung, die den Redenden mit dem Tode bedroht (v. 11. 12). Das läfst zunächst an die Gemeinde denken. Von einem falschen Zeugnils der Heiden wird 35, 11 bildlich geredet. Sind die Feinde dagegen die Gottlosen, so könnte man auch hier beim Wortsinn stehen bleiben, ohne dafs damit irgend etwas entschieden würde. Der Gemeinde allein eignet ferner die v. 13 ausgesprochene Gewifsheit, auch ist nur ihrem Gebet die Erhörung gewährleistet ( $\nabla .8)$. Ueber עבדך v. 9 vgl. zu Ps. 116, es handelt sich um die Verwerfung der Gemeinde. Ebenso wenig hat es Bedenken, wenn v. 14 die Gemeinde mit Du angeredet wird ${ }^{1}$ ). Uebri-

1) Die Anrede bezw. Selbstanrede der Gemeinde mit Du v. 14 findet sich aufser den oben S. 87 besprochenen Stellen woch 32, 8 . 55, 23. 120 , 3. 121,3 . 5 ff. 130,7 . 131, 3. Vgl. auch 42,6 . 12. 43,5 . 103,1 ff. $22.104,1.35 .116,7.146,1$ and ferner 50,16 ff. 52,3 ff. 
gens sind die Verse durchaus im Charakter der sogenannten „Klagepsalmen" gehalten, die sich sämmtlich als Gemeindelieder erweisen.

P8. 28 stammt aus einer Zeit allgemeiner Gefahr, wohl mit Recht denkt Ewald an eine Pest. Da fordert der Glaube die lange ersehnte Offenbarung der göttlichen Gerechtigkeit : jetzt soll sich's zeigen, dafs Jahve einen Unterschied macht zwischen den Gottlosen und den From. men! Angesichts der nahenden Katastrophe steigert die Spannung der Gegensätze sich auf's äufserste, fast mehr noch als um die eigene Bewahrung fleht die Gemeinde um die Bestrafung ihrer Gegner. Sieht sie aber auf den Frevelmuth der sicheren Sünder, die auch jetzt noch auf Jahve's Thun d. h. auf die Zeichen der Zeit nicht achten wollen, dann scheint wirklich die letzte Entscheidung unmittelbar bevorzustehen. Das quälendste Problem des Glaubens, nämlich das Glück der Gottlosen, wird endlich gelöst. Schon preist sie jubelnd den Gott, der sie erhört, damit aber das Heil der messianischen Zeit, auch Israels Triumph über die Heiden, herbeiführt. Dafs das Lied nicht erst später gedichtet ist, nachdem die Katastrophe (resultatlos) vorübergegangen war, beweist die ungeschwächte Spannung der Erwartung. Aus demselben Grunde kann der Schlufs v. 6-9 nicht erst nachträglich beigefügt sein. Auch schlägt der Dank zuletzt wieder in Bitte um (v. 9). Uebrigens handelt es sich um das eine grolse Anliegen der Gemeinde und man hat alle Ursache, sie als das redende Subject zu betrachten, wenngleich natürlich auch jeder einzelne Fromme v. 1-3 um seine Erhaltung bittet. Versteht man dagegen das Lied individuell, so ist der plötzliche Uebergang von flehentlicher Bitte ( v. 1-5) zum Dank für die Erhörung (v. 6. 7) schwer zu erklären und ebenso unvermittelt schliefsen sich dann v. 8. 9 die Hoffnungen und Bitten für die Gemeinde an das Vorige an.

Ps. 30. S. o. S. 83. 
Ps. 31. Dem Redenden stellen Feinde nach (v. 5. 9. 16), die ihm ans Leben wollen (v. 6. 14), dabei mit Verläumdung und Lügen gegen ihn vorgehn (v. 14. 19. 21), übrigens aber als hochmüthige Herren erscheinen (v. 19. 24). Der Verfolgte hat seit langer Zeit hierunter gelitten, er ist darüber an Leib und Seele alt und schwach geworden (v. 10 und v. 11, wo nach LXX בעני zu lesen ist). Bei den Menschen findet er nirgendwo Hülfe, die Nachbarn schmähen ihn, den Bekannten flölst seine Erscheinung Schrecken ein, wer ihn auf der Strafse von weitem sieht, eilt davon (v. 12). So von seinen Nächsten verlassen erscheint er als die sichere Beute seiner Feinde (v. 13). Aber er vertraut auf Gott. Es handelt sich nämlich um den Gegensatz von. Gottlos und Fromm, mögen die Gottlosen zu Schanden werden, nicht aber er, der Gerechte, den die Uebermüthigen lügnerisch befeinden (v. 18. 19). Deshalb soll Jahre ihn um der Gerechtigkeit willen (v. 2), ja um seines Namens willen ( $\nabla .4)$ retten. Denn er allein ruft den Jahve an (v. 18), Jahve ist nur sein Gott (v. 15) und er Jahves Knecht (v. 17). Er weils ferner, dafs Jahve seine Gegner hafst (v. 7, wo nach LXX שנאת zu lesen), und fühlt sich in der Nähe des Heiligthums vor aller ihrer Bosheit geborgen (v. 20.21). Sein Vertrauen steigert sich deshalb zur Gewifsheit der Rettung. Nicht nur dereinst will er den Jahve für seine Rettung preisen (v. 8. 9), er preist ihn schon jetzt (v. 22. 23). An letzterer Stelle drücken die Perfecta die Gewifsheit der Erwartung aus und ebenso ist das Perfectum v. 6 zu verstehn. Mögen alle Frommen auf Jahve vertraun, der ihnen Treue hält und mit den Gottlosen abrechnet (v. 24. 25)!

Bekanntlich wird dies Lied von Hitzig und auch von Ewald auf Jeremia gedeutet und zurückgeführt, wegen der Berührung von v: 14 a mit Jeremia 20, 10, v. 11 mit Jer. 20, 18, v. 13 mit Jer. 22, 28. 48, 38, v. 18 mit Jer. 17, 18. Dabei legt Hitzig besonders auf v. 22 Gewicht. 
Er thersetzt : „Gepriesen sei Jahve, dafs er mir wunder„bare Huld erzeigt hat in belagerter Stadt." Indessen ist von feindlicher Belagerung im ganzen übrigen Liede nichts angedeutet und es wäre sehr befremdlich, dafs wir diesen Nebenumstand gerade hier erführen. Man sieht namentlich nicht ein, wie die Rettung des Dichters vor den Gottlosen gerade dadurch noch wunderbarer erschiene, dals gleichzeitig die Stadt von Feinden belagert würde. Zudem heilst sonst eine feste Stadt und man wird eher übersetzen dürfen : „weil er mir wunderbar seine Gnade "beweist als eine feste Burg." Zur Noth läfst sich ein solcher Gebrauch der Präposition ב nach Ex. 6, 3 und ähnlichen Stellen rechtfertigen. Wir hätten dann $\nabla .22$ lediglich eine weitere Ausführung des Bildes von v. 21 und v. 3. 4. Ferner berührt das Lied sich nicht nur mit dem Buche Jeremia, sondern auch mit den Klageliedern, Jona 2 und manchen Gemeindeliedern des Psalters, der Eingang wird in dem Gemeindelied Ps. 71 wiederholt.

In der That wird das Leiden des Verfolgten und das Gebahren seiner Feinde hier ganz so geschildert wie in anderen Psalmen die Unterdrückung der Gemeinde durch ihre Gegner. Unverkennbar tritt v. $10 \mathrm{ff}$. das Bild der Krankheit und schliefslich des Aussatzes auf. Ferner erscheint der Gegensatz des Redenden zu seinen Feinden als der der Frommen gegen die Welt überhaupt. Auch hier fordert es die Ehre des Namens Jahves, dafs er einschreite (v. 4). Ferner ist nicht abzusehn, wie der einzelne Fromme durch die Nähe des Tempels vor der Verfolgung der Gottlosen geschützt sein könnte (v. 20. 21). Wohl aber beruht hierauf die Zuversicht der Gesammtheit der Frommen. Endlich kommt auch hier die Gewifsheit in Betracht, mit der der Redende von seiner Rettung überzeugt ist. Durchaus unzulässig ist die Annahme, dafs v. 20-25 oder v. $22-25$ später beigefügt oder aber das ganze Lied erst nach erfolgter Rettung entstanden sei. 
Das sind Gewaltthätigkeiten, die den Verzicht auf ein Verständnifs des Liedes bedeuten ${ }^{1}$ ). Die Gewifsheit der Rettung tritt schon $\nabla .6$ hervor. Ich betrachte daher die Gemeinde der Frommen als das redende Subject. Damit streitet es nicht, dafs zum Schlufs v. 24. 25 alle Frommen zum Gottvertrauen aufgerufen werden. Wahrscheinlich sind die Feinde aber Heiden und nicht die Gottlosen.

Ps. 32 scheint ebenfalls ein Gemeindelied zu sein. Der Jubelruf, in den alle Frommen ausbrechen sollen (v. 11), deutet wohl an, dafs nicht ein Einzelner, sondern sie alle gerettet sind. In der Schilderung des Leidens fehlt wieder die Durchsichtigkeit, die bei einer persönlichen Noth zu erwarten wäre. Die Bilder der Krankheit und der körperlichen Züichtigung spielen hinein (v. 3. 4). Es liegt ferner vor der Hand, v. 8 an dieselbe Adresse gerichtet sein zu lassen wie v. 9. Wird aber die Gemeinde mit Du angeredet, dann stellt sie auch gewifs das redende Ich vor. $\mathrm{Zu}$ der Seligpreisung v. 1.2 vgl. oben S. 50.

Ps. 34. Es redet hier Jemand, der jetzt eben Jahve's Hülfe erfahren hat (v. 5. 7). Wenn er deshalb sich Jahve's rühmt, sollen alle Frommen sich mit ihm freuen und mit ihm den Jahve preisen (v. 3. 4). Dabei constatiren sie aber nicht nur, dafs der Glaube sich am Schicksal eines beliebigen Einzelnen als wahr erwiesen hat (v. 7), vielmehr betrifft die Rettung dieses Elenden sie selbst, sie alle erfahren darin die Güte Jahve's (จ. 9). Die Frommen in ihrer Gesammtheit beschützt der Engel Jahve's und hat er jetzt in grofser Gefahr beschützt (v. 8). Man wird deshalb unter jenem Elenden (v. 7) die Gemeinde verstehn müssen und es hat kein Bedenken, mit Olshausen wie

1) Noch bedenklicher ist hier und anderswo die Auskunft Hupfelds. Er will das Nebeneinander von Dank und Bitte daraus erklären, dafs der Redende theils Rettung erfahren babe, theils noch in Noth sich befinde, also in einem "gemischten Zustande". 
v. 2-5 so auch $\nabla .12$ diese als das redende Ich $z u$ betrachten. Freilich soll das, was die Gesammtheit erfahren hat, auch jedem Einzelnen in seinem Leben zu Theil werden (v. 13). Aber die Frömmigkeit des Einzelnen wird wie Ps. 15. 24 dahin definirt, dafs er die Bosheit der Gottlosen meidet (v. 14. 15), und der Gegensatz zwischen der Gemeinde der Frommen und den Gottlosen beherrscht das Ganze. Jene wird Jahve immerdar schützen, diese aber vertilgen (v. 16-23). Augenscheinlich ist auch eine Rettung der Gemeinde vor den Nachstellungen der Gottlosen der Anlafs des Liedes (v. 16. 17. 22. 23). Zur zweiten Hälfte von $\mathbf{v} .9$ vgl. oben S. 50 . Vielleicht ist v. 6 mit LXX zu lesen, dann aber auch mit Hitzig אלי.

Ps. 35. Die Feinde, um deren Abwehr und Vernichtung hier gebetet wird, sind nicht etwa einzelne Privatpersonen. Mit Schild und Speer soll Jahve sie vertreiben (v. 2.3). Ebenso wenig stellt der Redende einen einzelnen Frommen vor. Er verlangt, dals der מלאך יהוה d. h. der in aulserordentlicher Weise sich manifestirende Gott dazwischen fahre ( dafs eine solche Manifestation Jahve's in einer blos persönlichen Angelegenheit nicht gefordert werden könnte. Ferner hat der Redende Freunde, die seine Rechtfertigung d. h. Rettung aufs lebhafteste wünschen und den Jahve dafür immerdar preisen werden ( $\nabla .27$ ), ja in grofser Versammlung und zahlreichem Volke wird der Dank gegen Jahve abgestattet ( $v$. 18). Wenn dabei der Redende sich elend und arm nennt (v. 10), so paist das auf kein Individuum, auch nicht auf Jeremia (Jer. 20, 13), sondern nur auf die Gemeinde der Frommen (vgl. zu 40, 18), auf die Stillen im Lande (v. 20). Daneben wäre es immerhin möglich, dafs v. 13 . 14 individuell verstanden sein wollten. Während aber Ewald aus der Gegenüberstellung v. 15 schliefst, dafs der Redende auch krank sei, werden eben wegen dieser Gegenüberstellung diejenigen recht haben, 
welche die Krankheit v. 13. 14 bildlich deuten. Daraus würde aber folgen, dals die Feinde auswärtige Völker sind und es sich um Fürbitte der Gemeinde für sie handelt. Dals derartiges vorkam, sieht man z. B. aus 1 Macc. 12,11 . Auch v. 2 sind leichter auf fremde Völker als auf die Gottlosen zu beziehn. Ueber עבדו (v. 27) vgl. zu Ps. 116. Es besteht somit kein Grund dies Lied anders zu beurtheilen als die nahe verwandten Klagelieder ähnlicher Art.

Ps. 36. Die Frommen haben von der heimtückischen Bosheit der Gottloson schwer zu leiden und sind ernstlich von ihnen bedroht, aber alledem gegenüber ist die göttliche Güte und Treue ihr Trost. Indem nämlich Jahve sie in seinem Tempel Zutritt finden lärst, läfst er sie seiner Gnade und Hülfe gewifs werden. Oder sollten die Gottlosen es wagen wollen, die Gemeinde der Frommen völlig zu unterdrücken und sie gar von hier zu vertreiben ? Dann würde Jahve einschreiten und die Bösen für immer vernichten. Dals das Ich v. 12 (neben Wir v. 10) die Gemeinde bedeutet, ist ebenso gewils als dafs die Perfecta v. 13 die bestimmte Erwartung ausdrücken. Der Personification der Gemeinde der Frommen entspricht die der Gegenpartei (v. 2-5); vgl. dagegen die Plurale v. 8. 9. 11. 13.

Ps. 38. S. 0. S. 75 .

Ps. 39. Die göttliche Gnade gegen die Gemeinde wird Ps. 103 (s. d.) aus der Kurzlebigkeit der Menschen begründet, mit der Jahve Erbarmen hat, und umgekehrt trösten sich dort die Einzelnen über ihre. Vergänglichkeit damit, dafs die Gnade Jahres gegen Israel ewig und immer neu sei. Das Gegenstück dazu bildet Ps. 90. In trüben Zeiten empfand man aufs bitterste das Schicksal der Sterblichkeit. Eine Generation nach der anderen mufs unter dem Druck des göttlichen Zorns dahin, ohne dafs das messianische Heil sich zeigte. Da fleht die Gemeinde um endliche Erfüllung der Hoffnung, oder wenigstens um an- 
dere Erweise der gottlichen Gnade im Hinweis auf die Kurze des menschlichen Lebens (vgl. auch 89, 48. 119, 84).

Denselben Sinn hat Ps. 39 (vgl. v. 5 mit 90, 12). Schon Raschi versteht dies Lied als Gemeindegebet, indem er den Thoren $\nabla .9$ auf die Heiden deutet, und sagt, dies sei מררש אגרה. Unnothiger Weise hat Olshausen diese Auffassung dahin eingeschränkt, dafs er das Lied zunächst aus den persønlichen Verhältnissen und Seelenzuständen des Verfassers hervorgegangen sein läfst. Individuelles tritt nirgends hervor, die Betrachtung ist völlig allgemein gehalten. Wie in $\mathrm{Ps}_{\mathrm{s}} 90$ handelt es sich um das allgemein menschliche Geschick, das aber von der Gemeinde der Frommen in ihrem Unglück am bittersten empfunden wird. Wichtig sind ferner die Worte ${ }^{80}$ lange der Gottlose vor mir ist" (v. 2). Die fromme Gemeinde darf sich vor den Gottlosen keine Blöfse geben, sie würde die Sache Gottes verächtlich machen, wenn sie vor jenen ihren Unmuth laut werden liefse. Hier handelt es sich aber nicht um persönliche Begegnungen zwischen Frommen und Gottlosen; es ist allzu selbstverständlich, dafs der Fromme bei Anwesenheit von Gottlosen über seine Glaubensnöthe schweigt. Vielmehr ist von der Existenz der Gottlosen die Rede. Dann aber ist hier das Erlebnifs des Untergangs der Gottlosen d. h. der messianischen Zeit ins Auge gefalst, worauf in dieser Weise nur die Gemeinde reflectiren kann. Diese bedeutet also das redende Ich. Allerdings bedeutet es mehr noch die jetzt lebende Generation, die wie alle früheren dahin mufs und nur Beisasse und Schutzbürger des im heiligen Lande allein ansässigen Jahve ist (v. 13. 5 f.). Die Rettung der Gemeinde aus allen ihren Sünden wäre die Aufhebung ihrer Noth, der Verzug der göttlichen Hülfe macht sie zum Spott der Gottlosen ( meinde ist auch der Mann von v. 12 (vgl. oben S. 50). Uebrigens beachte man, dafs das Leiden wiederum als Krankheit vorgestellt ist (v. 11. 12). 
Ps. 40. Der allgemeine Character des Liedes ergiebt sich zunächst aus dem Nachdruck, mit dem der Redende betont, dafs er Jahve den schuldigen Dank bezahlt habe (v. 10. 11, wo namentlich das אתה ידעת zu beachten ist). Gegenwärtig ist es nicht mehr um Abstattung des Dankes zu thun, sondern um die Rettung aus neuer Noth, auf die der Redende nicht zum wenigsten wegen seines zuletzt bewiesenen Verhaltens hofft. Die Bitte darum wäre aber v. 12 viel zu kurz ausgesprochen, deshalb müssen v. 14-18 ursprünglicher Bestandtheil des Liedes sein. Ferner bezieht der v. 10. 11 in Rede stehende Dank sich nicht sowohl auf alle früheren Rettungsthaten Jahves (v. 6), als vielmehr auf eine besondere. Von dieser müssen $\nabla .2-4$ berichten. Die Punctation ist hier also in Ordnung, nur

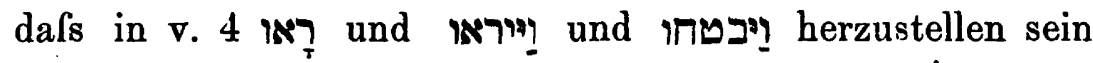
könnte. Es geht kaum an, mit Ewald bei תהלה den Wortlaut des damaligen „neuen Liedes" beginnen zu lassen. Eine solche wörtliche Anführung scheint auch im Folgenden nicht vorzuliegen. $D a f s$ es sich aber um frühere Rettung und neue Noth der Gemeinde handelt, ist aus der grofsen Aehnlichkeit und mehrfach wörtlichen Uebereinstimmung des Liedes mit anderen Gemeindeliedern zu schliefsen. Im Besonderen hebe ich noch Folgendes hervor. Die Rettung aus jener früheren Noth verdankte der Redende der göttlichen Gerechtigkeit (v. 10. 11) d. h. das gute Recht seiner Sache wurde von Gott anerkannt ${ }^{1}$ ).

1) Auf den letzteren Umstand bezieht es sich, wenn hier (v. 11) wie oft neben Jahres Gerechtigkeit auch seine Gnade und Treue genannt wird. Sieht man auf Israels Verbältnifs zu den Heiden und zu den Gottlosen, so ist es zweifellos, dafs die Gemeinde, die den Gottlosen und der Welt gegenüber ja immer im Recht ist, auch Recht bekommt, sobald nämlich Gott richtend einschreitet. Aber Jahve braucht nicht zu richten, er könnte die Dinge auch gehn lassen, wie sie wollen; dals er richtet, beruht auf seiner Gnade und Treue oder auch auf seiner Gnade allein : ${ }_{n} \mathrm{Du}$ bist gnädig, denn $\mathrm{Du}$ vergiltst dem Menschen nach ${ }_{n}$ seinem Thun" (Ps. 62, 13). 
Jetzt befindet er sich dagegen wieder in der gröfsten Noth und zwar zur Strafe für seine Sünden (v. 13), wenngleich cr daneben seinem guten Gewissen zu Gott lebhaften Ausdruck giebt (v. 7-11). Auf die Frage, wie denn der Redende fruher unschuldig litt, jetzt aber schuldig, giebt das Lied jedoch keine Antwort. Deutlich ist zunächst nur, dafs er beide Male verfolgt wurde. Indessen mufs die Sache so zusammenhängen, dafs er beide Male Gott gegenüber sich schuldig fühlte, dagegen seinen Verfolgern gegenüber sich im Recht wufste. Nur, dafs seine Noth aus dem ersteren Gesichtspunkt, seine Rettung aus dem letzteren begriffen werden mufs, daher denn im Rückblick auf die frühere Rettung der eine, im Blick auf die gegenwärtige Noth der andere vorwaltet. Dafs aber diese Voraussetzungen hier stillschweigend gemacht werden, beweist, dafs die Gemeinde redet. Die Gemeinde empfindet in ihrer Noth ihren Verfolgern gegenüber immer nur ihr Recht, Gott gegenüber ebenso lebhaft ihre grenzenlose Schuld. Für den Einzelnen dagegen liegt die Sache nicht immer so einfach, er kann deshalb von derartigen Voraussetzungen, wie sie hier und in vielen ähnlichen Liedern gemacht werden, nicht stillschweigend ausgehn. Uebrigens kommen hierfür noch andere Erscheinungen in Betracht. Ein „neues Lied“ wird dem Jahve gesungen, wenn er in neuer, bis dahin unerhörter Weise seine Herrlichkeit offenbart (Jes. 42, 10. Ps. 33, 3. 96, 1. 98, 1. 144, 9. 149, 1). Freilich kann der Sinn der Redensart einigermalsen abgeschwächt werden, namentlich da, wo es heifst, dafs man dem Jahve ein neues Lied singen wolle. Aber hier heifst es, dafs der Redende-damals nach seiner Rettung das Lob Jahves in ganz neuer Weise verkündet hat (v. 4). Also handelt es sich gewifs nicht um die Rettung eines Einzelnen, sondern um die der Gesammtheit. Ferner liegt es vor der Hand v. 6 als Explication von v. 5 zu betrachten, der hier glücklich gepriesene Mann ist die Gemeinde (wie 94, 12), 
das Haus Joseph war ${ }^{1}$ ), nicht der Stamm Juda, dem die Bewältigung dieser Gebiete gelang, ist höchst beachtenswerth.

Besonders schlimm scheint es mit v. 36 zu stehen, der oft genug völlig aufgegeben ist. Schon Studer hat viel Mühe daran gewendet und doch gestehen müssen, dafs er als inhaltlich unrichtig und ohne Zusammenhang mit dem Vorigen zu nichts zu brauchen sei. Den ersteren Anstofs hat nun Hollenberg ${ }^{2}$ ) beseitigt durch Verweisung auf die Lesart mehrerer Klassen von LXX-Handschriften, darunter die werthvollsten der gerade für das Richterbuch besonders wichtigen Lucianhandschriften ${ }^{3}$ ) - man mufs sich wundern, dafs darauf erst so spät hingewiesen wurde ${ }^{4}$ ). Daraus ergiebt sich der Text ונבול האמרי הארמי טמעלה ונו. Auch für den Nachweis, dals dies ó 'Idovuaios nicht gelehrter Einschub sei, darf ich auf jene Stelle verweisen. Aber nun wird, weil jenes „die Grenze des Amoriters war der Edomiter" in keiner Beziehung befriedigt, auch der von Hollenberg freigegebene weitere Schritt zu thun sein : das האמרי mufs als Einschub aus diesem Texte entfernt und

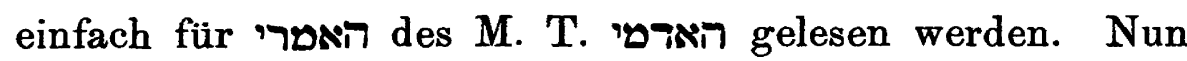
ist der Sinn klar und gut : „und das Gebiet des Edomiters erstreckte sich vom Skorpionensteige ${ }^{5}$ ) an, von Petra an

1) Schwerlich erst das getrennte Nordreich, wenn Stade mit seinem erklärenden „das Reich Israel“ (Gesch. d. V. Isr. I S. 167) dies meint. Der Beweis liegt für Beth-Schemesch, falls dies gemeint ist, in Sam. I, 6.

2) ZATW. 81. S. $102 \mathrm{ff}$.

s) Vgl. auch de Lagarde's Lucian-Text.

4) Den ausführlichen Nachweis, dafs mit dem M. T. nicht auszukommen ist, wird man mir auch Bertheau's neuestem Versuche gegenüber um so eher erlassen, als nach der Vorrede dieser Theil seines Commentars wahrscheinlich vor dem Aufsatze von Hollenberg im Drucke fertig geworden ist.-

5) Am wahrscheinlichsten doch der Pafs es-Safa, nicht ganz halbwege zwischen Hebron und Petra etwa 30,10 $0^{\circ}$ n. Br., 52,45 ö. L. von 
Will der Einzelne deshalb wiederhergestellt sein, damit er sich an seinen Feinden rächen könne, so wird das nur wenig dadurch gemildert, dafs er im Eingang Segen herabruft auf die, die anders als seine Feinde sich gegen den Unglücklichen barmherzig beweisen ( lends befremdlich ist es aber, wenn der Einzelne eben daran die göttliche Gnade erkennen will, dals Jahve ihn seinen Gegnern nicht unterliegen läfst. Räth man auf einen König oder ein anderes Volkshaupt, dem ein Prätendent gegenübersteht (2 Sam. 15, $25 \mathrm{f}$.), so enthält der Satz' etwas allzu selbstverständliches, als dafs er ausgesprochen sein dürfte. Sonst aber lälst sich kaum ein Fall denken, in dem die Worte von v. 12 persönlich verstanden nicht einen Individualismus ausdrückten, $\operatorname{der}$ im $\mathrm{A}$. T. keine Stelle hat. Ebenso mufs man auch hier wieder fragen, wie denn der Einzelne zu der in v. 13 ausgesprochenen Gewilsheit seiner Erhaltung kommt? Ewald und Olshausen nehmen dem Liede vollends alle Wahrheit, indem sie v. 13 erzählend fassen und danach das vorhergehende Gebet in die Vergangenheit setzen.

Dagegen hat schon Rudinger mit Recht behauptet, dafs die Krankheit auch hier nur Bild sei. Liegt der Redende nach Meinung seiner Gegner auf seinem Sterbebette ( $v .9$ ), so sieht man nicht ein, weshalb diese ihm noch eifrig nachstellen (vgl. Ps. 38). Denn darauf kommt ihre Anfeindung hinaus (v. 6-8). Wenn aber die Krankheit nur Bild der Noth ist, dann redet eben auch kein Einzelner, sondern die Gemeinde. Im Munde der Gemeinde haben nun auch v. $12 \mathrm{f}$. ihren sehr guten Sinn : Jahve mag alles nur denkbare Unheil über sie verhängen, aber ihre Feinde darf er über sie nicht triumphiren lassen. Für die Gemeinde hängt hieran allerdings die Wahrheit der Religion (vgl. zu Ps. 30). Schliefslich wird die Gemeinde auch selbst die Rache an ihren Verfolgern vollziehn. Sie, die der Welt gegenüber unschuldig ist, darf Jahve nicht 
untergehn lassen. Sie hat vielmehr die Gewifsheit ewigen Bestandes vor seinem Angesicht d. h. bei seinem Heiligthum ${ }^{1}$ ). Man mag aus diesem Liede lernen, wie weit die Personification der Gemeinde gehn kann.

Ps. 42. 43 deutete ich früher als das Lied eines einzelnen Juden, der in die Heidenwelt verschlagen wäre (Stud. und Krit. 1884 S. 733 f.). Indessen hat Olshausen doch wohl Recht, wenn er v. 5 übersetzt : „wie ich ein-

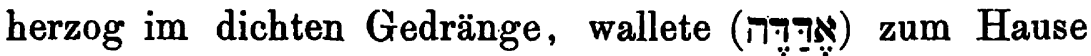
Gottes mit Jubelgesang und Dankgebet, als eine feiernde Menge ${ }^{\star}$. Dem Redenden steht ein ganzes Volk gegenüber (43, 1 vgl. v. 2 und 42, 10) und an seiner Rettung scheint die Wahrheit des Glaubens zu hängen (42, 4. 11), was auf einen Einzelnen, nicht leicht pafst. Auch wird der bildliche Ausdruck 42, 10. 43, 2 verständlicher, wenn die Personification einer Mehrheit vorliegt. Demnach glaube ich, dals eine exilirte Gemeinde redet; ob gerade die Gemeinde des babylonischen Exils, wäre weiter zu fragen. Auf Israel deuten das Lied die Rabbinen und früher schon Eusebius.

Uebrigens bleibt das a. a. O. Gesagte bestehn.

Ps. 44, 5. 7. 16 . S. o. S. 68.

Ps. 45. Hier klingt v. 2 durchaus individuell, über v. 18 kann man anderer Meinung sein. Es hängt das vom Sinne des ganzen Liedes ab, den ich hier nicht erörtern will.

Ps. 49. Soweit bei dem schlechten Zustande des Textes überhaupt ein sicheres Urtheil möglich ist, möchte auch hier das Ich von der Gesammtheit zu verstehn sein (v. 4 -6. 16). Der Streit der Exegeten über den Sinn von $v$. 16 würde sich damit ebenso erledigen wie bei

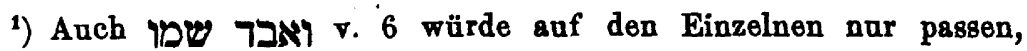
wenn er kinderlos wäre. Die Feinde möchten dagegen die Gemeinde völlig vernichten $(10,6)$. 
Ps. 16. 17. Die Gottlosen sterben und werden schliefslich überhaupt ausgerottet, aber die Gemeinde lebt ewig. Das Lied hat durchaus keinen persönlichen Character. Es handelt sich ganz allgemein um die Verfolgung, die die Gemeinde von den Gottlosen erleidet, und um die Noth, die die Thatsache ihres Glückes, ja ihres Daseins dem Glauben macht. Danach liegt es vor der Hand, v. 6 die Gemeinde als das redende Subject zu betrachten. Dabei könnten v. 4.5 allerdings mehr noch als Rede des Dichters verstanden werden.

Ps. 51. Hier ist es wichtig einzusehn, dals zwischen v. 20. 21 und v. 18. 19 kein Widerspruch besteht, dafs die ersteren vielmehr als ein ursprünglicher Bestandtheil des Liedes erscheinen. Als Correctur von v. 18. 19 hätten die Worte nur Sinn, wenn sie das Interesse des gegenwärtigen Tempeldienstes verträten. Es ist aber von der Zukunft die Rede, von der messianischen Zeit, und man sieht nicht ein, weshalb ein späterer Bearbeiter gerade für diese das Opfer hätte retten wollen, nicht aber für die Gegenwart. Sofern es sich v. 20. 21 aber um die Zukunft handelt, v. 18. 19 dagegen um die Gegenwart, sofern v. 18. 19 die sühnende Kraft des Opfers ins Auge gefalst ist, v. 20. 21 aber das Opfer als Form des Dankes erscheint, sofern endlich v. 18. 19 von der sündigen Gegenwart geredet ist, $\nabla$. 20. 21 dagegen von dem gerechtfertigten Volke der Zukunft, - bilden die beiden Behauptungen allerdings einen vollkommenen Gegensatz, aber von einem Widerspruch zwischen ihnen ist platterdings nichts zu entdecken. Verursacht ist das Urtheil von. v. 18. 19 übrigens wohl nicht durch eine thatsächliche Unterbrechung des Cultus, wie etwa während des babylonischen Exils (vgl. Hos. 9, 4. Ez. 20. Gebet Az. 14 ff.). Die Worte machen vielmehr den Eindruck, als ob es allerdings möglich wäre, zu opfern, und der Opferdienst bestände. Auch redet v. 20 wohl nicht von der Wieder- 
herstellung des zerstörten Jerusalems, sondern von seiner messianischen Herrlichkeit ${ }^{1}$ ). Eher könnte man hier jene Anschauung finden, die in der jüdischen Literatur der verschiedensten Jahrhunderte des öfteren auftritt, dafs nämlich der Cultus des zweiten Tempels Jahve überhaupt nicht gefiel, ohne dafs man darum natürlich aufgehört hätte, den gesetzlich vorgeschriebenen Gottesdienst zu üben (Hagg. 2, 14. Mal. 3, 4. Hen. 89, 73. vgl. Ps. Sal. 2, 1 ff. Lib. Jub. 30, 16. 17). Es war das ein Ausdruck des Bewufstseins, dafs Jahve an der neuen Gemeinde noch kein rechtes Gefallen habe, der Zorn noch nicht vorüber, die Schuld noch nicht gesühnt und das Gesetz noch nicht erfüllt sei. Indessen erscheint hier einfach die prophetische Denkweise, wonach Jahve überbaupt nur Gerechtigkeit und nicht Opfer will, dahin abgeschwächt, dafs die sündige Gemeinde mit ibren Opfern den Zorn Jahves nicht beschwichtigen kann (das kann nur ein zerschlagenes Herz), dafs Jahve aber einst in der messianischen Zukunft die Dankopfer der gerechtfertigten Gemeinde gnädig annehmen werde (vgl. 50, 14 f.).

Da somit v. 20. 21 sich sehr wohl als der ursprüngliche Schlufs des Liedes verstehen lassen, das mit $\nabla .19$ keinen guten Abschlufs fände, so wird man aus der inneren Beziehung, in der v. 18.19 zu v. 20. 21 stehn, allerdings schliefsen müssen, dafs auch dort von der Gemeinde die Rede ist und nicht von einem Einzelnen. Aber auch abgesehn von v. 20. 21 geht das aus dem übrigen Inhalt des Liedes deutlich genug hervor. Dafs v. 15 am besten von der Missionsaufgabe der Gemeinde verstanden wird, hat schon Olshausen bemerkt. Er hat auch betr. des vielerklärten v. 6 wesentlich das Richtige gesehen. Die Gemeinde ist von Feinden verfolgt und diesen vorläufig unterlegen. Danach könnte es scheinen, als ob sie ihren Gegnern gegenüber im Unrecht wäre. Demgegenüber

1) Wie z. B. 69, 36. $102,17$.

Zeitschrift f. d. alttest. Wiss. Jahrgang 8. 1888. 
wird hier ausgesagt, was für die gesammte Stellung der judischen Gemeinde zur Welt charakteristisch ist : Der Welt gegenüber ist sie im Recht, nur Gott gegenüber ist sie in grofser Schuld und auch so mufs sie zur Herrlichkeit Jahves beitragen, damit Jahre als der allein Reine und Gerechte dastehe. Alle anderen Erklärungen sind gezwungen ${ }^{1}$ ). Ferner befürchtet der Redende, von dem göttlichen Angesicht verstofsen zu werden (v. 13). Das wird sonst nur von der Verstolsung Israels aus dem heiligen Lande, bezw. von seiner Verwerfung gesagt ( 2 Reg. 13, 23. 17, 20. 24, 20. Jer. 52, 3. 2 Chr. 7, 20. Jer. 7, 15). Die Stellen Ps. 71, 9. 102, 11 sind schon ein wenig anders, gehen übrigens auch auf die Gemeinde. Ebenso wird das unmittelbar folgende ${ }_{n}$ nimm Deinen heiligen Geist nicht

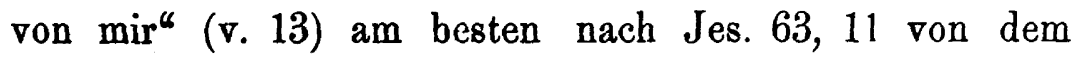
Geiste der Offenbarung verstanden, von dem überall geleitet zu sein Israels Vorzug ausmacht. Nach v. 10 betrifft die Rettung, um die gebeten wird, nicht einen Einzelnen, an dessen Schicksal auch andere Antheil nähmen, vielmehr handelt es sich unmittelbar um eine Gesammtheit. Die Gemeinde bittet, dafs Gott sie den Jubelruf der geretteten und neubeglückten Frommen vernehmen lasse (vgl. 106, 4. 5). Ferner klingt v. 12 stark an bekannte prophetische Stellen an, die von der Gesammtheit reden (Ez. 36, 26. 11, 19. Jer. 24, 7). Vgl. auch v. 5 mit Jes. 59,12 ; v. 19 mit Jes. 57, 15. 61, 1. Uebrigens findet sich in dem ganzen Liede nichts Individuelles. Denn v. 7 ist wie $22,10 \mathrm{f}$. zu verstehn, wenn nicht Ich einfach für Wir steht. Dagegen ist die Nothlage, der das Lied entstammt, wiederum als bekannt vorausgesetzt und nicht näher bezeichnet ( $v$.

1) In v. 16 bedeutet רמים allerdings, wie Olshausen urtheilt, Blut.vergielsen, das der Gemeinde droht. An eine Blutschuld der Gemeinde zu denken, verbietet die Berufung auf Gottes Gerechtigkeit, übrigens aber v. 6. 
6. 10. 14. 16). Es bleibt auch völlig unklar, ob die Verfolger der Gemeinde Heiden oder gottlose Juden sind ${ }^{1}$ ). Ps. 52 wird ein Gewalthaber apostrophirt, der sich seiner Bosheit rühmt, indem er mit tückischer List umgeht, übrigens aber auf seinen Reichthum vertraut (v. 3-6). Gott wird ihn dafür zur Freude der Gerechten vertilgen (v. 7-9). Dagegen ist der Redende sicheren Bestandes gewils, er will Gott preisen, wenn er den Gewalthaber vernichtet und damit dem Redenden seine Güte beweist (v. 10. 11). Bemerkenswerth ist die Art, wie der Redende seine Person der des Gottlosen gegenüberstellt. Diesen Baum wird Gott entwurzeln, er dagegen gleicht einem Oelbaum, der im Tempel gepflanzt ist ( wird der Redende von jenem Gottlosen angefeindet. Denn v. $10 \mathrm{~b}$ weist auf $\mathbf{v} .3 \mathrm{~b}$ zurück, übrigens aber sagt der Redende nur von sich, dals er Gott für die Vertilgung jenes Gottlosen preisen wolle (v. 11). Indessen muls man das errathen, auch nimmt das Lied da, wo der Untergang des Gottlosen angekündigt wird, auf die Rettung des Redenden gar keine Rücksicht, wohl aber auf die Freude, die dann bei allen Gerechten herrscht ( sehr auffällig, man erwártet von der Freude der nur indirect Betheiligten erst zuletzt zu hören. Das Auffällige dieses Gedankenganges schwindet aber sofort, wenn man die Gemeinde als das redende Subject betrachtet. Und dazu hat man alle Ursache. Nämlich die Worte von v. 10 erscheinen ähnlich 92, 13. 14 im Munde der Gemeinde (vgl. Jer. 11, 16), in den sie auch allein passen. Denn die Gemeinde hat im Besitz des Heiligthums die Gewähr ihres ewigen Bestandes, während den Einzelnen die Nähe des Tempels vor der Nachstellung der Gottlosen nicht

1) Richtig hat Olshausen den 51. Ps. verstanden. Wie weit vor ihm Paulus, kann ich nicht beurtheilen, da das betr. Werk mir unzugänglich ist. 
schützt. Ferner ist die in v. 3 in Rede stehende Gnade doch wohl die, welche immerdar uber der Gemeinde waltet (103, 17). Auch der Schilderung des gottlosen Reichen fehlt alles Individuelle, es ist die immer wiederkehrende Klage über die Heimtücke der bösen Herren. Vermuthlich ist die ganze Klasse dieser Leute gemeint. Auch 7 scheint anzudeuten, dafs es sich um die letzte Entscheidung zwischen Gottlosen und Frommen handelt. Dann kann aber auch aus diesem Grunde das redende Ich nur die Gemeinde bedeuten.

Ps. 54 darf nicht anders beurtheilt werden als die zahlreichen verwandten Lieder, die von der Verfolgung des Frommen durch die Heiden oder auch durch die Gottlosen (זרים ist vielleicht in זים zu ändern) handeln. Im Gegentheil zeichnet dies Lied sich durch farblose Allgemeinheit noch ganz besonders aus, so dals selbst Hitzig nach dem Vorgang von Paulus hier die Gemeinde als das redende Ich betrachtet.

Ps. 55. Zunächst ist das Verhältnifs von v. 2-6. 13. 17-19. 24 zu v. 10-12. 21 auffällig. Dort ist der Redende selbst in höchster Lebensgefahr ( $\nabla .2-6$ ), nur ihm scheint die Nachstellung der Feinde zu gelten (v. 13. 19. 24. 16. 17), - hier dagegen erscheint er wesentlich als Beobachter der allgemeinen Noth, die in der Stadt herrscht (v. 10-12. 21). Endlos ist die Unterdrückung, die die Frommen von Seiten der gottlosen Machthaber erfahren. Es handelt sich um förmliche Verfolgung der Einzelnen, ungerechtes Gericht mit Lug und Trug müssen die Frommen über sich ergehen lassen. Damit keines ihrer Opfer ihnen entgehen könne, lassen die Gottlosen Tag und Nacht sogar auf den Stadtmauern Wache halten. Dennoch bittet der Redende nur um die Rettung seiner Person und selbst die Vernichtung der Gottlosen scheint nur diesen Erfolg haben zu sollen (v. 16.17.24). Dafs v. 23 von dem ציק überhaupt die Rede ist, trägt nichts aus. Jener innere Widerspruch 
wird nur durch die Annahme zu heben sein, dafs die Gemeinde redet. Hierfür spricht übrigens auch v. 18. Dadurch dafs der Einzelne dreimal täglich Gott seine Noth klagen will, kann er schwerlich eine bestimmte Aussicht auf Erhörung gewinnen. Etwas anderes ists aber, wenn alle Frommen zu den drei feststehenden Gebetszeiten des Tages um die Rettung der Gemeinde flehen. Zu v. 7-9 vgl. 120, 5 und das zu der Stelle Bemerkte. Es scheint mir auch unbegründet, v. 14. 15 auf einen nunmehrigen Führer der Gottlosen zu beziehn, der bisher mit dem Dichter in Freundschaft gestanden hätte. Dieser Jemand stand auch mit anderen Frommen auf friedlichem Fufs (v. 21), vermuthlich mit ihrer Gesammtheit. Er ist aber schwerlich ein bestimmter Einzelner, so wenig wie der Andere, der ihm gegenübergestellt wird (v. 13). Der Klage über ihn entspricht die Verwünschung aller Gottlosen (v. 16) und auch in $v$. $19 \mathrm{ff}$. wechselt der Plural ohne weiteres mit dem Singular. Der Parteigegensatz bestand wohl nicht immer in gleicher Schärfe.

Ps. 56 wird von der ältesten jüdischen Ueberlieferung auf die Gemeinde gedeutet, indem nämlich die Angabe der Melodie : nach "die Taube der fernen Terebinthen" von den mafsgebendsten Versionen vom Inhalt des Psalms verstanden wird. LXX. Vulg. Aeth. : ívìे $\tau o \tilde{v} \lambda \alpha o \tilde{v} \alpha \dot{\pi} \boldsymbol{\jmath}$

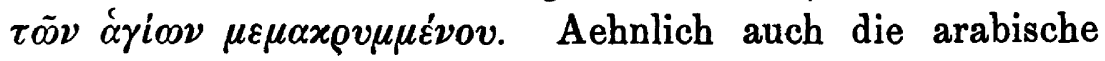
Uebersetzung und Symmachus, der an das verstofsene Ge-

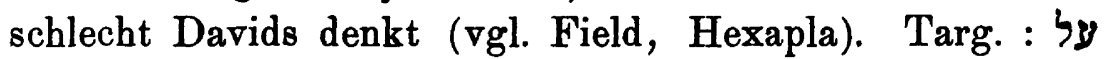

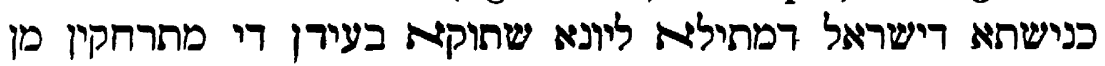

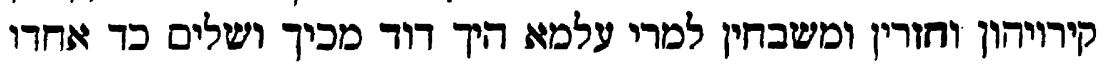
יתיה פלשתאי בגת מדת Der Inhalt des Liedes entspricht diesem Verständnifs durchaus. Es ist ganz in der Art der Gemeindelieder gehalten, die über Verfolgung klagen. Vielfach hat es mit solchen Liedern wörtliche Berührung. Hervorzuheben ist ferner die Gewifsheit der Rettung v. 13. 14, welche Verse Hitzig deshalb als späteren Zusatz 
betrachtet, sowie die Bezugnahme auf die prophetische Verheifsung v. 5. 11. Uebrigens erfahren wir v. 8 ausdrücklich, dafs das Fleisch, das Gott gegenüber nichts vermag, die Heiden sind. Die beiläufige Art, in der das zu Tage tritt, ist beachtenswerth.

Ps. 57 soll Gott sich über den Himmel erheben und auf der ganzen Erde seine Ehre zur Geltung bringen (v. 6. 12), d. h. er soll im Himmel und auf Erden seine Weltherrschaft wahr machen, um den hier redenden Verfolgten zu retten. Wie ein Einzelner einen solchen Anspruch erheben könnte, ist unerfindlich. Weiter ist der Verfolgte trotz aller Furchtbarkeit seiner Feinde ( seiner Erhaltung so vollkommen gewifs, dafs er schon jetzt in Lob und Dank gegen den rettenden Gott schwelgt (v. 8 ff.). Dies Lob Gottes wird aber laut im Gottesdienst der Gemeinde (v. 9), und darüber hinaus will der Errettete in der ganzen Welt seinen Gott preisen (v. 10). Es kann keinem Zweifel unterliegen, dafs die Gemeinde redet. Natürlich sind die Feinde von v. 7 dieselben wie in $\nabla .5$, v. 7 erklärt Ewald mit Kimchi richtig als Perf. proph. und ישלח v. 4 als Optativ. Noch besteht die Noth (v. 2 ff.) und die Rettung ist zukünftig.

Ps. 59. Während im vorigen Liede die Natur der Verfolger zweifelhaft ist, handelt sichs hier ebenso deutlich um Heiden. Denn Jahre Sabaoth, der Gott Israels, wird v. 6 aufgerufen, Rache zu nehmen an allen Heiden, kein Erbarmen zu haben mit den frevelhaften Verräthern (oder auch Räubern). Ebenso heifst es v. 9 bezüglich der bösen Reden der Feinde, dafs Jahve ihrer lacht, dafs er über alle Heiden spottet. Weiter beweist die Vertilgung dieser Feinde, dafs Jahve Herr ist über alle Welt (v. 14), und dals sie dem Volke Israel nicht angehören, wird aus v. 12 vollends deutlich. Es besteht nicht der mindeste Anhalt für die Annahme, dals neben den Heiden hier auch die Gottlosen in Betracht kämen. Dals die bösen Reden der 
Feinde so stark hervorgehoben werden ( keineswegs auf einen täglichen Verkehr mit ihnen, wie Olshausen meint. Man weifs, wie tief der Jude durch Religionsspott verwundet wurde (vgl. z. B. 42, 11. Dan. 7, 8. 20. 11, 36) ${ }^{1}$ ). Zweifellos ist das Lied zu einer Zeit entstanden, wo Jerusalem von feindlichen Schaaren beunruhigt wurde, die namentlich Nachts die Stadt umschwärmten $\left.{ }^{2}\right)$. Es müfste nun allerdings Wunder nehmen, wenn hier ein Einzelner die Nachstellung solcher Feinde ohne jede Rücksicht auf die Gesammtheit ausschliefslich auf seine Person bezöge (v. 4) und dem entsprechend auch nur um die eigene Rettung flehte. Kann ein Einzelner seiner Person wegen das Weltgericht aufbieten (v. 6) und seiner Rettung eine solche Bedeutung beilegen, wie hier (v. 12. 14) geschieht? Sollte er jeden Morgen Gott nur dafür preisen, dafs die Feinde während der Nacht nicht eingedrungen sind und ihn nicht getödtet haben (v. 17) ? In Wahrheit wird die Gemeinde verfolgt (v. 12), sie ist es auch, die in dieser gefahrvollen Zeit alle Morgen dem Jahve für seinen Schutz in der Nacht dankt.

Ps. 60. Neben dem sonst durchgehenden Wir erscheint v. 11 ein Ich, das von der Gemeinde zu verstehen das allein Natürliche ist ${ }^{3}$ ).

Ps. 61. Deutlich ist v. 6 von zukünftigen Dingen die Rede. Der Erhörung der Gelübde (v. 6) mufs ihre Bezahlung (

1) Ganz verschieden ist $55,22$.

2) Von einem Durchstreifen der Stadt ist nicht die Rede (יסובכו עיר), sondern nur von einem Umkreisen derselben. Dabei sind die Feinde bisher nicht zum Ziel gekommen und verhalten sich wie eine Meute von Hunden, die, wenn sie nichts finden, die Nacht über draufsen beulen (v. 15 f.). Die Worte 55, 11 lauten freilich wieder ähnlich, sind aber doch wesentlich anders.

3) V. 8-10 erklärt Hupfeld mit Recht für das eigene Werk des Dichters, der eine bestimmte Seite der messianischen Verheifsung frei reproducirt. Vgl. 2, 7 ff. 89,20 ff. 
wifs der Zukunft an, als diese erst nach Gewährung des v. 7. 8 Erbetenen stattfinden soll. Offenbar handelt es sich aber um das Heil Israels und wenn die Herbeiführung desselben in Erfüllung der Gelübde des Redenden erfolgt, so ist dieser nicht ein Einzelner, sondern die Gemeinde. Denn der König selbst, der etwa noch in Betracht käme, kann wegen des Inhalts von v. 7. 8 nicht wohl am Worte sein. Es ist ferner ein ständiges Anliegen der Gemeinde, immerdar in der Nähe des Heiligthums weilen zu dürfen (v. 5). Sie hat darin die Bürgschaft für die Erfüllung der messianischen Verheifsung (S. z. Ps. 23). Wegen v. 3 braucht man aber nicht mit Olshausen anzunehmen, dafs hier eine Gemeinde der Diaspora redet. Denn v. 5 versteht sich doch am besten im Munde von solchen, die jetzt schon in der Nähe des Heiligthums weilen. Dais die Gemeinde vom Ende der Erde her zum Himmel ruft, ist Ausdruck des Gefühls der Gottverlassenheit. Wenn Jahve aber somit zugleich fern und nahe ist, so ist das bei Vergleichung von Ps. 14,7 . 20, 3 mit 14, 2. 20, 7 nicht verwunderlich. Der Gedankengang des Liedes ist auch sonst etwas sprunghaft. Es ist willkürlich, wenn Ewald hinter v. 5 eine Lücke statuirt. Es entsprechen einander v. 4 und v. 6 , sowie v. 5 und v. 7. 8, das Sela theilt also richtig ab.

Ps. 62 scheint wirklich ein Haupt der Frommen das Wort zu führen, das die Gottlosen zum besonderen Gegenstande ihrer Angriffe machen (v. 4. 5). So urtheilt auch Olshausen. Ihre Hauptstütze hat diese Meinung an משאתו ( .5 ), das allerdings in den Mund der frommen Gemeinde gegenüber den Gottlosen schlecht palst. Dagegen wird v. 12 kaum auf eine persönliche Offenbarung gedeutet werden dürfen, die der Redende empfangen hätte. Vielmehr wird die messianische Verheifsung gemeint sein, wonach Jahve zuletzt dem Regiment der Gottlosen ein Ende macht, 
weil er 1) allein Herr sein und 2) den Frommen zu ihrem Recht verhelfen will. Vgl. auch den Schlufs dieserAbhandlung.

Ps. 63 hat den Auslegern viel Noth gemacht, m. E. ohne Grund. In seinem Elend blickt der Redende nach Gott aus, wie in der Wüste ein verschmachtender Reisender nach Wasser (v. 2). Mit solchem Verlangen schaut er jetzt Gott d. h. er ist jetzt (חויתך ist Perf. praes.) im Tempel vor Gott getreten, um hier Gottes Macht und Herrlichkeit zu sehen (v. 3 v.gl. 27, 4). Freilich ist die Herrlichkeit Jahves auch im Tempel zumeist nur für die Imagination der Andacht sichtbar, ebenso wie die Gnade Jahves, die besser ist als das Leben (v. 4), nur im Glauben erfahren wird. Aber in jener geistigen Anschauung der Herrlichkeit Jahves findét die Gemeinde Trost, weil Jahves Gnade sie dereinst an dieser Herrlichkeit theilnehmen lassen wird. In dieser Gewifsheit tragen die Gläubigen geduldig die Leiden der Gegenwart, sterben sie vor der Erfüllung der Verheifsung getrost dahin, z. Th. verlieren sie vielleicht gar in der Verfolgung (v. 10) das Leben. Trotzdem preisen sie Jahve immerdar in der Gewifsheit seiner Gnade und der blofse Gedanke an Gott ist deshalb auch in der Privatandacht ihnen die höchste Erquickung (v. 5-7). Denn Jahve erhält die Gemeinde, die ihm treu anhängt (. 8. 9). Es handelt sich um kein persönliches Anliegen, sondern um das der Gesammtheit. Gott soll die Feinde, von denen die Gemeinde verfolgt wird, schmählich vertilgen (v. 10.11) und des Reiches Herrlichkeit herstellen, wo König und Volk sich mit Stolz ihres Gottes rühmen werden (v. 12). Man hat also alle Ursache, auch hier die Gemeinde als das redende Subject zu betrachten, wenngleich v. 7 natürlich auch auf alle einzelnen Frommen geht.

Ps. 64 handelt von der Verfolgung der Frommen durch die Gottlosen, die durch plötzliches Einschreiten Gottes mit dem Untergang der Frevler ein Ende nimmt. Man kann die ganz allgemein gehaltene Bitte um Schutz v. 2 . 3 
von dieser behaglich ausgemalten Erwartung nicht trennen, es handelt sich nicht um eine individuelle Noth, sondern um die der Gemeinde uberhaupt. Ohne $Z$ weifel redet diese v. 2. 3.

Ps. 65, 4. Ist die Lesart מצי richtig, so ist die Be-

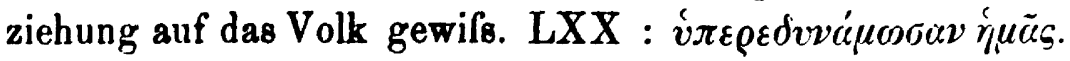

Ps. 66. Es besteht kein triftiger Grund, mit Ewald v. 13-20 von dem Uebrigen zu trennen und jene Verse für ein besonderes Danklied zu halten. Stellt der Psalm aber ein einheitliches Lied vor, so erscheint es selbstverständlich, dafs der, welcher v. 13-20 im Tempel dem Jahve mit glänzenden Opfern für seine Rettung dankt und allen Frommen davon erzählt (v. 16), identisch ist mit der Gemeinde, die wegen ihrer Rettung aus äufserster Noth die Heiden zur Bekehrung zu Jahve auffordert (v. 1-9) und auch dem Jahve selbst gegenüber den wunderbaren Charakter seiner Führungen anerkennt (v. 10-12). Es besteht enger Zusammenhang zwischen v. 12 und v. 13. Aber auch abgesehen von ihrer Verbindung mit v. 1-12 möchten v. 13-20 als Worte der Gemeinde zu betrachten sein. Schon die grolse Zahl von Opfern, die der Redende darbringen will, kommt hierfür in Betracht (v. 13-15). LXX hat übrigens schon v. 9 die 1. Sing. Richtig urtheilt Rudinger und nach ihm Rosenmüller und Olshausen ${ }^{1}$ ).

Ps. 69. Am Schlufs werden Himmel und Erde, das Meer und alles, was sich darin regt, zum Preise Gottes aufgerufen, weil er das messianische Heil herbeiführt (v. 35-37). Diese Verse bringen augenscheinlich keinen Fortschritt über v. 33. 34 hinaus, sondern sind damit parallel. Die Frommen erfahren auch nach v. 33. 34 in der Rettung des Redenden die Rettung der Gemeinde Dieser ganze Schlufs des Liedes (v. 31-37) kann nicht anders

1) Hupfeld wendet ein, die Ausdrücke ${ }_{n}$ mein Herz" und ${ }_{n}$ meine Seele" ( $\nabla .16 .18$ ) pafsten in den Mund der Gemeinde nicht. Das ist eine unbegreifliche Behauptung (S. o. S. 64). 
beurtheilt werden als der von Ps. 22, mit dem er sich auch sonst berührt (vgl. v. 33.34 mit 22, 27. 25). Danach ist die Gemeinde für das redende Subject zu halten. Dafs es sich in Wahrheit um eine allgemeine Verfolgung handelt, zeigt sich v. 27 und wenn der Redende sich als der Träger der Sache Gottes weifs und um Gottes willen verfolgt wird (v. 8. 10), so führt doch nichts darauf, dafs man ihn etwa als den Führer der Frommen zu denken hätte. Die Feinde sind nicht sowohl Heiden als vielmehr Juden, die Partei der Gottlosen (v. 28. 29). Deshalb braucht v. 9 nicht gerade individuell verstanden zu werden, auch der Schlufs von v. 5 kann wie 35,11 sprüchwörtliche Redeweise sein und dann ebenfalls auf die Gesammtheit gehn. Uebrigens würde die Einmischung einzelner individueller Züge nichts verfangen, Ich könnte für Wir stehn. Ferner ist zu beachten, dafs nach, v. 6, dessen Sinn manche Ausleger verdrehn, der Redende sich schuldig weifs und als von Gott geschlagen betrachtet (v. 27). Wenn er trotzdem als Träger der Sache Gottes zuversichtlich auf Rettung hofft, so versteht sich auch das eher im Munde der Gemeinde, als im Munde eines Einzelnen ( Die Gegner wollen die Frommen ins Unrecht setzen, während diese sich allein Gott gegenüber schuldig fühlen (v. 5. 6 vgl. 51, 6). Zur Unterscheidung zwischen der Gemeinde und ihren Gliedern in v. 7. 33 vgl. oben S. 80. Sonst vgl. zu Ps. 109. - Das richtige Verständnifs hat Rosenmüller nach De Wette. Das Targum deutet das Lied auf die Auswanderungen des Synedriums und die Wasser v. 2. 3 auf die Heiden, ähnlich urtheilen Aben Esra, Raschi und Kimchi.

Ps. 71. Gott soll an dem Redenden seine Allmacht so offenbaren, dafs er allen künftigen Geschlechtern davon erzählen könne (v. 18). Die Wunderthaten, nach denen er verlangt, stellt er denen gegenüber, um deretwillen er jetzt schon Gott beständig preist, nämlich die früheren 
Erweise seiner rettenden Gerechtigkeit in der Geschichte Israels ( $.14-17$ ). Auch nach v. 19 ist die Gerechtigkeit, die hier angerufen wird, die der Weltregierung Gottes, wodurch er sich als der allein wahre Gott beweist. Schon hiernach erscheint die Gemeinde als das redende Subject. Gott hat sie von Jugend auf sein Lob gelehrt, d. h. vom Anfang ihrer Geschichte an hat er ihr seine Gröfse geoffenbart, sie bittet, dals er sie im Alter nicht verlassen, d. h. jetzt in ihrer späteren Geschichte sich als derselbe erweisen möge wie früher (v. 17. 18 vgl. v. 5. 6. 9 und dazu Jes. 46, 3. 4). Nach dem unanfechtbaren Ketib wird v. 20 auch ausdrücklich im Namen der Gemeinde geredet. Die Annahme, dafs ein individuelles Anliegen des Dichters mit dem der Gemeinde eng zusammenhänge, ist völlig haltlos, da von Persönlichem überhaupt nichts $z u$ finden ist. Es handelt sich wahrscheinlich um die Verfolgung der Gemeinde von Seiten der Gottlosen (v. 4). Deutlich ist auch v. 22 von dem Gottesdienst der Gemeinde die Rede, vom Concentus der levitischen Musikanten. Dazu kommt die grofse Abhängigkeit dieses Liedes von anderen Gemeindeliedern. Selbst Hupfeld wird hier seiner Sache unsicher. Richtig urtheilt unter den Neueren Rosenmüller nach dem Vorgange älterer protestantischer Ausleger.

Ps. 73 entstammt wenigstens durchaus der persönlichen Frömmigkeit des Dichters, der den schwersten Zweifel durch die Treue gegen Jahve und gegen seine Gemeinde ( v. 15) überwand ${ }^{1}$ ). Möglicher Weise ist es darum

1) Ohne der einzigartigen Gröfse dieses Liedes zu nahe treten zu wollen, meine ich, dafs der Glaube hier doch nicht ganz auf sich selbst steht. Es bleibt für den Dichter immerhin auch eine Thatsache der Erfahrung, dals die Gottlosen ein Ende mit Schrecken nehmen und damit tritt die Wahrheit des Glaubens wenigstens einigermafsen auch objectiv in die Erscheinung. Obwohl ferner der Redende für seine Person auf jede äufsere Gewähr der göttlichen Gnade verzichtet, so hält er für die Gesammtheit doch gewifs an der messianischen Hoffnung fest. 
doch für den Gottesdienst der Gemeinde gedichtet (vgl. bes. v. 1. 28).

Ps. 74, 12 . S. o. S. 68.

Ps. 75, 10. Hier hat das Ich offenbar denselben Werth wie v. 2 das Wir. Ewig will die Gemeinde Gott preisen, wenn er einst zwischen ihr und den Gottlosen entscheidet. LXX liest vielleicht richtig אגיל. Das Gesagte würde natürlich erst recht gelten, wenn v. 11 die ächte Fortsetzung von v. 10 wäre.

Ps. 77. Die Noth des Redenden (v. 3) ruft in ihm die Erinnerung an die wunderbare Vorgeschichte Israels wach (v. 6. 12 ff.) und im Gedanken an diese findet er Trost gegenüber der Furcht, dafs Jahve ewig zürnen möchte (v. 8-10). Das Auf- und Niederwogen der Empfindung wird freilich"mit einer Lebendigkeit geschildert, die zunächst nur der Persönlichkeit des Dichters eigen ist, gleichwohl muls man aus dem angegebenen Grunde auch hier die Gemeinde als das redende Ich betrachten. So haben schon manche ältere Ausleger geurtheilt; vgl. die Commentare von Rudinger und J. H. Michaelis.

Ps. 84. Wegen v. 11 glaubte auch ich früher (Stud. u. Krit. 1884 S. 733), es rede hier ein einzelner Jude, der jetzt eben aus der Heidenwelt nach Jerusalem übergesiedelt wäre. Indessen scheinen die Worte vielmehr ganz allgemein auszusagen, dafs die armseligste Existenz im heiligen Lande jeder anderen unter den Heiden vorzuziehen sei. Von blofser Wallfahrt nach Jerusalem ist $\mathrm{m}$. E. v. 8 die Rede, der weitaus gröfste Theil auch der palästinensischen Gemeinde mufste zu den Festen hierher pilgern (v. 6-8). Dabei mag freilich besondere Rücksicht genommen sein auf von fern her gekommene Pilger im Unterschiede von der palästinensischen Gemeinde (v. 5). Sehnsucht nach dem.Heiligthum kann man aber auch in seiner Nähe empfinden ( $v$. 3) und der Redende scheint mit seinen Kindern ( $\mathbf{v} .4)$ längst da zu wohnen. Oft wird das 
Wohnen im beiligen Lande als ein Wohnen im Hanse Jahre's oder in seinen Vorhofen bezeichnet $(15,1.23,6$. 27, 4. 52, 10. 65, 5). Dafs nicht ein Einzelner sondern die Gemeinde spricht, schliefse ich nicht nur aus dem Wechsel von Singular ( .0 .11 ) und Plural ( .10 .12 ), sondern vor allem aus dom „mein Konig und mein Gott" (v. 4). So begreift sichs ferner, dafs das Gebet v. 9. 10 nichts als das allgemeine Anlicgen der Gemeinde ausdruckt, wie denn auch จ. 5. 1-13 rom Gluck der Gesammtheit reden. Aber ein Festlicd ist der Psalm allerdings. Der Vogel v. 4 ist also die Gemeinde.

Ps. 85, 9. Dies Ich (neben Wir v. 5-8. 10. 13) wird ebenso beurtheilt werden mussen wie das von 20,7 . Derselbe der bis dahin zu Jahve betete, erwartet nun die gottliche Antwort.

Ps. 80 ist ein Gebet der von Feinden verfolgten Gemeinde (v. 14. 17). Von Individuellem ist nichts zu finden,

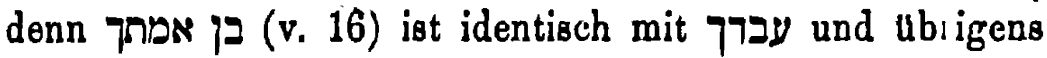
hierzu das zu Ps. 116 Bemerkte zu vergleichen. Uagegen verrïth der ganze Character des Palms das Gemeindelied. In Betracht kommt hierfur das starke Selbstbewufstscin des Redenden (v, 2. 16 f.), der Hinweis auf die geschichtlichon Grofsthaten Jahve's und dio zukunftige Bekehrung der Heiden (v. $8 \mathrm{ff}$ ) sowie die Anticipation der Erhorung (7. 12. 13). Durchweg erscheint das Lied ferner als abhlingig von anderen Gemeindeliedern; vgl. noch v. 15 mit Ex. 34,6.

Ps. 88 ist durchaus gleichartig mit Ps. 6. 22. 38 u. s. w. und wie dieso zu deuten. Versteht man das Lied individuell, so mufs man es folgerichtig mit Ewald als das Gebet eines Kranken betrachten. Denn von Krankheit ( $\nabla .16)$ und zwar von Aussatz (v. 9) ist zweifellos die Rede. Anderseits ist die Krankheit aber auch hier nur ein Bild des Leidens, wio v. 5 ausdrucklich gesagt wird. Es geht nicht an, גבר אין איל 'mit Ewald' als Schatten zu deuten. Ja 
sogar der Tod ist hier einigermalsen bildlich gemeint ( $v .7$ ), die Gemeinde stirbt eben nicht so wie der Einzelne. Auch ist v. $11 \mathrm{ff}$. die Meinung, dafs mit dem Untergang der Gemeinde das Lob Jahve's auf Erden überhaupt aufhören würde. Schon das Targum und der Syrer haben das Lied auf die Gemeinde bezogen, ebenso Raschi und Kimchi und ihnen folgend Rosenmïller und Olshausen.

Ps. 89. Hier tritt v. 2. 3 ein Ich auf, das die älteren jüdischen und christlichen Ausleger mit Recht auf die Gemeinde gedeutet haben. Denn vom geschichtlichen Beruf der Gemeinde ist v. 2 die Rede. Ueber die augenscheinlich verderbten Verse v. 48.51 ist nichts sicheres zu sagen. Sonst wäre v. 51 das Ich gleichbedeutend mit den Knechten Jahve's. Zu v. 48 f. ist 39, 5 zu vergleichen. Uebrigens ist es naturgemäls die Gemeinde, die um die endliche Erfüllung der messianischen Verheifsung bittet (Wir : v. 18. 19). Gewifs ist hier nicht etwa ein Davidide am Wort (Ewald). Der Gesalbte Jahves (v. 39. 52) ist längst dahin, die Heiden schmähen seine Spuren. Das davidische Königshaus ist nämlich v. $20 \mathrm{ff}$. als ein Individuum vorgestellt (wie auch 2 Sam. 7), sein Untergang erscheint v. 46 als ein frühzeitiger Tod. Richtig hat schon Aben Esra diese Worte verstanden.

Ps. 92 ist von dem Lobe Jahve's die Rede, das die Gemeinde im Tempel ertönen lälst, und zwar preist sie ihn wegen seiner geschichtlichen Grolsthaten, die er in seiner unergründlichen Weisheit ausführt ( Lob gebührt dem Jahve, weil er durch sein Walten nicht etwa einen Einzelnen, sondern seine Gemeinde beglückt, diese ist also v. 5 am Wort. - Die Gottlosen, heifst es weiter, wissen von der Gröfse Jahve's nichts, aber das kümmert den allmächtigen Gott wenig (v. 6-9). Denn die Herrschaft der Gottlosen hat einmal ein Ende, während Jahve's Herrschaft auf ewig besteht, mit ihm aber triumphirt über seine Widersacher die Gemeinde der Frommen. 
Nur dieser letzteren kønnen die Worte $\vee$. 11. 12 gehören. Das v. 14.15 Gesagte wird nach Jes. 46, 3. 4 zu verstehen sein (vgl. oben S. 66).

Ps. 94 wird Jahve zur Rache aufgerufen gegen die gottlosen Herren, die seine Gemeinde unterdrücken und die Frommen tödten, und dabei in ihrem Uebermuth vor dem himmlischen Richter völlig sicher zu sein meinen. Ihnen gegenüber wird der Mann selig gepriesen, den Jahve züchtigt und aus seinem Gesetze belehrt. Denn ihn will Jahve hierdurch vor Sünde und Strafe bewahren, bis endlich die Gottlosen für immer zu Fall kommen (v. 12. 13). Dieser Mann ist offenbar die Gemeinde der Frommen, wie zum Ueberflufs aus der Begründung v. 14. 15 völlig deutlich wird (vgl. oben S. 50). Wenn nun weiter v. $16 \mathrm{ff}$. ein Ich sich darauf besinnt, dafs allein Jahve sein Beschützer gegenüber den Gottlosen sei und es ohne Jahve längst von ihnen vertilgt wäre, so liegt es vor der Hand, auch hier die Gemeinde der Frommen zu verstehn. Nothwendig wird dies durch v. 22. Denn einerseits deckt sich das hier redende Ich mit dem allgemeinen צריק von v. 21, anderseits ziehn die Gottlosen durch ihren Angriff auf den Redenden sich selbst den Untergang zu (v. 23). Danach mufs hier aber die Gesammtheit der Frommen in Rede stehn. So urtheilen schon die älteren Exegeten der Mehrzahl nach.

Ps. 101 beabsichtige ich später zu besprechen.

Ps. 102. Ein Dulder fleht Jahve um Erbarmen an. Der göttliche Zorn hat ein Leben voller Unglück über ihn verhängt. Immerwährender Kummer hat seine Kraft aufgezehrt, von aller Welt abgeschieden und von seinen Feinden verhöhnt siecht er hin, ein vorzeitiger Tod wartet seiner. Möchte der ewig thronende Gott Mitleid mit ihm haben! (v. 2-13). Nun folgt eine weiter ausgeführte Bitte um endliche Erfüllung der messianischen Verheifsung. Die in der Weissagung hierfür vorgesehene Zeit ist ein- 
getreten, der traurige Zustand Sions dauert alle Frommen. Auch sollte Jahve bedenken, dafs die Heiden nur dann seine alleinige Gottheit erkennen können, wenn er durch Sions Wiederherstellung seine Herrlichkeit offenbart (v. 14 bis 23). Redet hier ein Einzelner, so kann dies beides in keine vernünftige Beziehung gebracht werden. Es wäre vielleicht denkbar, dafs ein Einzelner deshalb den Anbruch der messianischen Zeit zu erleben verlangte, weil sie auch seinen individuellen Leiden ein Ende machen, oder weil dies Erlebnifs an sich ihn für all sein persönliches Unglück entschädigen würde. Man müfste diese Annahme mit der weiteren stützen, wonach v. 2-13 im Sinne aller einzelnen ähnlich Leidenden gesprochen sind. Indessen fragt sich's, ob v. 2-13 wirklich auf viele Einzelne palsen. Ueberdies, aber ist dies Verständnifs durch v. 19 ausgeschlossen. Wie Ewald richtig sieht, wird die Erfüllung der messianischen Verheifsung nicht für das gegenwärtige, sondern nur für ein künftiges Geschlecht erbeten. Denn v. 19 ist nicht zu übersetzen : „Möchte dies (als geschehen) aufgeschrieben werden für ein künftiges Geschlecht" - sondern mit Raschi : „Möchte dies (als geschehen) aufgeschrieben werden von einem künftigen Geschlecht." Nicht die schriftliche Ueberlieferung betr. der eingetretenen messianischen Zeit wird Israel zum Lobe Jahve's veranlassen, sondern das Erlebnifs dieser Zeit, das dann freilich auch wohl aufgezeichnet werden mag. Die zukünftigen Geschlechter werden auch v. 29 ins Auge gefafst. So wäre also jede Beziehung zwischen v. 2-13 und v. 14-23 gelöst und auf Grund des herrschenden Verständnisses läugnet Hitzig mit Recht die Einheitlichkeit des Liedes. Sehr einfach stellt sich dieselbe aber her, sobald v. 2-13 die Gemeinde redet. Hieran darf man sich durch v. 24 . 25 nicht irre machen lassen. Wie sonst oft genug erscheint der Untergang der Gemeinde hier als möglich, ja als drohend. Gott scheint sie vernichten zu wollen,

Zeitschrift f. d. alttest. Wiss. Jahrgang 8. 1888. 
ehe sie ihren Lauf durch die Geschichte vollendet hat, wie wenn ein Mensch in der Mitte des Lebens stirbt. Ewig ist zunächst Gott allein (s. o. S. 82). Aber als der Unvergängliche soll er sich der vergänglichen Kreatur erbarmen und die Gemeinde forterhalten. Wahrscheinlich ist auch in der vielleicht späteren Ueberschrift (v. 1) mit Israel gemeint. Richtig verstehen den Psalm Raschi und Kimchi, de Muis, Junius, Piscator und neuerdings Rosenmüller.

Ps. 103 stammt aus einer Zeit, in der die Gemeinde sich eines verhältnifsmäfsig grofsen Glückes erfreute. Da schien der Zorn ein Ende zu haben und die Schuld völlig vergeben zu sein. Jahve bewies sich wieder als der Vater und Beschützer seines Volkes, wie er es von Urzeiten her gewesen war, ja die ganze Geschichte Israels schien von seiner Gnade durchwaltet zu sein. Der Erweis seiner Gnade gegen Israel war aber zugleich der Erweis seiner Weltherrschaft, die deshalb auch als eine bereits thatsächliche gepriesen wird. Das gegenwärtige Glück wird in Ausdrücken geschildert, wie sie sonst allein der messianischen Zukunft zukommen. Augenscheinlich hielt der Dichter diese für nahe bevorstehend, wenn nicht für schon gegenwärtig. Unbegreiflich ist mir Hupfeld's Urtheil, dals das Lied kein eigentlicher Nationalpsalm sei, sondern das allgemein menschliche Verhältnifs überwiege. Ebensowenig kann ich aber zugeben, dafs v. $1-5$ von den persönlichen Erfahrungen des Dichters handeln, der sich in seinem Alter durch Jahve's Gnade verjüngt fühlte. Vielmehr ist v. 1-5 Selbstanrede der Gemeinde, die im weiteren mit "wir" redet. Jahve rettet das Volk vom Untergang und stellt ihm das Glück und die Macht früherer Zeiten wieder her. Vgl. Jes. 40, 31, wo ebenfalls von der Gesammtheit und nicht von den Einzelnen die Rede ist ${ }^{1}$ ). Vermuthlich fand bei v. 6 ein Stimmenwechsel statt.

1) Es genügt nicht, wenn Olshausen sagt, jedes einzelne Mitglied 
Ps. 104. Man meint, es werde hier von allgemein menschlichem Standpunkt aus die in der Natur sich offenbarende Grölse Jahve's gepriesen. Inzwischen haben derartige Schilderungen im A. T. ihren Zweck niemals in sich selbst, am wenigsten im Judenthum, auf dessen Boden. wir uns hier befinden. In den Schicksalen der jüdischen Gemeinde war von Jahve's Gröfse zumeist wenig zu erkennen, die Heiden regierten die Welt und in Jerusalem hatten die Gottlosen die Oberhand. Die Juden redeten deshalb gern von vergangenen Zeiten, wo Jahre sich an den Vätern verherrlicht hatte, von der messianischen $\mathrm{Zu}$ kunft; wo er alle Welt zur Anerkennung seiner alleinigen Gottheit zwingen wollte, oder auch wohl von der Majestät, in der Jahve über den Wolken thronte. Wesentlich denselben Sinn hat die Naturbetrachtung der Juden, die recht eigentlich von Deutero - Jesaja datirt. Die Gemeinde weifs es, dafs $i h r$ Gott den Himmel und die Erde gemacht hat und erhält, für ihren Glauben ist die alleinige Gottheit Jahve's schon jetzt in der ganzen Natur offenbar. In der Naturbetrachtung wird ihr deshalb gewifs, dals ihr Gott und mit ihm sie selbst einst triumphiren werden, dals die Gottlosen umkommen müssen und die Herrschaft der Heiden ein Ende nimmt ${ }^{1}$ ). Hierauf kommt Ps. 104 zuletzt hinaus. Von der endlichen Vernichtung der Gottlosen ist $\mathbf{v}$. 35 die Rede, schon $\nabla$. 32 wird darauf präludirt ${ }^{2}$ ). Es ist deshalb auch nichts Individuelles, wenn es $\mathbf{v}$. 34 so empha-

der Gemeinde ermuntere sich zum Preise des Herrn und spreche in dem ganzen Eingange die Erfahrungen der Gemeinde als seine eigenen aus. Aehnlich Ewald.

1) Das Buch Hiob beweist hiergegen nichts. Denn die dort auftretenden Personen sind im Grunde doch nur verkleidete Juden.

2) Hengstenberg hat hier wie öfter in den Psalmen richtiger gesehn als Hupfeld. Letzterer hätte v. 35 am liebsten mit Olshausen gestrichen. Aber der Binn des Ganzen wäre kein anderer, wenn die Worte auch fehlten. 
tisch heifst : ${ }_{7} I c h$ (אנכ) freue mich in Jahve." Die Gemeinde ist auch v. 33 am Wort und das „Preise den Jahve, meine Seele" (v. 1. 35) begegnete uns schon Ps. 103, 1. 22 in ihrem Munde ( $\nabla g l$. noch 146, 1) ${ }^{1}$ ). - Ebenso deutlich ist der specifisch jüdische Charakter von Ps. 8. Denn v. 3 ist offenbar vom jüdischen Gebete die Rede und übrigens fällt aller Nachdruck auf „Jahve, unser Herr" (v. 2. 10) so gut wie Ps. 104, 1 auf "Jahve, mein Gott." Ich verstehe deshalb auch das Ich 8, 4 von der Gemeinde ${ }^{2}$ ).

Ps. 106, 4. Ich glaube, dals hier (wie v. 6. 7. 47) die Gemeinde redet, die auch sonst öfter zwischen sich und den Gläubigen unterscheidet (vgl. oben zu 22, 23. 26). Diese Annahme ist leichter als die andere, wonach hier eine Diaspora-Gemeinde oder auch ein einzelner Jude der Diaspora das Wort führt. Auch v. 47 ist als das Gebet der Gesammtheit aller Juden wohl verständlich, dieser allein aber gehört die Huld Jahve's gegen sein Volk (v. 4). Im anderen Fall würde ein Theil des Volkes für sich das messianische Heil erbitten, dasselbe aber für das Ganze als gegeben voraussetzen. Die besondere Situation der Diaspora tritt auch allzuwenig hervor. LXX setzt wirklich den Plural : $\mu \nu \dot{\eta} \sigma \vartheta \eta \tau \iota \grave{\eta} \mu \tilde{\omega} \nu \varkappa \tau \lambda$. Richtig Rudinger.

Ps. 109 ist von Individuellem keine Spur zu entdecken, das Treiben der Feinde wird v. 2 ff. 16 ff. in ebenso farbloser Allgemeinheit geschildert wie $\nabla .22 \mathrm{ff}$. das Leiden des Redenden. Dieser ist der עני ואביון schlechthin (v. 16. 22. 31 vgl. zu 40,18), sein Gegner ist die Gesammtheit der Gottlosen, der Uebergang vom Plural zum Singular und umgekehrt (v. 5. 6 und จ. 19. 20) vollzieht sich auf die ungezwungenste Art. Es handelt sich hier wie sonst um den stets gleichen Parteigegensatz von Gottlosen und

1) Zu בחי 73 vgl. zu 23, 6.

2) Auch Ps. 19 hat diesen Sinn. Ps. 29, über den ich anderswo zu reden denke, ist dagegen ganz anderer Art. 
Frommen, der sich immer wieder in denselben Formen äufsert. Möchte doch endlich einmal Gott dazwischen treten : „Mögen sie fluchen, Du aber segnen, mögen meine Gegner zu Schanden werden (LXX), Dein Knecht aber sich freuen" (v. 28)). Es ist keine persönliche Angelegenheit, die hier eine solche Entscheidung erfordert; vgl. auch das שמען vo 21. Die Flüche v. 6 ff. würde man in diesem Falle allerdings mit Hupfeld für affectirt erklären. müssen, weil eine entsprechende individuelle Noth nicht hervortritt. Es handelt sich aber in Wahrheit um die allgemeine und allen bewufste, um die gröfste, die der alttestamentliche Glaube kennt, das Glück der Gottlosen, das für den Glauben ein viel qualvolleres Problem bedeutet als das Unglück der Frommen. Die grässlichen Flüche entstammen der Angst des Glaubens, der gerade den Gottlosen gegentiber nach der endlichen Offenbarung der göttlichen Gerechtigkeit verlangt. Vgl. noch 69, $23 \mathrm{ff}$. und v. 4 mit 120, 7. 35, 12 ff. Betr. עברך v. 28 vgl. zu Ps. 116. Uebrigens ist v. 17. $18 \mathrm{zu}$ sprechen ותרחק , וּתבואהו und וןתבא. In seiner Weise richtig verstand Raschi als das redende Subject die Juden und als die Gegner die Christen. Zu v. 30 vgl. zu 22, 23. 26.

Ps. 116. Dals hier die Gemeinde redet, halte ich nicht nur mit Rudinger für möglich, sondern für gewifs. Die Unterscheidung des redenden Subjects vom ganzen Volke (v. 14. 18) beweist nichts dagegen (vgl. zu 22, 23. 26), dafür spricht der ganze Charakter des Liedes, übrigens die Plurale v. 5. 6. 15 und namentlich auch v. $16:$ Denn ich bin Dein Knecht. ${ }^{*}$ Von den beiden Bedeutungen des Ausdrucks עבד יהוה, Verehrer und Knecht Jahves, die übrigens öfter in einander übergehn, kann hier und 119, 125. 143, 12 nur die erstere in Betracht kommen. Er will sagen : ${ }^{\text {als }}$ dein Verehrer habe ich Anspruch auf Erhörung." Das pafst schwerlich in den Mund eines Einzel- 
nen ${ }^{1}$ ), sondern wohl nur in den Mund der Gemeinde, die eben allein den Jahve verehrt. So heifst Israel auch 136, 22 der Verehrer Jahve's. Mit Hochgefühl nennen die VollJuden sich die Verehrer Jahve's im Gegensatz gegen die Halb-Juden und Samariter (Neh. 2, 20. Esra 5, 11) und das ist auch in den Psalmen der Ebrenname der Gemeinde (Ps. 34, 23. 69, 37. 102, 29. 105, 25. 113, 1. 134, 1. $135,1$. 14) oder auch der Märtyrer (79, 2. 10). Wie die vorliegende Stelle scheinen mir aber alle Stellen des Psalters beurtheilt werden zu müssen, an denen עברך oder dafür עבדו erscheint $(19,12$. 14. 27, 9. 31, 17. 35, 27. 69, 18. 86, 2. 4. 16. 109, 28. 143, 2, aufserdem oft in Ps. 119). Denn alle diese Lieder müssen auch aus anderen Gründen für Gemeindelieder gelten ${ }^{2}$ ).

Ps. 118 wird nach rabbinischem Vorgang auch von Ewald und Delitzsch auf die Gemeinde gedeutet. In der That ist es nicht abzusehn, wie ein Einzelner (und wäre er noch so hoch gestellt) seine persönliche Rettung so sehr zum Mittelpunkt der gottesdienstlichen Feier hätte machen können, wo doch die ganze Gemeinde in der äufsersten Gefahr gewesen und wunderbar gerettet war. Vielmehr mufs die letztere unter dem redenden Ich verstanden werden. Nur so erklärt sich der Wechsel von Ich (v. 5-7. 10-14. 17-19. 21. 28) und Wir (v. 23. 24. 27) in befriedigender Weise. Bemerkenswerth ist auch, dals dem

1) Anders sind Stellen wie 1 Sam. 25, 39 23, 11. (wo übrigens David redet) und Neh. 1, 6. 11. Zuweilen ist עברך Gott gegenüber ebenso gesagt wie gegenüber dem Könige und dem Hochgestellten überhaupt (1 Sam. 3, 9. 10).

2) Uebrigens scheint Ps. 116 eher eine Bitte um Rettung als der Dank für eine solche zu sein. Die Bitte wird noch am Schlufs sehr energisch laut (v. 16) und das Versprechen, dem Jahve danken zu wollen (v. 14. $17 \mathrm{ff}$.) hat nur so rechten Sinn. Auch nach v. 7 ist die Gefahr wohl noch nicht vorüber. Die Perfecta drücken die zuversichtliche Erwartung der göttlichen Hülfe aus und von da aus sind auch v. 11 (vgl. 31, 23) und v. 12 zu verstehn. Richtig sieht Ewald. 
Singular v. 19. 26 a in v. $20.26 \mathrm{~b}$ der Plural entspricht. Umgekehrt werden auch die heidnischen Feinde v. 13 wie ein einziges Individuum vorgestellt. $\mathrm{Zu}$ beachten ist noch, dafs v. 14 auf Exod. 15, 2. Jes. 12, 2 zurückgeht und v. 18 an Jer. 10, 24 anklingt. Von der Erhaltung Israels und seiner geschichtlichen Aufgabe ist v. 22. 17 die Rede.

Ps. 119. Auch hier ist die Gemeinde am Wort. Denn die Noth der Gemeinde besteht vor allem in der Anfeindung, die sie von der Bosheit und List der Gottlosen (v. 51. 61. 69. 78. 85. 86. 95. 110. 150. 157) und der Fürsten (v. 23. 161) erfährt. Sie vertraut dem gegenüber auf ihr gutes Gewissen, weiter aber auf den ewigen Besitz des Gesetzes ( Königen redet (v. 46), und harrt auf die Erfüllung der Verheifsung (v. 25. 38. 41. 42. 50. 74. 76. 81. 114. 116. 123. 154. 174). Durch die Strafen, die Jahve über sie verhängte, ist sie bekehrt (v. 67. 71. 75), aber noch sind ihre Leiden grofs, fast hätten die Gottlosen sie völlig aus dem Lande vertilgt (v. 87 vgl. v. 109), Jahve soll sie diesen Gegnern nicht preisgeben (v. 121. 122. 133. 134) und ihrer Schmach ein Ende machen ( an der Zeit, dafs er, der die Gottlosen verwirft (v. 21. 52. 119. 155), endlich sein Gericht an ihnen vollziehe (v. 84. 126). Dafs die Empfindung hin und wieder sehr individuell sich äufsert (จ. 53. 115. 136. 139. 158) und das Ich gelegentlich geradezu persönlich wird (v. 63. 79. 99. 100), kann an dem Gesammtcharakter des Ganzen nichts ändern. Im Ganzen richtig urtheilt unter den Neueren Olshausen. Schon Rudinger verstand als Subject des Psalms das israelitische Volk.

Ps. 120. Pfeile, die bei irgend welchem Kohlenfeuer geschärft werden, also Pfeile mit hoblzernen Spitzen, sind nicht gefährlich und überhaupt keine Kriegspfeile ${ }^{1}$ ). Also

1) Vgl. Land, Theol. Tijdschr. 1872, 568 f. 
kann v. 4 yur "sammt" bedeuten. Die böse Zunge schiefst gleichsam scharfe Pftile and schleudert Ginsterkohlen, die, weil sie das Fener lange halten, zum Brandstiften besonders geeignet sind ${ }^{1}$ ). Der Redende kommt sich ferner in seiner Umgebung vor, wie wenn er unter Moschern und Kedarenern, den fernsten und rohesten Barbaren des Nordens und Ostens, wohnte (v. 5). Diese Klage wäre unverständlich, wenn er etwa in Babylonien oder in Aegypten lebte ${ }^{2}$ ). In Wahrheit mufs er an einem Orte sein, wo er sich von Rechts wegen heimisch fühlen sollte. Augenscheinlich lebt er in seinem Vaterlande, unter seinen Volksgenossen, aber diese stehn ihm so fremd und so feindselig gegenüber, als ob es die genannten Barbaren wären. Nun hat aber der einzelne Fromme in Judäa zweifellos Gesinnungsgenossen, es redet also die Gemeinde und die böse Zunge v. 2 bedeutet die Gottlosen, die hier wie nach so vielen anderen Psalmen vor allem mit Lug und Trug den Frommen nachstellen; vgl. noch 57, 5 ff. 52, 3-6. Man beachte, dafs das Lied uns von vornherein in eine bekannte, allen bewufste Situation versetzt. Wenn der Redende schliefslich klagt, er habe schon lange genug unter diesen Leuten gewohnt (v. 6), so braucht er darum nicht gerade an Auswanderung zu denken, er kann auch verlangen, dals die Gegner das Land räumen. Vgl. sonst 55, 7 ff. und 123, 3. 4. Schon Raschi betrachtete die Gemeinde als das redende Subject.

1) Vgl. Psalt. Sal. 12, 1 ff. Dies Lied, in welchem die fromme Gemeinde ebenfalls mit Ich um den Untergang der Gottlosen betet, hat überhaupt grofse Aehnlichkeit mit Ps. 120. Hier ist die Frage v. 3 nur eine rhetorische Figur, der Fragende und der Antwortende sind dieselbe Person.

2) Dies führt Olshausen richtig aus. Ganz verfehlt ist dagegen seine Auskunft, das Lied sei überhaupt für israelitische Gemeinden in der Zerstreuung geschrieben, wobei der Dichter einige Völker, in deren Mitte Juden wohnten, herausgegriffen and statt aller möglichen namhaft gemacht bätte. Es handelt sich vielmehr um eine bestimmte Lage, in der der Fromme von bösen Zungen verfolgt wird. 
Ps. 121. Höchst wahrscheinlich liegt hier ein Stimmenwechsel vor und eben daraus ergiebt sich dann wohl der Charakter des redenden Ich. Denn dieser Stimmenwechsel möchte beweisen, dafs das Lied für den Gottesdienst gedichtet ist. Wäre nun das Ich individuell zu verstehen, so ergäbe sich ein $Z$ wiegespräch zwischen den einzelnen Seelen. Dafs aber der öffentliche Gottesdienst der Juden niemals diesen Sinn gehabt haben kann, dürfte einleuchten. Uebrigens geht auch aus dem Verhältnifs von v. 3. 4 hervor, wen das Ich bedeutet. Das zweifelnde und das glaubende Israel treten hier wie zwei Individuen einander gegenüber. Richtig urtheilt Aben Esra.

Ps. 122 ist deutlich das Lied eines Pilgers (vgl. Theol. Stud. und Krit. 1884 S. 731 f.) oder auch einer Pilgerschaar. Für Ich (v. 1. 8. 9) kann man überall Wir setzen.

Ps. 123 ist mit Ps. 131 (s. d.) verwandt und ebenso wie jenes Lied zu beurtheilen. Schwerlich redet $\mathbf{v} .1$ ein Einzelner, der sich v. 2-4 mit den Glaubensgenossen zusammenfafste. Schon v. 1 wird der Gemeinde gehören ${ }^{1}$ ).

Ps. 129 bedarf keiner Erörterung.

Ps. 130. Dafs die Gemeinde redet, ist aus dem Verhältnifs von v. 7.8 zu v. 5.6 deutlich. Hier sagt der Redende, dafs er auf Jahve's Hülfe sehnsüchtiger warte als die Wächter auf den Morgen - dort wird Israel zum Ausharren ermuntert und ihm die Erlösung aus allen seinen Sünden $d$. h. die Befreiung von allen seinen Leiden für die messianische Zukunft in Aussicht gestellt. Beides gehört nothwendig zusammen, v. 1-6 spricht also Israel. Ferner ist das Wort Jahves v. 5 die prophetische Verheifsung von der messianischen Zukunft, die zunächst allein der Gemeinde gehört. Endlich kann die Gemeinde als Ganzes unmöglich von einem einzelnen Frommen auf

1) Ob man deshalb bei v. 2 einen Stimmenwechsel annehmen mufs, ist fraglich. Der Wechsel des Numerus kann durch die Vergleichung v. 2 herbeigeführt sein. 
sein eigenes Vorbild verwiesen werden, wie das nach der herrschenden Auslegung der Fall ist (B. zu Ps. 131 und oben S. 54 f.). Richtig versteht den Psalm aufser Olshausen nur Rosenmüller, Rudinger schwankt.

Ps. 131 wird Israel aufgefordert, sein Vertrauen allein auf Jahve zu setzen (v. 3) und zwar so, wie der vorher Redende es von sich aussagt (v. 1. 2). Dieser hat nämlich alle eigenwilligen $W$ tinsche in sich niedergeschlagen und alles Verlangen nach hohen Dingen ist in ihm so erloschen wie in einem Entwöhnten das Verlangen nach der Mutterbrust. Nach der herrschenden Auslegung stellt sich auch hier der Einzelne zum Vorbild auf für die Gesammtheit. Indessen wäre das höchst unzutreffend, da die Gesammtheit eben viel höhere Ansprüche hat und erheben mu؟s als der Einzelne. Allein das Umgekehrte hätte Sinn (Jer. 45). Auch träte die Application sehr unvermittelt ein. Man wird also in v. 1. 2 die Gemeinde als das redende Subject betrachten müssen, v. 3 wird sie ermahnt, in der von ihr geäulserten Gesinnung den Eintritt der messianischen Zeit geduldig zu erwarten ${ }^{1}$ ). Richtig erklären Rosenmüller und Olshausen.

Ps. 135, 5. Dafs Jahve gröfser ist als alle anderen Götter, ist nicht die individuelle Einsicht eines Einzelnen, sondern eine Erkenntnifs, die das ganze Volk vor den Heiden voraus hat. Ihm gehört nothwendig das emphatische אני (vgl. 20,7).

Ps. 137, 5. 6. Diese Worte können den einzelnen Exulanten beigelegt werden. Aber dann ist Ich $=$ Wir.

Ps. 138 ist von einer unübertrefflichen Wunderthat Jahve's die Rede, die alle Welt zur Anerkennung seiner

1) Entgehen könnte man diesem Schlufs nur durch die Annabme, dafs das Lied wirklich dem David in den Mund gelegt sei. Aber eine solche Annahme wäre hier durchaus willkürlich und das Lied ist jedenfalls nach Analogie von Ps. 130 zu erklären. 
Gottheit zwingt ( $\nabla .2$ ). Sofern nun diese That Jahve's auf das Gebet des Redenden hin erfolgt ( $v$. 3), wird dieser das Volk Israel vorstellen. Ein Einzelner, etwa ein König, könnte seinem Gebet keine solche Bedeutung beilegen, noch auch die Sache des Volkes und Jahve's schlechthin als seine persönliche betrachten (v. 7. 8). Auch ist es wohl nicht die Stimme des Einzelnen, die vor allen Göttern laut wird (v. 1). Richtig urtheilen Lengerke und Olshausen. Uebrigens möchte das Lied von der messianischen Zukunft handeln.

Ps. 139 klingt freilich sehr individuell, sogar allgemein menschlich, gleichwohl redet auch hier die Gemeinde. Wenn es v. 19 heifst : „Wenn Du doch tödtetest, o Gott, den Gottlosen und die Blutmenschen von mir wichen"! (יסורו), - so ist das nicht etwa der persönliche Wunsch eines Einzelnen, der mit den Gottlosen nichts zu thun haben will. Vielmehr handelt es sich um die Ausrottung der Gottlosen aus der Gemeinde, wie aus dem Wortlaut v. $19 \mathrm{~b}$ deutlich hervorgeht, und diese ist das redende Subject (vgl. 6, 9). Die Herrschaft der Gottlosen, ja ihr blolses Dasein in der Gemeinde erschüttert den Glauben, der vorher nach seiner ernsten und nach seiner tröstlichen Seite geschildert wurde. Freilich wollen die dortigen Aeufserungen z. Th. auch individuell verstanden sein, wie sonst oft schlägt das allgemeine Ich gelegentlich in das individuelle um, überall aber ist das Gemeinbewufstsein im Spiel, das dem Ganzen seinen Charakter giebt. Die Ausleger finden den Gedankengang von v. 19 an nur deshalb unbegreiflich, weil sie dies übersehn. Richtiger urtheilt Raschi über $\nabla .19$.

Ps. 140 handelt von dem Parteigegensatz der Frommen und der Gottlosen, der in der Katastrophe der messianischen Zeit zum Austrag kommen soll. Da schafft Jahve den verfolgten Frommen Recht, sie dürfen in seiner Nähe wohnen, während die Gottlosen vertilgt werden (v. 11-14). 
Man hat alle Ursache, diesen Psalm als Gemeindelied zu betrachten. Vgl. Ps. 11.58. Richtig versteht Rosenmüller das Lied und fruher schon Raschi.

Ps. 141. Hier wird จ. 5 ein Fall gesetzt, der für die Gesammtheit nicht wohl eintreten kann, auch mülste die Bitte v. 3. 4 nach unserer Redeweise in der 1. Pluralis ausgesprochen sein (vgl. Ps. Sal. 16, 7 ff.). Aber es handelt sich um eine Verfolgung der Gemeinde (v. 7) und deshalb wird diese nicht nur in v. 8-10 sondern im ganzen Liede das Wort führen.

Ps. 142 hat denselben Inhalt und mufs trotz der Unterscheidung zwischen dem redenden Ich und den Gerechten (v. 8) als Gemeindegebet gelten. Ebenda מסגר verlangt so wenig im Wortverstand genommen zu werden wie sonst שבות; vgl. Jes. 42, 7.

Ps. 143. Dafs hier die Gemeinde redet, schliefse ich aus der Bezugnahme auf die Wunderthaten Jahve's in der Vorzeit (v. 5), aus dem Appell an die Ehre Jahve's (v. 11) sowie aus der Art, in der der Klagende seine Lage schildert. Es ist ganz dieselbe wie in den früher besprochenen Gemeindeliedern dieses Schlages. Zu v. 3 vgl. Thren 3, 6 und zu v. 7 Ps. 6. 13. Das Schlufswort v. 12 will besagen, dafs eben nur die Gemeinde den Jahve verehrt, er also auch in seinem Interesse sie nicht verlassen darf (vgl. 116, 16). Richtig deutete das Lied schon Raschi.

Ps. 144 ist bis v. 11 ein Gebet um Erfüllung der messianischen Hoffnung, bezw. um Befreiung der Gemeinde von der Herrschaft der Heiden, wobei der Redende im Gedanken an diese letzte Zukunft die unbegreifliche Gnade Jahve's gegen die Menschen d. h. gegen Israel preist (v. 3. 4). Schon Saadia und Kimchi haben das Lied messianisch gedeutet. Dafs v. 1. 2 nicht etwa von kürzlich errungenen Siegen die Rede ist, ergiebt sich aus v. 5-11 deutlich genug. Vielmehr handelt es sich dort wie im übrigen Liede 
um den künftigen Triumph über die Heiden ${ }^{1}$ ). Eine Nachahmung von Ps. 18 verräth der Psalm ein wesentlich richtiges Verständnifs seines Vorbildes. Jedenfalls hat man alle Ursache, mit Ewald die Gemeinde als das redende Subject zu betrachten. Sonst könnte es nur der Messias sein, was aber durch nichts angedeutet ist. - Auf die messianische Zukunft müssen auch v. 12-16 gehen, wenn sie ursprünglicher Bestandtheil des Liedes sind. Freilich mülste dann der Text am Anfang von v. 12 beschädigt sein.

Ps. 145. Das v. 1. 2. 5. 6. 21 auftretende Ich von der Gemeinde zu verstehn ist das allein Natürliche. Ich verweise auf „mein Gott, du König“ (v. 1) und die Parallelisirung aller Generationen (v. 4-6) und der ganzen Welt (v. 21) mit dem Redenden. Richtig urtheilt Olshausen.

Ps. 146. Hier verhält sichs ebenso mit v. 1. 2. Der v. 5 glücklich Gepriesene ist Israel (vgl. v. 10), das den lebendigen Gott zum Könige hat und auf ihn in allen Dingen sich verlassen kann, während die Heiden auf ihre sterblichen Fürsten vertrauen. Es ist die Gemeinde, die deshalb den Jahve lobt. Zu v. 2 vgl. 23, 6. 104, 33.

Dals das Ich der Psalmen vielfach die Gemeinde bedeutet, ist zweifellos. Die Frage kann nur sein, in wie weit das der Fall ist. Für mich hat sich hierauf eine Antwort ergeben, die ich beim Beginn meiner Untersuchung am wenigsten erwartet habe, wider meinen Willen hat sie sich mir anfgedrängt. Es begreift sich in der That, weshalb Hupfeld das Ich ausnahmslos persönlich verstehn wollte. Jedes Zugeständnifs ist hier von den weittragendsten Folgen. Giebt es überhaupt Psalmen, in denen die

1) Notwendig ist v. 2 nach 18, 48 y zu lesen. Weder David noch ein anderer darf dem Jahve dafür danken, dafs er ihm sein Volk unterworfen habe. Vgl. auch 47, 4. 
Gemeinde mit Ich redet, dann darf das Ich nur da individuell gedeutet werden, wo positive Gründe hierfür bestehn. Das ergiebt sich daraus, dafs der Psalter das Gesangbuch der Gemeinde des zweiten Tempels war. Diese Probe halten aber höchstens Ps. 3. 4. 62.73 und zuletzt wohl auch diese Lieder nicht aus, die weitaus meisten geben sich im Gegentheil deutlich als Gemeindelieder zu erkennen.

Auf vielseitigen Widerspruch bin ich gefalst, indessen wird derselbe sich wesentlich darauf beschränken müssen, meine Auslegung im einzelnen zu bekämpfen, und gerade auf diesem Punkte glaube ich meiner Sache im Grofsen und Ganzen 1) sicher zu sein. Ich meine gezeigt zu haben, dafs bei consequenter Verfolgung des von Olshausen eingeschlagenen Weges die Psalmen sich nach Inhalt und Form als sehr viel verständlicher und, was dasselbe ist, als in sich wahrer ausweisen, als das bei der herrschenden Auslegungsweise der Fall ist. Mindestens ist es ein grofser Irrthum zu meinen, dals Olshausen's Psalmenexegese bereits abgethan sei. Dals vielmehr die jetzt übliche Exegese des Psalters an principiellen Mängeln leidet, dürfte der durch viel Gelehrsamkeit, Fleifs und Scharfsinn höchst verdienstliche, im Ganzen aber gleichwohl unfruchtbare Commentar Hupfeld's gezeigt haben. Es bedarf hier neuer Fragestellung und dabei möchte vor allem die hier aufgeworfene Frage in Betracht kommen.

Dagegen darf die durchgängige Personification der Gemeinde im Psalter nicht befremden. In überraschendem Mafse findet sich diese Personification schon aufserhalb des Psalters (vgl. oben S. 60 ff.), naturgemäls hat sie aber erst recht im Gemeindegebet ihre Stelle, wo Gott und

1) Natürlich mache ich nicht den Anspruch, jeden der oben erörterten 80 Psalmen richtig verstanden zu haben. Jeder Sachkundige weifs, dafs mancher Psalm einer Festung gleicht, die allein durch einen glücklichen Zufall erobert werden kann, regelrechter Belagerung aber trotzt. 
Volk in den lebendigsten Verkehr mit einander treten. Wichtig sind hierfür übrigens die Parallelen aus dem Psalter Salomos. In der That haben wir in den Psalmen meistens mit eigentlicher Personification zu thun und es sind verhältnifsmäfsig nur wenige Lieder, in denen Ich einfach statt Wir steht. Meistens tritt, wenn auch nur an einzelnen Stellen des Liedes, dieses oder jenes Moment auf, das auf wirkliche Personification hinweist. Je weiter aber die Personification getrieben ist, um so gewisser ist in der Regel ihre Thatsächlichkeit (z. B. Ps. 6. 22. 38. 41. 102). Deshalb ist es auch nicht zu verwundern, dafs der Empfindung der Gemeinde zuweilen eine Lebendigkeit geliehen ist, die in Wahrheit nur der concreten Persönlichkeit zukommt (z. B. Ps. 32. 39. 77). Uebrigens finden sich jene unreinen Redeweisen, die sonst wohl der Personification Israels anhaften (vgl. oben S. 65 f.), in den Psalmen ziemlich selten.

Kein Gewicht könnte ich dem Einwande beilegen, dafs manche Ich-Psalmen in den Ueberschriften auf bestimmte Situationen aus Davids Leben bezogen, also schon in alter Zeit individuell gedeutet seien. Denn wenn auch manche der hier in Frage kommenden Lieder schon früh individuell verstanden wären, so würde das für ihren ursprünglichen Sinn gar nichts beweisen. Es ist ganz natürlich und selbstverständlich, dafs die individuelle Frömmigkeit beim Gemeinbewufstsein Anlehen machte, dagegen ist das Umgekehrte widersinnig und unannehmbar. Vor allem ist daran zu erinnern, dafs David als Typus des wahren Israel galt, die Beziehung eines Liedes auf seine individuelle Lage also niemals eine schlechthin individuelle Deutung desselben ist. Uebrigens aber wird man jenen PsalmUeberschriften den Werth einer ernst zu nehmenden Exegese nicht beilegen dürfen. Ihre Verfasser haben erstlich nicht daran gedacht, die betreffenden Lieder wirklich individuell zu deuten, sodann wäre eine solche Deutung exegetisch 
völlig werthlos. Es verhält sich mit diesen Psalmen doch schwerlich anders als mit 1 Sam. 2, $1 \mathrm{ff}$. Das sogenannte Lied der Hanna ist, wie schon der Zustand des Textes vorher und nachher zeigt, von einem Späteren eingeschoben, der wegen $\nabla .5$ die Hanna für die Dichterin hielt. In Wahrheit redet das Lied von Israels Triumph über die Heiden und über die Gottlosen (v. 1. 2. 9) und zwar vom Weltgericht (v. 10). Deshalb kann das redende Ich v. 1 nur die jüdische Gemeinde bedeuten. So urtheilte schon Kimchi und neuerdings Ch. G. Hensler. - Ein gleicher Fall scheint mir in dem sogenannten Liede Hiskia's Jes. 38, 10-20 vorzuliegen. Hier redet am Schlufs (v. 20) mit Wir die Gemeinde, die der Einzelne nicht so ohne Weiteres mit seiner Person zusammenschliefsen kann. Also wird auch vorher das Ich auf die Gemeinde bezogen werden müssen. Ferner sind die Worte v. 18. 19 offenbar gleichbedeutend mit Ps. 6, 6 und ähnlichen Psalmstellen ${ }^{1}$ ).

1) Uebrigens ist das Lied allerdings nicht die Bitte (so Stade, ZATW. 86, 185 f.) um Genesung oder vielmehr um Rettung der Gemeinde, sondern der Dank dafür. יהוה להושיעני (v. 20) heifst :

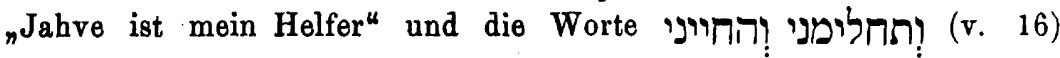
könnten sehr wohl die frühere Bitte referiren. Deutlich wird ferner v. 10 f. $13 \mathrm{zwischen}$ der früheren Angst und dem gegenwärtigen Gemüthszustande unterschieden, dieser Wechsel mufs hier durch die Rettung herbeigeführt sein, da keine andere Ursache angedeutet ist. Sonach sind die Perfecta v. 17 als Präterita zu verstehn. V. $15 \mathrm{ff}$. glaube ich übersetzen zu sollen : ${ }_{n}$ Was sollte ich reden und $\mathrm{ihm}$ sagen n(i) (i) nbetrübnifs. 0 Herr, hiervon lebt man, alle haben hierin das "Leben ihres Geistes (רוחו) und so machtest Du mich gesund und

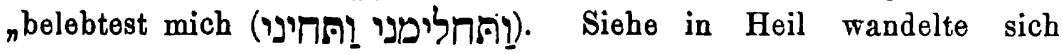

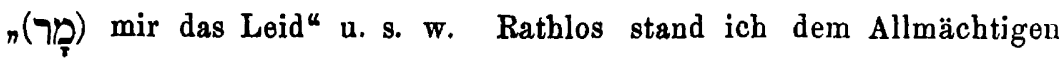
gegenüber, dem niemand dreinreden kann und der mich zeitlebens hatte leiden lassen, bis ich einsah, dafs nur wer leidet, leben kann. Durch Leiden bekehrt nämlich Gott die sündigen Menschen und rettet sie so vor dem Untergang. 
- Auch Hanna und Hiskia sind nicht gleichgültige Individuen, sondern Typen des wahren Israel ${ }^{1}$ ).

Schliefslich brauche ich kaum auseinanderzusetzen, dafs die Frage nach dem Ich der Psalmen von einer Bedeutung ist, die weit über das Verständnifs der einzelnen Lieder hinausreicht. So lange man das Ich dieser Lieder individuell versteht, scheinen sie sich dem Versuche zeitlicher Datirung einigermafsen zu entziehen. Wer sie für vorexilisch hält, meint unbedenklich bei einzelnen Individuen der vorexilischen Zeit eine solche Vertrautheit mit prophetischen Ideen und überhaupt eine solche geistliche Religiösität voraussetzen zu dürfen, wie diese Lieder sie durchweg verrathen. Setzt man dieselben aber in nachexilische Zeit, so freut man sich constatiren zu können, dafs einzelne Auserwählte unter dem Joch der Gesetzesherrschaft in Nachfolge der Propheten eine lebendige und freie Frömmigkeit festhielten und sogar neu entwickelten. Sobald man dagegen das Ich dieser Lieder auf die Gemeinde bezieht, ergiebt sich meistens sofort auch die Nothwendigkeit, dabei an die nachexilische Gemeinde zu denken. Ueberhaupt möchte es schwer sein, auch nur einige von diesen Ich-Psalmen aus dem Gemeinbewufstsein des vor-

1) Das Lied Jona 2 darf kaum anders beurtheilt werden, als die Psalmen, denen es nachgebildet ist. Zu v. 5 vgl. Ps. 27, 4. - Das Lied Sir. 51, 1-12 wird dort nicht auf die Person des Siraciden bezogen und mufs wie 33, 1-11. 36, 16 b-22 ein Gemeindegebet sein. Das beweist der ganze Character des Liedes, in dem Gott übrigens als König (v. 1) und Vater (v. 10 ?) angeredet wird. In ihrer Noth batte die Gemeinde sich mit der Erinnerung an die früheren Rettungen Israels (v. 8) getröstet und Gott half ihr um seines Namens willen (v. 3 ?). Man hatte die Gemeinde bei ihrem Oberherrn verläumdet (v. 5). - Auch in dem Liede Judith 16, 2-17 redet mit Ich (v. 2. 3. 5. 11-13. 17) die Gemeinde. Allerdings hebt Judith das Lied an, aber das ganze Volk singt mit (v. 1). Von Judith wird $\nabla$. 6-10 in der 3. Person geredet und v. 5. 11 passen durchaus nicht in ihren Mund.

Zeitsclurift f. d. alttest. Wiss. Jahrgang 8. 1888. 
exilischen Volkes zu begreifen. Haben wir hier aber Gebete der jüdischen Gemeinde vor uns, so erfährt die herrschende Vorstellung vom älteren Judenthum eine sehr wesentliche Umgestaltung. Es ist völlig verkehrt zu meinen, dafs die nachexilische Gemeinde kurzweg mit der Unterwerfung unter das göttliche Gesetzbuch charakterisirt sei. Die Gesetzesherrschaft hat freilich mit dem Exil ihren Anfang genommen, aber zunächst erstreckte sie sich doch nur auf das Gebiet des Cultus und der religiösen Sitte und nur ganz allmählich konnte von hier aus das ganze Leben und Glauben in ihren Zwang gebracht werden. Erst die Pharisäer haben dies Ziel erreicht. Bis dahin war neben dem Gesetz in hohem Mafse die Weisheit Richtschnur des Lebens, wie man aus der nachexilischen Weisheitsliteratur, vor allem aus der Schrift des Siraciden deutlich sieht ${ }^{1}$ ). Wie aber einerseits die ihrem Ursprung nach profane Weisheit neben dem Gesetz ihren Platz behauptete, so hat anderseits der Gottesglaube der Propheten im Gemeinbewufstsein des älteren Judenthums lange Zeit fortgelebt, ehe er im Supranaturalismus erstarrte. Dals das sogar noch vom älteren Pharisäismus gilt, lehrt der Psalter Salomos ${ }^{2}$ ); es gilt aber mindestens ebenso sehr von der vormakkabäischen Gemeinde, die in den Psalmen Davids redet. Nun ist aber das Subjekt der Alttestamentlichen Religion zuletzt immer nur die Gesammtheit des Volkes oder der Gemeinde, ein Individualismus geht überall nur daneben her. Deshalb hat jede Darstellung der Alttestamentlichen Religion ganz besonders auf die jüdische Gemeinde ihr Augenmerk zu richten, weil hier der Glaube der Propheten als Gemeinglaube erscheint. Man darf nicht meinen, dafs über die Zeit nach Esra nichts zu

1) Es ist merkwürdig genug, dafs nach Sir. $39 \mathrm{der}$ Schriftgelehrte fast mehr noch Weisheitslehrer als Gesetzeslehrer ist.

) Vgl. Wellhausen, die Pharisäer und Sadducäer S. $112 \mathrm{ff}$. 
sagen sei, vielmehr ist hier die Blüthezeit der Alttestamentlichen Religion zu suchen, sofern dieselbe Religion der Gemeinde war.

Die vorstehenden Untersuchungen lagen abgeschlossen vor, als mir durch die Gefälligkeit des Herrn Pfarrers A. Bernus in Basel die Erklärung der Psalmen von Reufs (in La Bible V 1. 2) zugänglich wurde. Mir war entgangen, was Reufs in seiner Geschichte des Alten Testaments § 282 Anm. 2 und $\S 478$ sagt, jetzt sah ich zu meiner Ueberraschung, dafs ich fast überall mit ihm übereingekommen war. Freilich versteht Reufs einige Psalmen, die ich für Gemeindelieder halte, individuell (32), in anderen Fällen hält er die individuelle Deutung wenigstens für wahrscheinlich (42 f. 84) oder doch für möglich (6. 13. 16. 27 b. 120. 144). Umgekehrt versteht er Ps. 62 als Gemeindelied, indem er dort die Verfolger als Heiden betrachtet. Aber diese Abweichungen fallen nicht ins Gewicht gegenüber der grofsen Uebereinstimmung, die zwischen uns besteht. Ich hätte also oben S. 58 neben dem Namen Olshausens den von Reufs nennen müssen. Ueber Olshausen hinausgehend hat er zuerst gesehn, wie weit die Personification Israels in den Psalmen reicht. Er hat sogar, wie ich höre, seit fünfzig Jahren dem entsprechend in Stralsburg gelehrt. Die Anspruchslosigkeit des Ortes, an dem er seine Einsicht veröffentlicht hat, möge es entschuldigen, dafs ich davon nichts wufste. Um so mehr aber darf ich glauben, auf dem rechten Wege zu sein, wenn ich finde, dafs das Ich der Psalmen nicht viele unbekannte Individuen, sondern Eine wohlbekannte Gemeinde bedeutet.

Berichtigung: S. 50 Z. 8 v. u. lies : 32, 1. 2. $34,9$. 